San Jose State University

SJSU ScholarWorks

Master's Theses

Master's Theses and Graduate Research

Spring 2011

\title{
Differences in Eubacterial and Archaeal Soil Communities Along a Precipitation Transect in the Mojave Desert
}

Elaine Pressly Bryant

San Jose State University

Follow this and additional works at: https://scholarworks.sjsu.edu/etd_theses

\section{Recommended Citation}

Bryant, Elaine Pressly, "Differences in Eubacterial and Archaeal Soil Communities Along a Precipitation Transect in the Mojave Desert" (2011). Master's Theses. 3913.

DOI: https://doi.org/10.31979/etd.w3cc-vjrr

https://scholarworks.sjsu.edu/etd_theses/3913

This Thesis is brought to you for free and open access by the Master's Theses and Graduate Research at SJSU ScholarWorks. It has been accepted for inclusion in Master's Theses by an authorized administrator of SJSU ScholarWorks. For more information, please contact scholarworks@sjsu.edu. 


\title{
DIFFERENCES IN EUBACTERIAL AND ARCHAEAL SOIL COMMUNITIES ALONG A PRECIPITATION TRANSECT IN THE MOJAVE DESERT
}

\author{
A Thesis \\ Presented to \\ The Faculty of the Department of Biological Sciences \\ San José State University \\ In Partial Fulfillment \\ Of the Requirements for the Degree \\ Master of Science
}

by

Elaine Pressly Bryant

May 2011 
(C) 2011

Elaine Pressly Bryant

ALL RIGHTS RESERVED 
The Designated Thesis Committee Approves the Thesis Titled

DIFFERENCES IN EUBACTERIAL AND ARCHAEAL SOIL COMMUNITIES ALONG A PRECIPITATION TRANSECT IN THE MOJAVE DESERT

\author{
by
}

Elaine Pressly Bryant

\begin{abstract}
APPROVED FOR THE DEPARTMENT OF BIOLOGICAL SCIENCES SAN JOSÉ STATE UNIVERSITY
\end{abstract}

May 2011
Dr. Sabine Rech
Department of Biological Sciences
Dr. Leslee Parr
Department of Biological Sciences
Dr. Christopher P. McKay
NASA Ames Research Center 


\title{
ABSTRACT
}

DIFFERENCES IN EUBACTERIAL AND ARCHAEAL SOIL COMMUNITIES ALONG A PRECIPITATION TRANSECT IN THE MOJAVE DESERT

by

\author{
Elaine Pressly Bryant
}

Deserts occupy one third of the total land mass of Earth, yet little is known about microbial soil communities under conditions of low precipitation and humidity. The Mojave Desert of the Southwestern United States provides an opportunity to observe microbial communities along a precipitation transect. The diversity of these communities can elucidate which specific groups of Eubacteria and Archaea are best adapted to limited liquid water.

Two methods were utilized to determine patterns and trends of the microbial soil communities under varying precipitation levels. Viable plate counts allowed comparison of culturable microorganisms over a four-year period. Molecular techniques distinguished unculturable Eubacteria from Archaea. The results indicated three trends. First, the number of culturable microbes decreased from $10^{7}$ to $10^{6} \mathrm{CFUs} / \mathrm{g}$ dry soil as the annual precipitation decreased. Also, the diversity of the eubacterial communities increased as the annual precipitation decreased, indicated by Shannon-Wiener indices increasing from 3.51 to 3.76 . Finally, the diversity increases for archaeal communities were small, producing Shannon-Wiener indices from 1.21 to 1.36. Possible indicator bacteria for desertification processes were suggested by the increasing numbers and diversity of cyanobacteria at the drier sample sites. 


\section{ACKNOWLEDGEMENTS}

This work was supported by the NASA Graduate Student Research Program \#NNX07AV93H for 2006-7, 2007-8, and 2008-9, and the SJSU Department of Biological Sciences Departmental Fellowship, 2006.

This research would not have been possible without the assistance of several outstanding individuals:

Sabine Rech - Thank you for accepting me as your graduate student. I don't believe I could have found a better advisor. You have provided insight during confusing periods, encouragement in the face of contamination, and a calm rationale when frustrations occurred. I am in your debt, and look forward to continuing to work with you in your lab.

Chris McKay- Thank you for suggesting the Mojave precipitation transect and supporting me through the NASA GSRP. I am also appreciative for inclusion in the Spaceward Bound Expeditions in the Mojave and Australia. I have enjoyed working with you and becoming acquainted with the cohort of scientists involved in SB. It has been an incredible learning experience and I hope to continue to be involved in desert research.

Leslee Parr - Thank you for your encouragement, support, and suggestions on my research. I value your opinions and appreciate your participation on my committee.

Monika Kress - Thank you for offering me the initial opportunity to work in Astrobiology. You were responsible for introducing me to Chris and starting this research effort in the Mojave. I'll forever be in your debt for that, and hope we can combine our research again someday.

Doris Spanggord - Thank you for introducing me to microbiology and allowing me to tutor so I could "really learn it!"

Paula Matheus-Carnevali - It was tremendous fun working with you in the early days of our research. I learned quite a lot from you and have missed you since you moved on to your PhD program. I have looked at your thesis numerous times for clarification and am always touched by your acknowledgements. Thanks for your friendship, kindness, and sharing your insight all those hours in the lab.

Milena Lilles \& June Shinseki - You two have saved my sanity more times than I can count. I appreciate your laughter, your concern, your insight, and your friendship more than you will ever know. Thank you for being there. 
There are groups of people to whom I owe many thanks for their time, efforts, results, and friendship:

The Environmental Microbiology Laboratory assistants:

- Antranig, April, Behnaz, Bianca, Carlo, Dionne, Eric, Giovanni, Katya, Kim, Mahsa, Maria, Mihn Tri, Rawni, Steven, Trang, Vahig, and Victor

- You dedicated scores of hours cloning gene sequences, performing plasmid preps, running agarose gels for restriction digests, and analyzing sequence data. I am forever in your debt.

The participants of the NASA Spaceward Bound Mojave Expeditions 2007, 2008, 2009 and 2010.

- To the teachers who gladly participated in sample collections, culture inoculations, and DNA extractions - your enthusiasm for my work was intoxicating, and I am thrilled many of you have adapted my techniques to enhance learning in your science classrooms.

- To the scientists: Henry Sun, Jim Nienow, Penny Boston, Rosalba Bonaccorsi, Heather Smith, Mike Spilde, Rakesh Mogul, Jamie Molaro, Jim Thompson, Bill Leibman , Andrew Duncan, Liza Coe, Linda Conrad, Christy Thompson Benjamin Hulsey - thanks for all your suggestions, discussions, friendship, and occasional help in the lab!

- To the support staff: Robert Fulton, Jason Wallace, - thanks for your help with the on-site lab and the rainfall data. You made working at DSC a pleasure.

The participants of the NASA Spaceward Bound Australia Expedition 2009

- To the teachers: Jo, Nicci, Jane, Mark, Naomi, Liz, Keith, Steven, and Luther - Thanks for introducing us to Down Under, helping with sample collection and processing, and teaching us how to drive on the wrong side of the road - you were fabulous and I am so proud to call you friends

- To the scientists: Reut Abromovich, Adrian Brown, Vic Gostin, Jen Heldmann, Eriita Jones, Shannon Rupert, and Johnathan Clark - it was wonderful meeting you and I look forward to running into you again someday.

- To the support staff: David and Maureen Cooper, Guy Murphy, Nina Stanfield, and David Wilson - you made the expedition a very pleasant experience. Thanks for your efforts and company. 
The SJSU Biological Sciences Support staff:

- Art Valencia, Veronica Zavala, Matt Voisinet, and Tim Andriese

- Thanks for all your assistance when problems with media, equipment, and procedures appeared. You are wonderful people with which to work.

Finally, I must thank my family for their patience, love, support and encouragement:

- My parents, David and Velma Pressly - you always supported my love of science, encouraged me to think for myself, and never insisted that I "act like a girl." Thanks for the telescope, the late nights stargazing, and for trusting me. I hope l've made you proud.

- My children, Michael and Camille - I appreciate you putting up with my class schedules, my long hours studying, and my frequently mentioned love of microbiology. Thanks for helping with lab stuff when I needed you. I am very proud of you both and look forward to a bit more time with you.

- My husband, David - You will never know how appreciative I am that you have supported me these many years in my extended education. I now feel I am doing what I love - the teaching, the lab work, and the expeditions. I am also thrilled that you wanted to become involved as my field and lab assistant. We've had so much fun and gotten to know many wonderful people. I love you very much and hope we're still driving out to the desert in another 31 years!!!!!! 


\section{TABLE OF CONTENTS}

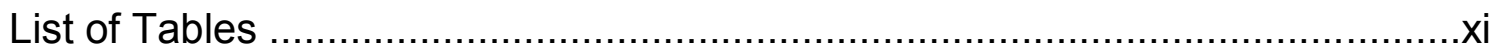

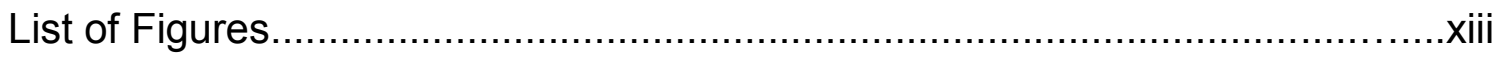

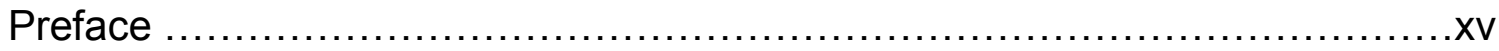

Chapter 1: Literature Review..................................................

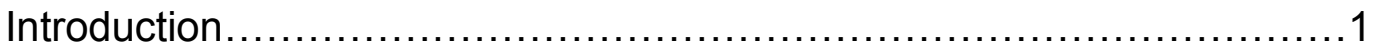

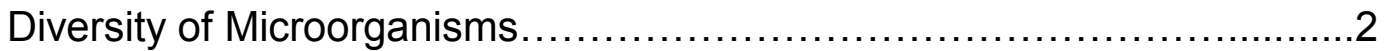

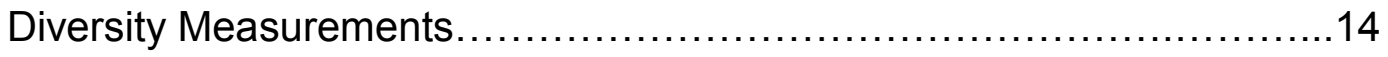

Physical Characteristics of Deserts ...................................16

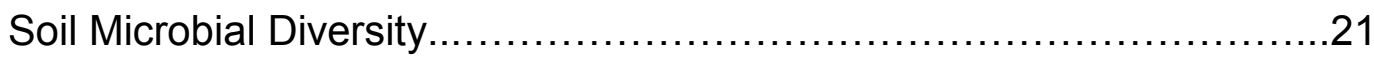

Microbial Diversity in Arid Desert ........................................23

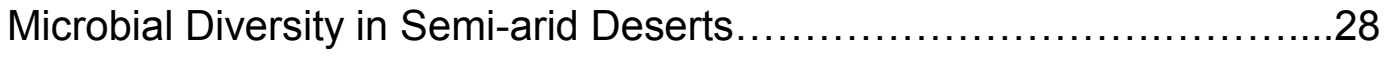

Microbial Diversity in Coastal Deserts......................................33

Microbial Diversity in Cold Deserts......................................35

Microbial Diversity in Antarctica.......................................37

Global Warming and Soil Health.......................................43

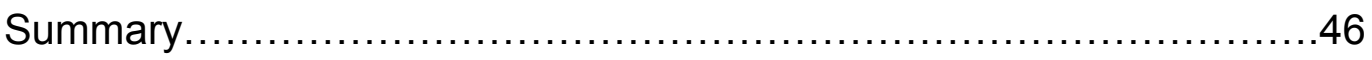

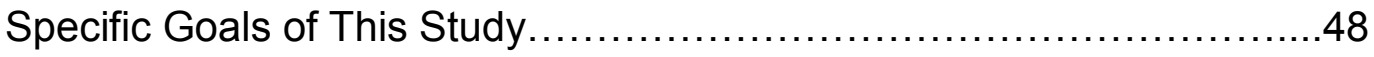

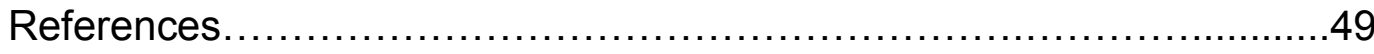

Chapter 2: Differences in Eubacterial and Archaeal Soil Communities Along a Precipitation Transect in the Mojave Desert..............................57 


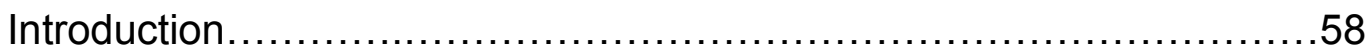

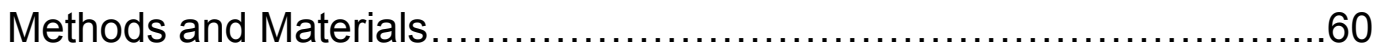

Precipitation Transect...........................................60

Sample Collection ...............................................

Soil Sample Analysis.............................................. 64

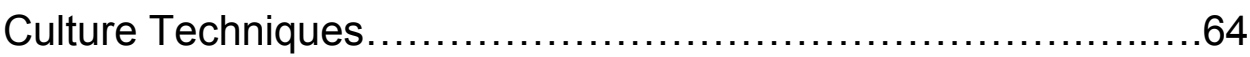

DNA Extraction .................................................. 65

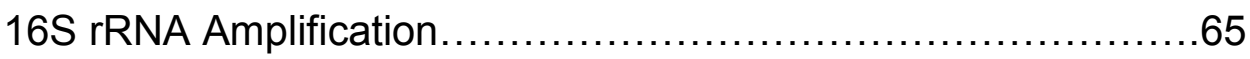

Cloning and Sequencing ..........................................

Phylogenetic Analysis............................................67

Diversity Analysis............................................... 68

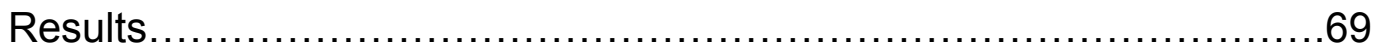

Vegetative Coverage.............................................69

Soil Characteristics.................................................

Viable Plate Colony Counts.......................................75

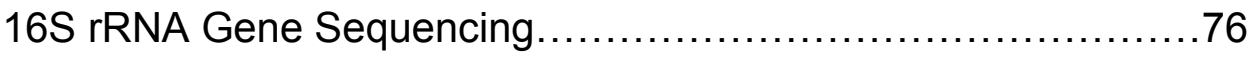

Eubacterial 16S rRNA Gene Sequences, Phyla Classification......77

Eubacterial 16S rRNA Gene Sequences, Class Classification......81

Eubacterial 16S rRNA Gene Sequences, Family Classification.....83

Eubacterial 16S rRNA Gene Sequences, Operational Taxonomic Unit Classification........................................... 86

Archaeal 16S rRNA Gene Sequences.............................93 


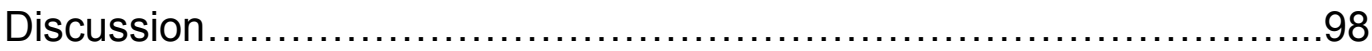

Sample Site Considerations .................................... 98

Vegetation and Soil Characteristics...............................99

Viable Plate Counts and Precipitation Totals.....................101

16S rRNA Sequence Analysis, Database Selection................107

16S rRNA Sequence Analysis, Classification Parameters.........111

16S rRNA Sequence Analysis, Eubacteria ........................113

16S rRNA Sequence Analysis, Archaea..........................120

Diversity Analysis of 16S rRNA Gene Sequences.................121

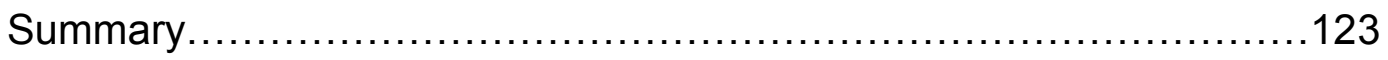

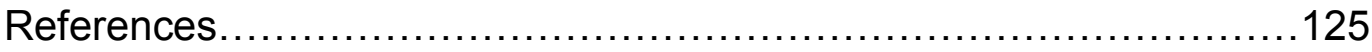




\section{LIST OF TABLES}

Table 1. Designations used for arid regions, the related Thornthwaite Moisture Index, the approximate annual precipitation and the percent of terrestrial land associated with this designation.

Table 2. Summary of microbial research in different types of deserts.

Table 3. Geographical data for sample sites

Table 4. Primers used for amplification of the $1.5 \mathrm{~kb} 16 \mathrm{~S}$ rRNA gene. 66

Table 5. Vegetative coverage of sample sites by type and size of vegetation...70

Table 6. Soil and rock descriptions of sampling sites

Table 7. Nitrogen content at sample sites

Table 8. Chemical analysis of soil samples

Table 9. Averaged colony forming units for statistically significant dilution plates for four years of sampling. Values are in terms of CFUs/g soil. .75

Table 10. Number of $16 \mathrm{~S}$ rRNA genes sequenced for transect .76

Table 11. Number of eubacterial $16 \mathrm{~S}$ rRNA gene sequences assigned to specific class designations. Phyla with one sequence per class are indicated. 82

Table 12. Classification for two $16 \mathrm{~S}$ rRNA gene sequences by three Databases. 
Table 13. Number of OTUs and $16 \mathrm{~S}$ rRNA gene sequences in a bacterial Taxon

Table 14. Number of OTUs found at a single sample site and the number of actual $16 \mathrm{~S}$ rRNA gene sequences represented

Table 15. Annual precipitation amounts $(\mathrm{cm})$ at DRI weather stations and the DSC for 12-month period prior to each expedition

Table 16. Comparison of phylum assignments by three Greengenes databases for classification of sequences at two sites. Values are $\%$ of total sequences.

Table 17. rRNA gene sequences of doubtful classification as determined by the Greengenes, NCBI, RDP and GenBank databases. ("Unc" $\rightarrow$ uncultured) 


\section{LIST OF FIGURES}

Figure 1. FRAP average precipitation map of California from 1900-1960 with the precipitation transect identified.

Figure 2. Sample site locations representing a precipitation transect

Figure $\mathbf{3} \mathbf{a}$ and $\mathbf{b}$. Location of soil samples taken from each sample site for 2007 (a) and 2008 - 2010(b) Spaceward Bound expeditions.

Figure 4. Scatter plot of $\mathrm{pH}$ values along precipitation transcript including a linear regression trend line.

Figure 5. Relative abundance of $16 \mathrm{~S}$ rRNA gene sequences at the Phylum taxonomic level from Sand Canyon, Site 15

Figure 6. Relative abundance of $16 \mathrm{~S}$ rRNA gene sequences at the Phylum taxonomic level from California City, Site 16. .78

Figure 7. Relative abundance of $16 \mathrm{~S}$ rRNA gene sequences at the Phylum taxonomic level from Fields Road, Site 18

Figure 8. Relative abundance of $16 \mathrm{~S}$ rRNA gene sequences at the Phylum taxonomic level from Henry Springs Road, Site 21

Figure 9. Comparisons of the proportion of major Alphaproteobacteria families which vary along the precipitation transect....

Figure 10. Family classification indicating interesting trends in eubacterial community proportions along the precipitation transect.

Figure 11. Upper graph: Number of OTUs per sample site for the most highly populated OTUs found at all sites along the precipitation transects. Lower graph: trend lines for each numbers of OTUs at each sample site. 


\section{LIST OF FIGURES (CONTINUED)}

Figure 12. Upper graph: Minor OTUs associated with all four sample sites. Lower graph: trend lines for each numbers of OTUs at each sample site.

Figure 13. Taxonomic classes and corresponding number of archaeal $16 S$ rRNA gene sequences.

Figure 14. Rarefaction curves for the Eubacterial 16S rRNA gene sequences for the four sample sites of the precipitation transect

Figure 15. Rarefaction curves for the Archaeal 16S rRNA gene sequences for the four sample sites of the precipitation transect.

Figure 16. Shannon-Weiner function for Eubacteria 16S rRNA gene sequences.

Figure 17. Shannon-Weiner function for Archaea $16 \mathrm{~S}$ rRNA gene sequences.

Figure 18. Trend in CFUs/g soil as In(CFUs) vs. sample site

Figure 19. The recorded precipitation amounts for specified years along the precipitation transect. 


\section{PREFACE}

The following thesis is presented as two journal articles. Chapter 1 is a literature review of research on microbial soil communities in deserts around the world. The analyzed communities include the Eubacteria, the Archaea, fungi, and bacteriophage populations associated with arid, semi-arid, coastal, and cold deserts. The desert regions of interest include locations on all continents.

Chapter 2 presents research on bacterial and archaeal communities along a precipitation transect through the Mojave Desert in southern California. Microbial soil communities were investigated using culture and molecular techniques to examine changes in diversity as a function of annual precipitation. Also examined was the selection of an indicator microbe that could be used to detect the advancement of desertification in semi-arid environments. Sequence analysis of the 16S rRNA gene indicated that the diversity of the eubacterial communities increased as precipitation decreased, though the archaeal communities indicated no change in diversity along the transect. Cyanobacterial species found only in the driest sample site were suggested as possible indicator organisms for increasing desertification in the Mojave Desert. 


\section{CHAPTER 1: LITERATURE REVIEW}

\section{Introduction}

Microorganisms have been studied in terms of their pathogenic characteristics or for their use in industries such as the production of food, agriculture, bioremediation, and biotechnology. However, the function and structure of microbial communities in the natural world have proven to be highly complex. As detection methods have improved, microbes have been discovered in environmental and anthropomorphic niches thought to be too harsh for any form of living organism. The study of these organisms offers potential rewards in terms of enzymes for industrial and medical use as well as providing an idea of life on other planets [46, 42].

The extreme arid biomes on Earth present microorganisms and higher life forms with unique challenges. All life on Earth requires liquid water, and therefore the discovery of microorganisms existing in soil of the Atacama Desert that received a single precipitation event of $2.3 \mathrm{~mm}$ of rainfall in a period of four years was quite surprising [42]. The complex desert soil communities of bacteria, fungi, and protozoa have proven difficult to assess and have yet to be characterized in terms of the identities of the microbes, their function in the ecosystem, and their means of coping with the extremes of arid environments.

Understanding the relationship between microbial communities and precipitation may also prove useful in predicting effects of global warming. 
Resulting data might indicate possible conditions such as the presence or absence of certain bacteria or archaea or changes in the microbial community that might reveal the advancement of desertification. Identifying such indicator organisms may allow conservationists and communities time to develop appropriate responses to the decreasing moisture conditions [8].

This review will focus on the state of research on microorganisms existing in arid biomes on Earth in terms of desert locations, specific microorganisms targeted, techniques used for analysis, and conclusions derived from the resulting data. The intention is to use this information to determine gaps in the overall picture of microbial diversity in arid environments and to identify directions for future research.

\section{Diversity of Microorganisms}

Definitions of microbial diversity often focus on species richness - the number of species in an environment and species evenness - indicating the number of individuals per species. However, this interpretation does not take into account the community structure and function of the microbial population. Hunter-Cevera [64] presented a more comprehensive definition of microbial diversity: "Microbial diversity includes the genetic composition of microorganisms, their environment or habitat where they are found and their ecological or functional role within the ecosystem." Thus, an examination of the 
microorganisms existing in a defined community should encompass several aspects of microbial communities:

- the genetic differences based upon examination of nucleic acid sequences for conserved genes

- possible symbiotic relationships between microorganisms in terms of contributions to:

- nutrient access and microbial stratification (threedimensional location of communities)

- species progression related to changing physical characteristics of the environment

Kirk [35] outlined the problems of assessing microbial diversity and identified four areas of concern: microbial distribution in soil, inability to culture most soil microorganisms, the chemical and physical challenges of extracting DNA or RNA, and the overall difficulty of classifying microbes.

The distribution of microorganisms in soil is not uniform, but often seen as existing in "several nested levels of organization" or horizontal and vertical stratification related to the presence or absence of required nutrients. This produces an uneven distribution or clumps of microhabitats throughout an area of interest. Also, the spatial and temporal distribution of microbial communities has proven difficult to evaluate. Many early studies based their conclusions on fungal growth by examining the fruiting bodies above ground, which do not correlate to the below-ground fungal expansion. Thus, the actual sampling pattern and the 
number of samples taken in an area are important considerations for determining microbial diversity [35].

The second problem defined by Kirk, et al. [35] focused on assessing microbial diversity by using culture techniques. Culturing microbes has become a necessity for the identification and understanding of pathogenic microbes. The temperatures, nutritional sources, and other growth conditions are easily replicated based upon knowledge of the host organism - animal or plant. The application of such culturing techniques is not appropriate for environmental microbial communities. Research over the last twenty years indicates less than $1 \%$ of microscopically observable soil bacteria can actually be cultured in the laboratory $[57,35]$. Thus, microbial diversity based upon culturing the microbes from soil samples has been grossly under-estimated and skewed. The growth conditions for environmental microbes appear to be quite complicated. Kaeberlien, et al. [34] demonstrated this situation by using a diffusion chamber to simulate an intertidal marine sediment. Marine sediment provided the source of bacteria, and organisms from that source were transferred to warm agar made with seawater, and separated from the sediment by polycarbonate membranes. This allowed exchange of environmental constituents but restricted movement of the microbes. The resulting colonies represented at most $40 \%$ of the initial inoculum. Purification of isolates was attempted, resulting in the isolation of two bacteria. Further growth of these isolates was maintained on the marine sediment, but the only growth on culture media was observed when other 
organisms from the marine sediment were also present. This interdependency between multiple microorganisms was termed "coculture." The researchers posit that the isolates required something from the other organisms, possibly chemical signaling, before becoming metabolically active [57, 34].

Kirk's [35] third problem in assessing soil microbes deals with the extraction of conserved genes that can be used for identification of the various microbes. With the advent of molecular techniques, such as the polymerase chain reaction (PCR), cloning plasmids, transformation, and various forms of gel electrophoresis, a broader picture is forming of the true nature of microbial diversity in soil. However, these processes also have limitations based upon selection of the conserved gene for comparison and the physical act of extracting DNA and/or RNA.

Most of the molecular techniques used for identifying microorganisms focus on the gene for the small ribosomal subunit $[23,20,6,25,59]$. Eukaryotic or prokaryotic universal or specific primers are used for the amplification of a 1,500 base pair $16 \mathrm{~S}$ rRNA gene with the assumption that the resulting copied segment can be cloned and separated to identify individual microorganisms at the genus and possibly the species level. However, there are inherent problems with trying to identify microorganisms this way due to different affinities between primers and templates, differing amounts of $\mathrm{G}+\mathrm{C}$ content in the DNA (resulting in different strand separation times) and preferential amplification - DNA strands with higher quantities of guanine and cytosine take longer to copy than those with 
low quantities of these nucleotides. Finally, microorganisms found in low percentages in a community may not be amplified to the same degree as the more plentiful microorganisms resulting in little or no presence in a gel and no further analysis.

Kirk, et al. further elaborates on problem of conserved genes for microbial identification by examining the current procedure for separating microbes from soil particles. Most DNA extraction kits combine a specified amount of soil with a tube of buffered solution, containing small beads. The tubes are then vortexed, causing the beads to collide with soil particles, detaching microbes attached to those particles. This often results in damaging the cell and the nucleic acids. Lysing the cells to extract their nucleic acids is done mechanically, chemically or by combination of both methods. The efficiency of lysis protocols depends upon several factors:

- the volume of cells per sample: a low volume indicates the need to minimize loss, whereas a high volume may require dilution to obtain a balance between the concentration of chemical agent (typically a detergent) and the number of cells to lyse

- the type of cell to lyse: different microbes have different cell walls and membrane structure, which may require buffer solutions of different ionic strengths

- the presence of humic acids in the samples effect future PCR processing thus must be removed from the sample 
- the nucleic acid purification techniques often result in a decrease in the final concentration of nucleic acids. For samples with low cell volume, this limits the number of uses for the nucleic acids.

These factors all affect the quantity and quality of resulting DNA or RNA template [35].

The final area of concern for determining microbial diversity as outlined by Kirk, et al. focuses on the confusion regarding the taxonomy of microorganisms and the definition of the term "species" as it applies to prokaryotes. In 1753, Linnaeus presented the binomial system of genus and species as the most exacting means of identifying a multicellular organism. Since then, numerous efforts have been proposed for the determination of this level of specificity. Staley points out that there are three basic taxonomic classification systems currently in use: the biological species concept (BSC), which basis speciation on reproductive isolation; the morphospecies concept (MSC), which uses external characteristics such as size, shape, color, etc to speciate organisms, and the phylogenetic species concept (PSC), which relates species by their evolutionary relatedness based on gene sequence comparisons. Because Eubacteria and Archaea do not demonstrate meiotic sexual reproduction, the BSC is not applicable to this group of microorganisms.

In The Prokaryotes: Symbiotic Associations, Biotechnology, Applied Microbiology, Stackebrandt discusses the attempts to use the MSC for bacterial speciation. Cohn first applied the binomial system to bacteria in the late $1800 \mathrm{~s}$ 
using observable morphological differences to distinguish between six genera. His attempt resulted in the acknowledgment that morphological features of bacteria did not directly relate to physiological attributes, and thus were not sufficient for differentiation beyond the genus level [21].

As technology provided more levels of testing to separate one bacterium from another, more observable and biochemical characteristics were included as necessary for the distinction of a species. Buchanan combined all these characteristics into one system that was then used for the production of Bergey's Manual of Determinative Bacteriology. Problems with this empirical system arose when bacteriologists realized that many of the notable distinguishing characteristics were not mutually exclusive. An example of this is the ability to produce clumping factor in the genus Staphylococcus: S. aureus produces this factor, but S. lugdunensis also produces it in a delayed manner. No other staphylococci related to human or animal diseases produce clumping factor. Therefore, the use of clumping factor alone does not clearly delineate between these two species of Staphylococcus.

Further development of techniques to distinguish pathogenic bacteria led to the establishment of the taxonomic level of strain, which assumed great importance when treating diseases caused by variants of bacteria exhibiting characteristics possibly acquired by horizontal gene transfer, such as antibiotic resistance. The inclusion of the taxonomic level of strain allowed for the grouping of bacteria at the genus and species level, while allowing some 
variation in one or two attributes [53]. Thus, the distinction of genus and species using the MSC has expanded to incorporate not only morphological characteristics, but observable and measurable attributes such as the Gram reaction, oxygen requirement, motility, nutritional requirements, biochemical test reactions, and other such demonstrable traits that are consistent for a group of Eubacteria or Archaea.

In the 1960 s scientists recognized that evolutionary changes were detectable by examining cellular DNA and RNA, leading to the PSC [21]. Comparison of the nucleotide bases for a conserved gene, such as the $16 \mathrm{~S}$ ribosomal subunit, identified sites of mutations that can be assessed in terms of ancestral relationships. Interpretation of the results is based upon how many different bases in the gene are detected with the assumption that two very similar genes indicate the two organisms are closely related. The process of DNA-DNA hybridization (DDH) heats double-stranded DNA (dsDNA) until the two strands separate (melting temperature of strands $=T_{m}$ ). The temperature is then cooled to within $5^{\circ} \mathrm{C}$ of $\mathrm{T}_{\mathrm{m}}$ and the single strands are allowed to reattach. The stability of the resulting dsDNA is indicative of the level of similarity in the original DNA molecules [53]. Using this technique, two dsDNA strands demonstrating $70 \%$ or greater similarity at the temperature within $5^{\circ} \mathrm{C}$ of $\mathrm{T}_{\mathrm{m}}$ indicate they are from the same species. Stackebrandt further related DNA reassociation with 165 rRNA gene analysis, indicating bacteria that meet the same species criteria using DNA reassociation demonstrate $\geq 97 \%$ similarity between 16 SRNA genes [60]. 
In 1970 Colwell suggested a new method of species assignment that "assembles and assimilates" information regarding the genetic, molecular, morphological, biochemical and ecological aspects of an isolate before assigning it to a species. Colwell proposed the term polyphasic taxonomy and used this to relate 86 strains of the genus Vibrio. Specifically, thirty strains of V. cholerae, broken down as classic V. cholerae, El Tor vibrios, and non-cholerae vibrios, thirty-five strains of $V$. parahaemolyticus, and 21 strains representing control genera and Vibrio species from marine environments were selected for comparison. Standard laboratory tests, such as growth on specific media, motility, carbohydrate fermentation, colonial characteristics, antibiotic susceptibility, nutritional requirements, and electron microscopy, were scored and tallied. The conclusion offered by scoring the phenotypic data and comparing it to the DNA-DNA reassociation data indicated that the current assignment of strains cholerae, El Tor and all but 2 of the non-cholerae should be classified as the same species. Strains of $V$. parahaemolyticus demonstrated a separate cluster, and the control bacteria were separate from all Vibrios [16].

Mola, et al. also used a polyphasic approach in 1997 to assign six halophilic Gram-positive cocci isolated from salt ponds in Huelva, Spain to the genus and species Nesterenkonia halobia. The species had been previously created based upon a single strain isolated from an unknown salty deposit outside Noda, Japan. Mola, et al. utilized standard biochemical tests such as fermentation of carbohydrates, hydrolysis tests, citrate utilization, and antibiotic 
susceptibility, as well as the determination of guanine-plus-cytosine content, $16 \mathrm{~S}$ rRNA similarity, and DDH to conclude that the six isolates from a saltern in Huelva, Spain should be assigned to N. halobia [41].

In February 2002 a group of European microbiologists formed an ad hoc committee funded by the Federation of Microbial Societies (FEMS) to evaluate the definition of bacterial species with regards to the advancement of molecular techniques. The committee determined that the rigid application of DDH is still the gold standard for the taxonomic assignment of species. The current definition of a species: "a category that circumscribes a (preferably) genomically coherent group of individual isolates/strains sharing a high degree of similarity in (many) independent features, comparatively tested under highly standardized conditions," was upheld. However, the committee further encouraged researchers to develop new techniques to support and/or supplant DDH [61].

A recent attempt to further elucidate the taxonomic level of species has been the inclusion of ecological characteristics to the overall polyphasic approach to classification. Konstantinidis and Tiedje identified conserved protein-coding genes in seventy related, fully sequenced genomes from the NCBI database, the Sanger Center, the Institute for Genomic Research and the Advanced Center for Genome Technology, University of Oklahoma. These highly conserved protein-coding genes are directly related to phenotype, thus give a more concise comparison of the ecological conditions of the bacterial environment than simply using the $16 \mathrm{~S}$ rRNA gene. BLAST was used to perform 
pairwise comparisons of all the protein-coding genes and the average nucleotide identity (ANI) of the conserved genes between strains was computed. The ANI scores were used as a measure of evolutionary distance between strains. DNADNA reassociation and 16S rRNA gene sequence were also performed on the related genes. The researchers concluded that the ANI scores clearly support 16S rRNA sequence identity matches and DNA-DNA reassociation results, and an ANI score of $93-94 \%$ represents the species gold standard of $70 \%$ DNA-DNA reassociation level. Interestingly, a direct comparison of conserved genes between strains grouped as the same species (94\% ANI) yielded gene code differences of $5-35 \%$. By comparison, the ANI value for gene similarities of humans and chimpanzees is $98.7 \%$, indicating that the level of acceptable gene coding differences between highly similar bacteria is too low and, thus, too homogeneous to associate with phenotype and environmental niche [37].

Koeppel et al. implemented an algorithm to identify ecotypes of bacteria existing in arid desert environments. Cohan first defined the term ecotype as a more specific term than species, thus indicative of strains. An ecotype reflects the related characteristics of a group of organisms due to environmental pressures related to a specific environment. This environment is subjected to natural selection such that a mutant resulting from environmental stressors will out-compete all other strains of that ecotype, resulting in the extinction of the original ecotype. Strains of other ecotypes will not be affected [15]. Koeppel, et al. investigated the application of the ecotype simulation model (ES) to examine 
the members of two clades of the genus Bacillus. Sequence differences for three genes were used to establish diversity within and between two clades of Bacillus isolated from Evolution Canyons in Israel. For the B. simplex clade, gapA, rpoB, and uvrA were compared. For the second clade, the only different gene examined was gyrA instead of uvrA. Complete linkage clustering was employed to group the samples from each clade such that the evolutionary pattern of divergence was produced. Interpretation of the resulting pattern indicated periods of constant ecotype formation as well as inflection points indicative of increased diversity. Application of the ES model resulted in 9 ecotypes for the $B$. simplex clade and 13 ecotypes for the $B$. subtilis-B. licheniformis clade. The authors mention that the current species demarcation for $16 \mathrm{~S}$ rRNA is $>3 \%$ divergence, but that Stackebrandt had more recently suggested that level be changed to $>1 \%$ to reflect the species differences for eukaryotic organisms [62]. Using this suggested degree of similarity, the 16S rRNA gene comparison for the B. simplex clade showed $100 \%$ identity between all isolates. Within the second clade of Bacillus, the isolates separated into two species groups based upon $16 \mathrm{~S}$ rRNA similarity, except for 6 ecotypes. Four of these phylogenetically related to B. licheniformis, and two were more closely related to $B$. spizizenii. Thus, the model indicated that the even using the $1 \% 16 \mathrm{~S}$ rRNA gene similarity does not recognize measurable ecotype diversity, and suggest that the utilization of such ecologically oriented models should be incorporated into further attempts to speciate bacteria [36]. 
These four concerns - microbial distribution in soil, inability to culture most soil microorganisms, the chemical and physical challenges of extracting DNA or RNA, and the overall difficulty of classifying microbes - indicate the complexity associated with assessing soil microbial diversity. A 2008 report from the American Society for Microbiology, entitled "The Uncharted Microbial World: Microbes and their activities in the Environment," acknowledge these problems and further indicate the need for new techniques used to perform communitylevel studies detailing the physiological contributions from various microbes. In addition, the current limitations associated with the detection of microbial interactions should be eliminated [30].

Harwood, et al. continue the examination of the current state of microbial research to include the lack of knowledge of how microorganisms function in the global biogeochemical cycles, including nitrogen fixation, recycling of greenhouse gases, and recycling basic nutrients from dead material. Baseline data on microbial community members, structure and functions have yet to be determined, thus the effects of disturbance of such communities are unknown, whether the environment be internal to animals (gums/teeth), waste management systems, or soil communities [30].

\section{Diversity Measurements}

The current techniques used for microbial community investigations incorporate culturing, fluorescent labeling, microscopic observation, and 
molecular techniques focusing on DNA, protein and phospholipid fatty acid analysis (PFLA), as well as the use of ribosomal sequence tags. The results from these techniques provide insight into microbial diversity in one of two ways. DNA/RNA analysis may identify microorganisms to the genus and sometimes species level. Fluorescent labeling, culture plates, microscopic observation, PFLA, and ribosomal sequence tags provide relative assessments of microbial diversity.

Many culturing and molecular techniques depend on the application of mathematical models to relate the resulting data to species diversity. Diversity indices mathematically measure the species diversity in a community by assessing the species richness - the number of species present, and the species evenness - the number of individuals of each species. The most common diversity index is the Shannon or Shannon-Weiner Index. Based on information theory, this index reflects the degree of randomness, or order, in a population. The index is determined by the expression:

$$
\mathrm{H}=-\sum_{i=1}^{s}\left(p_{i}\right)\left(\ln p_{i}\right)
$$

where $\mathrm{H}=$ information content of the sample or index of species diversity, $\mathrm{s}=$ number of species, and $p_{i}=$ proportion of total sample belonging to the $i$ th species. 
The value of $\mathrm{H}$ reflects the diversity of a community based upon the maximum value of $\mathrm{H}_{\max }$, where $\mathrm{H}_{\max }=\ln \mathrm{S}$ when the number of individuals is the same for all species [38].

\section{Physical Characteristics of Deserts}

Defining or classifying types of deserts typically reflects the type of research or concern of interest to scientists. Agricultural researchers emphasize the differing precipitation and temperatures, and the resulting vegetation. Geographers and meteorologists use physical systems such as wind patterns, proximity to open water or mountain ranges, and seasonal variations to characterize arid environments. Geologists examine the soil and mineral content, possibly related to mining and new oil reserves. Regardless of the discipline, one characteristic of deserts holds true - they are the driest regions on the planet [40].

Aridity indices have been utilized to delineate deserts from surrounding areas offering more hospitable conditions for life. The Thornthwaite Moisture Index is a calculation based upon the water balance of an area:

$$
I_{m}=\frac{s-0.6 d}{e} \times 100
$$

$I_{m}$ is the moisture index, $s=$ sum of monthly surpluses of precipitation greater than the estimated evaporation, $d=$ sum of monthly precipitation deficits, and e=estimated annual potential evaporation. The e value includes adjustments for 
seasonal changes, monthly temperatures and a soil-moisture factor. Meigs expanded the aridity index and further defined designations of arid lands in terms of agricultural potentialities [43]. Thus the extremely arid, or hyperarid regions have recorded 12 months of more of no precipitation. Arid areas receive rainfall inadequate for the propagation of crops. Semi-arid zones are predominately grass or steppes. Thornthwaite's designation of "subhumid" relates to the Mediterranean or chaparral climate, with very dry summers and wet winters. Meigs' designations have been widely used as the standard for classification of arid environments [65]. Table 1 identifies the resulting designations for arid regions.

Table 1. Designations used for arid regions, the related Thornthwaite Moisture Index, the approximate annual precipitation and the percent of terrestrial land associated with this designation.

\begin{tabular}{cccc}
\hline Designation & $\mathrm{I}_{\mathrm{m}}$ & $\begin{array}{c}\text { Annual } \\
\text { Precipitation }\end{array}$ & $\begin{array}{c}\text { Global } \\
\text { Land Area }\end{array}$ \\
\hline Extremely arid & $<-56$ & $<2.5 \mathrm{~cm}$ & $7.50 \%$ \\
Arid & -40 to -56 & 2.5 to $20 \mathrm{~cm}$ & $12.10 \%$ \\
Semi-arid & -20 to -40 & 20 to $50 \mathrm{~cm}$ & $17.70 \%$ \\
Dry subhumid & 0 to -20 & 50 to $75 \mathrm{~cm}$ & $9.90 \%$ \\
\hline
\end{tabular}

Based upon these global circulation patterns and the existing terrain of the continents, the United States Geological Society acknowledges 5 physical and climatological situations that result in the formation of deserts: proximity of 
mountain ranges, predominant wind direction, predominant pressure system, proximity to large bodies of water (oceans, lakes), and ocean currents [65].

Several deserts exist due to the rain shadow effect caused by mountain ranges that uplift the air, resulting in precipitation on one face of the range, and dry air flowing down the back side of the range. The Mojave, the Chihuahuan, the Taklimakan, and the Turpan Depression are examples of rain shadow deserts. Also, included under this designation might be deserts resulting from seasonal wind alterations, such as the Thar Desert. Monsoons bring heavy rain to eastern India, but much of the precipitation is lost as the storm crosses the continent. By the time the air mass reaches the India-Pakistan border, very little precipitation remains [45].

The deserts of Australia exhibit the characteristics associated with midlatitude deserts. There are few mountain ranges to produce rain shadow deserts, and evidence of seasonal lakes and rivers are abundant. The average annual precipitation ranges from $200 \mathrm{~mm}$ in the Simpson Desert to $400 \mathrm{~mm}$ with the extremely dry central area averaging $150 \mathrm{~mm}$. Temperature averages range from $25-42^{\circ} \mathrm{C}$ in the Great Sandy Desert to $4-36^{\circ} \mathrm{C}$ in the Simpson Desert. Surface composition includes sand dunes, pebbles, and red soils. Vegetation includes acacia shrublands, grasslands, and succulents. Wildlife diversity in the Simpson Desert includes 34 mammals, 231 birds, 22 amphibians, 13 fish and 125 reptiles $[40,45]$. 
Trade wind deserts are north and south of the equator, and form due to the influx of dry winds from the Horse Latitudes. These deserts are primarily extreme arid or arid environments and include the Sahara and the Arabian deserts. Characteristics of trade wind deserts vary considerably due to size and geographic location. The Sahara Desert is larger in area than the continental United States, and exhibits ecoregions from extremely arid to Mediterranean. Rainfall can occur at any time of year and the annual precipitation for the core of the Sahara is less than $25 \mathrm{~mm}$ while the eastern portion receives less than $5 \mathrm{~mm}$. Temperature ranges are extreme with highs over $50^{\circ} \mathrm{C}$ and lows below freezing.

Coastal deserts are located on the western side of continents. Cold water currents moderate the climate, causing fog that blocks solar radiation resulting in cooler temperatures, and very little precipitation. The Atacama Desert, located along the coast of Peru and Chile, is west of the Andes Mountains. The Peru Current moves south to north parallel to the South American coast, resulting in heavy fog that moderates the temperature and introduces minimal levels of precipitation to the area. Average temperatures range from $14.5^{\circ} \mathrm{C}$ in winter months to $21^{\circ} \mathrm{C}$ in summer. Movement of the fog further inland is dependent upon air temperature, humidity and wind speed, thus the average precipitation amounts decrease from north to south, with $0.8 \mathrm{~mm}$ in Arica, to $1.20 \mathrm{~mm}$ in Antofagasta [44]. Research performed over a 4 year period in the central portion of the Atacama recorded a single precipitation event occurring at midnight that measured $2.3 \mathrm{~mm}$. Averaged over 4 years the annual precipitation amount would 
be $0.58 \mathrm{~mm} /$ year. The differing infiltration of the fog establishes a gradient of flora and fauna decreasing from the southern desert to the northern areas [42]. The surface of the Atacama consists of sand and pebbles. Approximately 550 plant species manage to exist in this xeric land, with numbers increasing with proximity to the fog zone. The only animals found in the dry areas are arachnids, insects, lizards, mice, fox and some birds. The fog zones show an increase in the number of observed birds.

Polar deserts exist due to the extremely cold, dry air, bringing very little moisture to the area. The Antarctic plateau averages $51 \mathrm{~mm}$ of precipitation per year, whereas coastal areas may experience up to $510 \mathrm{~mm}$ rainfall. In many cases, the precipitation is very light so little is absorbed into the ground, even during the summer season. Mean Antarctic temperatures range from $-55^{\circ} \mathrm{C}$ at Vostok Station, to $-49^{\circ} \mathrm{C}$ at the South Pole. Daily temperature ranges from $-50^{\circ} \mathrm{C}$ to $20^{\circ} \mathrm{C}$ have been measured during the austral summer. The continent has the lowest average humidity of any location on earth - less than $10 \%$, with humidity often dropping to as low as $1 \%$. Should melting of ice occur due to seasonal temperature increases, the ice may sublimate, resulting in no liquid water production. These polar areas may have snow drifts, frozen ground or gravel and boulders. Often the freeze-thaw cycle seen in the Antarctic create hexagonal patterned textures in the ground that have recently been observed on Mars $[40,45]$. 


\section{Soil Microbial Diversity}

The study of soil microorganisms has been very important in terms of agriculture. Plants and microbes have interesting interactions, each providing nutrients to the other, and often dictating what grows where. According to Atlas, there are $10^{6}-10^{9}$ bacteria per gram of soil [3]. Soil provides numerous microhabitats that offer protection, water and minerals to a variety of microbes. Aerobes make use of extensive surface areas on organic litter, as well as irregular rocks and soil particles. Facultative and strict anaerobes find appropriate anoxic conditions at depth and particularly in flooded soils. The diversity of niches results in a wide variety of bacteria associated with soil. Acinetobacter, Arthrobacter, Bacillus, Caulobacter, Clostridium, Micrococcus Pseudomonas, Streptococcus and Xanthomonas are just a few of the genera identified from soil samples.

Studies of soil microbial diversity in extreme environments were initially performed using various clinical laboratory media for culturing microbes extracted from soil samples. A 1962 study of Ross Island in the McMurdo Sound of Antarctica plated dilutions of samples on nutrient agar, Sabouraud Dextrose Agar, Thornton's standardized agar, and ferric ammonium-citrate-nitrate medium. Algae as well as Eubacteria and Archaea were isolated, including Chromatium minutissimum, Bacillus stearothermophilus, Bacillus licheniformis, Micrococcus cryophilis, Flavobacterium peregrinum, Pseudomonas fluorescens, and molds from the genera Penicillium and Aspergillus. Culture media for soil microbes has 
progressed from general media to lower levels of nutrients more suggestive of the original chemical makeup of the soil. Previously uncultured bacteria have been identified by employing low-nutrient culture media, thus introducing new genera to the families Acidobacteria, Actinobacteria, Verrucomicrobia, and Planctomycetes. [11]

Microbial diversity of soil communities has also been determined using molecular techniques based upon the evolutionary alterations to the 16S rRNA gene. Fierer, et al. used 16S rRNA genes and metagenomic techniques to create clone libraries for bacteria, Archaea, fungi and viruses taken from three different soils: the Mojave Desert in southern California, the Kansas prairie and the rainforest of Peru. Using parametric models to estimate the diversity of the different microbial communities, they estimated that the highest number of operational taxonomic units (OTUs) for the Archaea was found in the desert, the highest diversity for fungi was in the prairie soils, and viruses demonstrated highest diversity in rainforest soils. The bacterial diversity remained relatively constant regardless of the sample. The archaeal diversity in the arid environment was mentioned as unusual. The authors proposed that this may result from the decreasing competition from bacterial communities that are under greater stress in such extreme conditions. The high diversity of fungi in prairie lands was supported by a previous study of the Konza Prairie. No other concise analysis of viral diversity in soils has been undertaken. Comparisons of the viral 
sequences to GenBank led to the observation that the viral communities differ due to bacteria in distinct habitats [23].

\section{Microbial Diversity in Arid Deserts}

Arid deserts are found on all continents except Europe. Their environments are characterized by sand dunes, clear blue skies, little to no vegetation, reptilian creatures and no visible water. The Sahara Desert in northern Africa, the Judean Desert in Israel and the Arabian Desert of Saudi Arabia are typical examples of arid deserts. Investigations of microbial diversity in these extremely hot and dry regions vary with technique and microbial groups investigated. The molecular techniques of nested PCR, 16S rDNA clone libraries and colony hybridization were used on soil from Sturt National Park in New South Wales, Australia [32] to identify species of Rubrobacter. Culture techniques and microscopic examination were employed to examine protozoa in central Australia, bacteriophage forms in the Sahara, and fungi found in Egypt and around the Dead Sea of Israel and Jordan [55, 29, 58, 54].

The Australian studies focused on specific groups of microorganisms - the subclass Rubrobacter in the high $\mathrm{G}+\mathrm{C}$ phylum Actinobacteria, and the variety of protozoa in the soil and in cyanobacterial crust. Rubrobacter clones were isolated from eight samples and analyzed using 16S rRNA gene amplification. Resulting clone libraries indicated a high abundance of Rubrobacter in these samples, which was verified by group-specific probe hybridization. The summary 
of this research expressed as a phylogenetic tree indicated four deep-branching, highly diverse monophyletic groups: Actinobacteria, Acidimicrobidae, Coriobacteridae and Rubrobacteridae. The Rubrobacteria further split into three groups, which were not evenly represented in existing clone databases, and the predominant Rubrobacter species identified in the Sturtz National Park were not the predominant species identified in previous studies of desert soil bacteria [32].

The protozoa of Australian deserts were analyzed from 27 samples collected from bare soil between plants, under termite mounds, under plant litter, from plant hummocks and from cyanobacterial crust. Numbers of each type of protozoan were determined using stained slides, plaque counts, and microtiter plates. The results indicate 145 species of protozoa exist in arid soils. Forty-two flagellates were counted, with 9 species being identified. Amoebae were the most abundant, with the Acanthamoeba genus present at 24 of the 26 sample sites. The ciliates were primarily under plants and termite mounds, and 57 species were found with 52 identified to the species level. The most prominent ciliate was the genus Holosticha. Protozoa tests were also more abundant in litter or under plants, though only $10 \%$ of the tests were inhabited. The predominant testacea was the genus Euglypha. The sample from the cyanobacterial crust was shown to house an amoeba, Thecamoeba, and a ciliate, Nassula picta, which were consuming the bacteria filaments, as well as two heliozoans, and several other ciliates [55]. 
Steiman, et al. presented a survey of fungal organisms in arid soils around the Dead Sea in Israel and Jordan. Fifty-six samples were taken, incorporating the upper 10 centimeters of soil, and were isolated via culturing plates. Further analysis of the soil included determination of the level of soluble salts and recording the $\mathrm{pH}$ of the soil in each sample. With some exceptions, the salt content was found to decrease with distance from the Dead Sea and the data indicated that the number of isolates was inversely proportional to the salt content of the soil. The first journal article concentrated on identifying organisms of the taxonomic classes Ascomycetes, Basidiomycetes, and Zygomycetes. Twenty-three genera and 90 species were isolated from the 56 soil samples, with the most plentiful fungi being of the order Eurotiales - a sac fungi, with the genera Aspergillus, Eurotium and Penicillium found most often. Most of the more common fungi had been previously noted in related research on the arid soils of the area and are, in fact worldwide in distribution. New species were identified for genera Aspergillus and Microascus [63].

The second paper from the same research group examined the fungi of the class Deuteromycetes that were not of the genera Aspergillus or Penicillium. From the 56 soil samples analyzed, 51 genera and 106 species were identified. The most common genera were from the class Dematiaceous hyphomycetes and were Alternaria, Botrytic, Cladosporium, and Ulocladium. The genus Fusarium from different taxa was also very common [29]. 
Prigent, et al. analyzed 13 surface sand samples of the Sahara in Tunisia and Morocco for the presence of bacteriophages. The technique used to identify possible phage particles involved two methods of phage extraction resulting in phage suspensions- direct chemical extraction with centrifugation and extraction with incubation. The phage suspensions were placed on microscopy grids and stained with $1 \%(\mathrm{w} / \mathrm{v})$ phospho-tungstenic acid, then examined by electron microscope. Bacteriophages were extracted from the soil through a process of sonication, gravity sedimentation, centrifugation and filtration. Bacteriophage nucleic acids were then isolated with buffer-saturated phenol, ether extraction and ethanol precipitation. Electrophoresis in 1\% agarose gels were treated with ethidium bromide for visualization. The 13 sites produced from 4 to 44 viral particles observable with a transmission electron microscope. The morphologies of the viral particles corresponded to the Myoviridae, the Siphoviridae and the Podoviridae families [54].

Bacterial and Archaeal microorganisms were identified from sand dunes in south Tunisia. Colonies were cultured on 0.1xTSA medium, the DNA was extracted, and partial sequencing of the 16S rRNA gene was performed. Bacterial diversity was determined from 117 sequences, and indicated a predominance of Proteobacteria - primarily in the $\gamma$-Proteobacteria sub-phylum, Actinobacteria and Acidobacteria. The 43 Archaeal clones were all members of a non-thermophilic group of Crenarchaeota. Radiation tolerance was also detected by exposing $1 \mathrm{~g}$ of sand to a $15 \mathrm{kGy}$ cobalt-60 source, which was then 
cultured and analyzed. Nine morphotypes were identified, four associated with the genus Bacillus, two were associated with phylum Deinococcus-Thermus, and the remaining three were related to two genera in $\alpha$-Proteobacteria [14].

As the previous descriptions of research suggest, the arid deserts have been the focus of many in-depth studies concerning a variety of microorganisms. While the primary focus is simply to expand the knowledge of microbial communities in such extreme environments, the relationship between these microorganisms and humans, animals and crops is also of tremendous interest and concern. The identification of fungi associated with such dry environments contributes to a problem observed in the dry southern areas of California. Though not as extreme as the Dead Sea, winds often introduce fungal spores into the air and result in an increase in fungal respiratory diseases. Thus, the identification of possible pathogens may insure proper preventive measures for the local animal population.

The presence of bacteriophages in the Sahara indicates the presence of a variety of bacterial host, which may not be discernable using typical culture techniques or may be found in such low numbers that molecular techniques do not adequately represent them. Furthermore, the studies concerning Bacteria and Archaea continue to expand the range of harsh environments populated by members of these domains. These arid environments present such incredible swings in diurnal temperatures, moisture, and humidity, and exhibit very high levels of ultra-violet radiation, as well as extremely low levels of nutrients, making 
these deserts inhospitable for most of the species on Earth. Yet, even here we find populations of microorganisms managing to survive.

\section{Microbial Diversity in Semi-arid Deserts}

Semi-arid deserts are common in North and Central America, China and South America. These deserts typically contain many shrubs and small nocturnal mammals, and have more precipitation than the arid deserts due to seasonal monsoon rains. Molecular techniques were used to examine cyanobacterial crusts in Utah, and to determine the bacterial composition of soil samples from Northern Arizona $[28,39,20]$. Also in Utah, protozoa were isolated and identified using culture techniques [7]. Eastern Washington's desert environment provided soil samples from an elevation transect that were chemically analyzed to determine the microbial biomass, nitrification potential, mineralizable carbon and nitrogen [58].

Garcia-Pichel, et al. examined four cyanobacterial crusts from the Colorado Plateau in Utah to identify the components of the crusts and the soil substrate. The polyphasic approach involved microscopic examination of the Cyanobacteria to group into morphologically distinct clusters, and the molecular analysis of the 16S rRNA genes using Denaturing Gradient Gel Electrophoresis (DGGE). The soil was categorized as silt, gypsum, shale, or sandy soils. Six cyanobacterial morphotypes were isolated and identified microscopically as belonging to the genera, Shcizothix and Scytonema - found in all soil types, 
Phormidium - not found in shale, Nostoc - found only in gypsum and silt, Chlorogloeopsis - found only in silt, and Microcoleus, specifically the species vaginatus - not found in gypsum. Single cells and filaments were teased apart and cultured separately. DNA was also extracted from dry desert crust, and used as template for PCR. The resulting $450 \mathrm{bp}$ fragments were then processed using DGGE. Phylogenetic analysis using sequences from the DGGE bands resulted in six distinct cyanobacterial clusters. Five clusters proved to be novel, contradicting the microscopic analysis. Analysis of the data demonstrates that: 1. morphological identification clearly underestimates the diversity of cyanobacterial crusts; 2 . the physiochemical conditions of soil greatly influence the cyanobacterial species; 3 . Microcoleus vaginatus is the dominant species in these crusts, and 4. the presence of the filamentous species grouped as Xeronema are ubiquitous and are related to the morphological genera Schizothrix and Phormidium [28].

Protozoa found in Utah's Great Basin were identified by culturing soil samples collected in two locations: north of the Great Salt Lake where the average precipitation is $300 \mathrm{~mm}$ and close to Bonanza, Utah - annual precipitation of $200 \mathrm{~mm}$. The samples were tested for water content and $\mathrm{pH}$, then $2 \mathrm{~g}$ samples of each were plated and cultured for protozoa. Thirty-four species of protozoa were found and all but four are considered cosmopolitan, or commonly found species. The most common protozoa of the cool deserts were ciliates, followed by the flagellates. Further analyses of the data indicate that protozoa 
inhabit pores located between or inside the mineral particles where water is trapped by capillary processes. Thus, the distribution of protozoa is dependent upon the physical characteristics of the soil [7].

Conditions similar to the Great Basin Desert extend through eastern Oregon and Washington. An elevation transect in southeastern Washington State provided samples to investigate climate change and microbial activities. Twenty-five sample sites between elevations of $228 \mathrm{~m}$ to $844 \mathrm{~m}$ were selected at $25 \mathrm{~m}$ elevation increments. This transect represented a mean annual maximum temperature decrease from 30 to $24^{\circ} \mathrm{C}$. The samples were analyzed for $\mathrm{pH}$, electrical conductivity, soluble carbon, inorganic nitrogen, total carbon and nitrogen and biomass. Other sample measurements were made for dehydrogenase activity, nitrification potential and total mineralizable carbon and nitrogen. The biomass was calculated by using substrate-induced respiration (SIR), which relates the ratio of $\mathrm{CO}_{2}$ to biomass carbon. Flasks of prepared soil were weighed, and then glucose was added to each sample. The flasks were incubated for 2 hours and the evolution of $\mathrm{CO}_{2}$ was then measured by gas chromatography. The biomass results indicated no difference in biomass with elevation, but a notable difference in biomass between grassy soil and crustal soil consisting of seedless plants such as mosses, algae, ferns and fungi [58].

Two articles were based upon a study done by the Environmental Molecular Biology Group of Los Alamos National Laboratory that compared two sample sites on the cinder cone of Sunset Crater to two sites in the Coconino 
National Forest approximately $30 \mathrm{~km}$ away. Each site was sampled under plants and between plants. The two sites exhibited different soil and tree concentrations; however the inorganic nitrogen concentrations were similar. Other organic materials were in much lower concentration on Sunset Crater than at the forest site. DNA was extracted and used as template for PCR of the $16 S$ rRNA gene. The initial research resulted in the sequencing of 16 clones from each soil sample (total of 60 clones), which were partially sequenced and analyzed. Four clones were dropped from the analysis after being identified as chimeric artifacts or contained extraordinarily long insertion sequences and unknown origin. Out of the remaining 56 clones, 20 proved to be associated with previously known or identified bacterial groups, primarily with Proteobacteria, gram-positive organisms and flexibacteria. The remaining $64 \%$ of the sequences represented novel bacterial groups and actually fell into 5 clades. Four of the clades appear closely related to the Acidobacteria; however the fifth group appears to be more closely related to the common ancestor [39].

The second study performed with the same samples involved the comparison of molecular techniques to culturing. The soil samples were used to inoculate culture plates, which were incubated and purified by streaking. Restriction fragment length polymorphism identified genera, resulting in 801 clones and 179 isolates. Sequencing of these resulted in the identification of 526 RFLP patterns. Analysis of the isolate and the clone RFLP patterns showed differences in phylogenetic diversity. Data from the cultured organisms indicate 
most of the bacteria were from the phylum 'Gram Positive', whereas the clone libraries based upon the RFLP analysis indicated the phylum Acidobacteria were the dominant bacteria [20].

Several studies have been performed to identify Archaea in semi-arid deserts around the world. The Great Salt Plains National Wildlife Refuge encompasses a highly saline river bottom area. Extreme conditions of the area include daytime temperatures of over $50^{\circ} \mathrm{C}$, desiccating winds, low humidity, intense UV radiation, and an alkaline $\mathrm{pH}$. Caton et al. cultured microbes from soil samples then extracted DNA from the isolates. Nineteen phylotypes related to the archaeal halophiles, were identified, specifically Haloarcula, Haloferax, Halorubrum, Haloterrigena and Natrinema. The archaeal diversity demonstrated by the isolates was shown to be representative of the environment by rarefaction curves, indicating a rather low level of diversity in this sampling area [13].

A different alkaline lake bed was the sample site for investigating Archaea capable of reducing nitrate. Lake Texcoco near Mexico City is a central desert area very similar to the Chihuahuan Desert to the north. Rather than use the 16S rRNA gene for sequencing, primers for the archaeal narB and nirA genes were used for amplification and then used to create clone libraries. The resulting sequences from narB and narA indicated close association with the Halobacteriaceae [5]. 


\section{Microbial Diversity in Coastal Deserts}

The coastal deserts are restricted to the western coast of South America and Africa. The Atacama Desert in Chile is situated between the Pacific Ocean and the Andes Mountains and extends from $20^{\circ}-30^{\circ}$ South latitude - the horse latitudes. The altitude of the desert ranges from 800 to $1200 \mathrm{~m}$ above sea level. The ocean currents, a coastal mountain range, and a strong high-pressure system are responsible for the extreme aridity of the area [42]. Due to the extremely low humidity and lack of liquid water for many years at a time, this area has become regarded as a terrestrial analog to Mars. Research performed there may result in new experiments or techniques that can be incorporated into a robotic or possibly a manned mission to the red planet.

D.R. Bagaley examined microbial life in the Yungay region of the Atacama by making culture-dependent dilution plates of 33 samples. Five media were used to culture heterotrophic microbes: plate count agar, marine agar, nutrient agar, 0.1 strength plate count agar and 0.01 strength plate count agar. Broth cultures of each media were also used. Counts were made of the colony forming units (CFUs) per gram of soil for each plate resulting in a range of CFUs from 0 to $7.4 \times 10^{5} \mathrm{CFU} / \mathrm{g}$ soil on 0.1 strength plate count agar. Isolates were then use as template for amplification of the 16S rRNA gene to sequence and identify the bacteria. Most of the bacteria were identified as from the phylum Actinobacteria and specifically from the genus Blastococcus. The remaining bacteria fall under the phyla Proteobacteria and Firmicutes [6]. 
Another study examined the possible relationship between bacteria and fungi, particularly the vesicular arbuscular mycorrhizae (VAM), in the Atacama Desert. VAM are fungi, which exist, in a symbiotic relationship with plant roots. The researchers examined the difference in soil constituents and microbial biomass from two sampling areas: "fertility islands," represented by native shrubs, and between plants after periods of drought and periods of above average rainfall. During the fall or dry season, soil samples were taken under randomly selected shrubs. Adesmia bedwellii is a thorny shrub providing 2.6$5.7 \%$ coverage of the study site. Several other samples were taken a distance of $5 \mathrm{~m}$ from the shrub canopy. Soil samples were again taken from the same locations at the end of the rainy season, resulting in 48 soil samples total. Chemical analysis was performed for $\mathrm{pH}$, organic matter concentration, electrical conductivity, available phosphorus and soil moisture. Dilution plates were used to culture bacteria and fungi, using plate count agar for bacteria and potato dextrose agar for fungi. The results of the soil characteristic analysis indicated that only the soil moisture content and $\mathrm{pH}$ differed in the dry and rainy seasons. The soil under the canopy showed a significantly higher amount of organics and nitrogen, and the values doubled during the wet season. Microbial population under the canopy was observed to increase by two orders of magnitude compared to the intraspace samples during the dry season. However, the difference between the canopy and between-shrub areas was lower during the rainy season. VAM spores were also counted and plant root infection by these 
spoors was determined. Analysis indicated that spoor infections were low during periods of increasing organic matter and nitrogen, indicating that the mycorrhizal infection allows the desert shrub to overcome the environmental stress of drought conditions [4].

\section{Microbial Diversity in Cold Deserts}

The cold deserts are located where the availability of liquid water is restricted by extremely cold air/winds, year round snow, ice pack and low surface temperatures. These conditions inhibit plant growth and place severe restrictions on microbial growth. The higher peaks of many mountain ranges and portions of Antarctica, Greenland, and islands of Russia and Canada experience these types of extreme conditions [45]. Given a rather high relative humidity range of $66-78 \%$, average annual precipitation ranges from 10.33 to $24.45 \mathrm{~mm}$. Average temperatures range from $-6.71^{\circ} \mathrm{C}$ in summer to $-15.32^{\circ} \mathrm{C}$ in winter [44].

Microbial activity in the frozen soils of the Arctic has been assessed by measurements of the carbon dioxide produced by bacteria as the final product in respiration. Three sites from Arctic areas were selected: Barrow, Alaska, West Siberia and Kopparas Mire in Sweden. These sites differ in length of time the soil is frozen and average air temperatures. The presence of $\mathrm{CO}_{2}$ and thus, respiration was measured for temperatures down to $-39^{\circ} \mathrm{C}$, indicating that microbes were active at all three sites even at that extreme temperature [49]. 
The relative abundance and diversity of bacteria were assessed by serial analysis of ribosomal sequence tags (SARST) on soil samples from three arctic tundra sites and three boreal forest sites, encompassing a latitude range from $47^{\circ}$ to $82^{\circ} \mathrm{N}$. SARST generated a total of 12,850 ribosomal sequence tags (RSTs) and produced the largest collection of 16S rRNA gene sequences from environmental samples to date. RSTs are genus or species specific thus were used to provide phylogenetic information on the microbial community. The results indicated higher diversity in the undisturbed Arctic tundra sites than in the forest soil, which counters the assumption that diversity decreases as sampling approaches the polar region. The resulting RSTs showed affiliation with the alpha, beta, gamma and delta Proteobacteria, Acidobacteria, Firmicutes, Aquificae, Nitrospira, Planctomycetes, Verrucomicrobia and Cyanobacteria though eleven others were unclassified at the genus level [47].

Biolog sole-carbon-source utilization microplates were used to assess microbial diversity and community structure for three arctic samples sites. Replicate soil samples were taken from three sites: one located in proximity to human settlement, another taken at the foot of bird rock perches, and the third site was from unenriched tundra. The Biolog microplates offered 95 different carbon sources for utilization by a community of microorganisms. Inoculated plates were incubated at $30^{\circ} \mathrm{C}, 10^{\circ} \mathrm{C}$ and $4^{\circ} \mathrm{C}$ for 29 days. The resulting pattern of carbon source utilization was then analyzed statistically using multiple methods. Based upon color development within the 96 wells, indicating growth 
due the utilization of the specific carbon source, calculations of the Shannon index, Shannon evenness and the Jaccard coefficients were made [19]. Interestingly, the results indicated that color development was dependent upon incubation temperature. The colder temperatures yielded the greatest differences in indices, richness and substrate utilization. Between the three sample sites, the Shannon diversity indices were not significantly different at incubation of $30^{\circ} \mathrm{C}$, but at the lower temperatures the diversity indices of the tundra dropped lower than for the other two sites that were influenced by human and animal presence and thus had a higher content of organic material. Substrate richness, or the number of available substrates providing growth requirements, was less for the tundra than the other two soils [19].

\section{Microbial Diversity in Antarctica}

Antarctica has been the site of active microbial investigation since the early 1960s. Researchers have examined bacteria, archaea, protozoa and fungi found in coastal areas as well as the dry valleys, to ascertain how these microbes manage to survive the cold, dry and windy conditions.

Boyd, et al. in 1962 and Cameron, et al. in the late '60s performed early studies of Antarctic microbes. Boyd's study was based on Ross Island in the McMurdo Sound and consisted of three soil sites - a rookery, an area supporting lichen growth, and a site with no obvious supply of organic matter. Cameron's study was based in Wheeler Valley - one of the dry valleys of Antarctica. The 
sample sites for Wheeler Valley followed a transect of the valley and consisted of 6 samples. Both studies based their results primarily on culturing soil microbes on a variety of media. Cameron's data was categorized in terms of the type of microorganisms and the biochemical characteristics of the bacteria, such as oxygen usage, lactose fermentation and nitrate/sulfate reducers [11, 12].

Boyd's data was analyzed to examine Ross Island bacteria by genus and species. Azotobacter chroococcum, Bacillus, Micrococcus cryophilis, Streptomyces, Flavobacterium, Achromobacter and Pseudomonas spp were identified, though many were associated with anthropomorphic sources. Few filamentous fungi were present, though Penicillium and Aspergillus were identified at one site [11].

Other early studies of Antarctica indicated that the community of Antarctic soil microbes belong to a limited number of cosmopolitan taxa, are primarily aerobic, and related to the genera Arthrobacter, Brevibacterium, Cellulomonas, Corynebacterium as well as the gram-negative Eubacteria and Firmicutean bacteria. Cyanobacteria were also identified, but thought to be restricted to only coastal, moist environments [26].

Pointing, et al. examined three niches occupied by bacteria in the Dry Valleys. Endoliths are bacteria that colonize tiny spaces or pores inside rocks. Chasmoliths inhabit cracks or fissures in rocks. These two groups of bacteria are associated with the higher altitude valleys of the region. Hypolithic bacteria live under translucent rock, where sunlight is able to pass through the rock, allowing 
photosynthesis for carbohydrates, and where moisture is trapped and does not sublimate. These niches were examined for the presence of bacteria, archaea, and algae by amplification of extracted DNA using primers specific for the bacterial and archaeal 16S rRNA gene and the eukaryotic 18S rRNA gene. No archaeal genes were amplified after numerous PCR adjustments, indicating that archaea were not part of the microbial communities in the Dry Valleys. Evaluation of resulting clone libraries indicated the Chroococcidiopsis and Nostocales were the predominant Cyanobacteria found as endoliths and chasmoliths, and the hypoliths were Oscillatoriales. Chloroflexi was also found in the soil samples and as an endolith. Fourteen other phyla were identified in the soils of the Dry Valleys, though only Acidobacteria and Actinobacteria were ubiquitous. Eukaryotic analysis indicated the presence of algae - specifically Chlorphyta, and two fungi - Ascomycota and Basidiomycota. The algae were associated with the soil and all lithic niches, however the fungi were only associated with endoliths and chasmoliths [52].

The 5S rRNA sequence was used to investigate endolithic microorganisms from the Linnaeus Terrace of the Upper Wright Valley in the McMurdo Dry Valley region of Antarctica. This study reflected an interest in cryptoendolithic microbes inhabiting the "porous sandstone rocks" of the area. These organisms take the form of lichens involving algae or Cyanobacteria and fungi, accompanied by free-living microbes. In many cases, these communities are visible as green zones between crystals or rock layers. The $5 \mathrm{~S}$ rRNA 
fragments retrieved from three soil samples were sequenced and analyzed by cluster analysis involving principal component analysis and the construction of a phylogenetic tree. The resulting $5 S$ rRNA sequence was matched to a marine species Vibrio and verified by the construction of an evolutionary tree [17].

A recent study by Smith, et al. compared results from previous culturing methods of microbial identification to identification of bacteria using molecular techniques based upon the 16S rRNA gene. Three sites within the Dry Valleys of the Ross Dependency of Eastern Antarctica were sampled. The sites ranged from sea level under the carcass of a crabeater seal, to a mid-slope site in Miers Valley to a high altitude site in Penance Pass. The samples were processed for protein, lipid, DNA and water content. PCR and DGGE were used to make clone libraries from the sequencing of plasmids. The resulting 181 clones indicated that there were unique patterns for $57 \%$ of the carcass site, $51 \%$ of the mid-slope site, and $43 \%$ for the high altitude site. The dominant phyla at the three sites were uncultured environmental clones, Actinobacteria, and Cyanobacteria, respectively. The latter two phyla agree with the previously identified culturedependent studies. However, the previously isolated organisms from Achromobacter, Bacillus, Corynebacterium, Micrococcus, Planococcus, or Pseudomonas were not evident in this analysis. Conversely, Acidobacteria, Verrucomicrobia, and Bacteriodetes are not found in historical or recent culturebased libraries yet are major constituents of the soil community based upon $16 \mathrm{~S}$ rRNA gene analysis [59]. 
In summary, desert soil communities have been examined for different microbiological populations for many years. No comprehensive studies focusing on similar treatment of samples have been performed for a single microbial group in multiple desert environments. An analysis of the previously mentioned research (Table 2) is difficult to assess in terms of a concise description of microbial soil communities existing under conditions of limited liquid water.

Table 2. Summary of microbial research in different types of deserts

\begin{tabular}{|c|c|c|c|c|c|c|}
\hline $\begin{array}{l}\text { Eubacteria: } \\
\text { Phylum }\end{array}$ & Arid & $\begin{array}{l}\text { Semi- } \\
\text { arid }\end{array}$ & Coastal & Cold & Antarctica & References \\
\hline Acidobacteria & $x$ & $x$ & & $x$ & $x$ & $14,17,20,38,46$ \\
\hline Actinobacteria & $x$ & & $x$ & & $x$ & $6,11,14,26,31,58$ \\
\hline Aquificae & & & & $x$ & & 46 \\
\hline Bacteriodetes & & $x$ & & & $x$ & $11,20,38$ \\
\hline Chloroflexi & & & & & $x$ & 52 \\
\hline Cyanobacteria & & $x$ & & $x$ & $x$ & $26,27,46,52,58$ \\
\hline $\begin{array}{l}\text { Deinococcus- } \\
\text { Thermus }\end{array}$ & $x$ & & & & & 14 \\
\hline Firmicutes & $x$ & & $x$ & $x$ & & $6,11,46$ \\
\hline Gram Positive & & $x$ & & & & 20,38 \\
\hline Nitrospirae & & & & $x$ & & 46 \\
\hline Planctomycetes & & & & $x$ & & 46 \\
\hline Proteobacteria & $x$ & $x$ & $x$ & $x$ & $x$ & $6,11,14,17,20,38,46$ \\
\hline Verrucomicrobia & & & & $x$ & $x$ & 46,58 \\
\hline
\end{tabular}


Table 2. (Continued)

\begin{tabular}{|c|c|c|}
\hline Archaea: Phylum & Genus & References \\
\hline Crenarchaeota & NA & 14 \\
\hline \multirow[t]{5}{*}{ Euryarchaeota } & Haloarcula & 5,13 \\
\hline & Haloferax & \\
\hline & Halorubrum & \\
\hline & Haloterrigena & \\
\hline & Natrinema & \\
\hline Protozoa: Order & Genus & References \\
\hline Acanthamoebidae & Acanthamoeba & 54 \\
\hline Thecamoebidae & Thecamoeba & \\
\hline Holostichidae & Holosticha & \\
\hline Euglyphidae & Euglypha & \\
\hline
\end{tabular}

Fungi: all from

Ascomycota

Ploesporaceae Genus

Alternaria

References

Ulocladium

Trichocomaceae

Aspergillus

Penicillium

Davidiellaceae

Cladosporium

Microascaceae

Microascus

mitosporic Hypocreales

Fusarium

\begin{tabular}{llc} 
Viruses: Order & Family & References \\
\hline Caudovirales & Myoviridae & 53 \\
& Siphoviridae & \\
& Podoviridae &
\end{tabular}




\section{Global Warming and Soil Health}

International organizations as well as individual countries are investigating the possible impact of global warming on arid and semi-arid regions of the world. In a 2007 report by the Intergovernmental Panel on Climate Change (IPCC) an international group of scientists examined evidence for altered climactic conditions due to man-made emissions of $\mathrm{CO}_{2}$ into the atmosphere compared to natural atmospheric cycles, and concluded that anthropogenic forces are the major factor driving climate change. Based upon current research and predictions from various climate modeling programs, the IPCC forecasts the following: 1- increasing temperatures, particularly in currently arid or semi-arid environments, 2 - a shift in precipitation patterns, and 3 - increasing frequency of extreme weather, climate and ocean level events over the next decade $[33,50$, $51]$.

Desertification, or the degradation of formerly productive land, is of major concern to governments living on the borders of the arid and semi-arid regions of Earth [65]. Human encroachment on fragile borderlands has enhanced desertification, however a growing concern focuses on climate changes resulting in the increase of desert borders, and a loss of pasture and crop lands. Degradation of sub-Saharan areas has been linked to global weather patterns, specifically the North Atlantic Oscillation (NAO) and the El Nino Southern Oscillation (ENSO). Observed vegetation dynamics of the Sahel were found to correlate to very closely to fluctuations in the NAO [48]. 
IPCC models also indicate desertification of semi-arid regions of Africa and an increase in periods of drought for the western United States and Canada, inland areas of Australia, portions of the Iberian Peninsula, large inland areas of Asia and possibly even the inhabited Arctic regions [10, 31, 1, 22, 18, 2]. Gao, et.al used three aridity measurements to analyze simulations of the Mediterranean countries to estimate alterations in precipitation and temperature due to global warming. Their results indicate a high probability that by the end of this century, the southern Mediterranean area, the peninsula areas, and southeastern Europe will experience an increase in arid lands, due primarily to global warming and decreased precipitation [27].

A 2007 study of climate models for southwestern North America further supports the IPCC findings. Out of nineteen climate models only one model indicated a wetter climate. Of 49 individual projections, only three gave rise to a wetter climate. The remaining projections indicated a warming and drying trend, measured by estimated precipitation - estimated evaporation (P-E). Models indicated movement of the Hadley Cell and Ferrell Cell poleward, expanding the tropical low pressure areas and dry zones [56].

To monitor the threat of global warming and possible resulting desertification of semi-arid regions, efforts are being made to identify indicator species that might be used to measure the expansion of arid conditions. Foissner suggests the use of certain protozoa as indicators of their environment. Because they are ubiquitous and single-celled organisms, they survive where few higher 
organisms do not, and since they are Eukaryotes, their genome more closely resembles higher organisms than the genomes of bacteria or archaea. This latter relationship offers a closer approximation for the response of animals and plants to changing conditions. For detecting oxygen depletion or enhancement, ciliates have shown to be very sensitive to $\mathrm{O}_{2}$ levels due to their need for microaerophilic or anaerobic conditions for growth and reproduction. Certain flagellates were shown to increase in concentration as $\mathrm{CO}_{2}$ levels increased, whereas naked amoebae decreased in concentration [24].

Bending, et al. examined possible indicators for managed farmland in Warwickshire, UK. The organic matter content (SOM) has been utilized as a bioindicators for the health of agricultural soils, and incorporates a variety of specific measurements: organic nitrogen, light-fraction organic matter (LFOM), and carbon from organic and inorganic substances. Also utilized were Biolog Gram negative sole-carbon-source microplates. These characteristics were measured and compared from two different soil treatments at three different times: August 1996, April 1997 and December 1997, thus allowing an opportunity to gauge changes in the microbial communities over time. One segment of the farmland was sown with rye grass, red clover, and ley. This area was mown and mulched on a monthly basis. The second segment of farmland was planted with Vicia sativa for winter months, then plowed under and replanted with spring barley and white clover. The results of the SOM measurements were to yield negligible differences between the two treatments of the soil, with subtle 
differences attributed to the season as opposed to the management treatments. However, the patterns of carbon usage presented by the Biolog GN plates reflected a notable difference in the treatments. Metabolic diversity was greater in the ley segment than in the crop rotation (second) soil treatment, particularly after the disruption of the microbial community due to plowing prior to planting the barley crop. Also, the carboxylic acid utilization was observed for the microbial community of treatment 1 over the fall and winter months, but subsided by the following winter. This may be due to a shift in the microbial community where, over time, different bacteria out-competed the carboxylic acid users. Thus, Biolog GN may prove to be helpful as an indicator of soil health [9].

\section{Summary}

The literature regarding microbial diversity in arid terrestrial environments is patchy in its coverage of both the geographically and characteristically similar deserts as well as its overall examination of microorganisms. A lateral comprehensive look at the microbial populations of deserts that have similar temperature ranges, annual precipitation, circulation patterns, and other physical characteristics would allow the determination of local microbial fauna vs. cosmopolitan visitors. A horizontal approach that would examine the microbial populations in deserts of varying degrees of precipitation, radiation, and temperature extremes would also allow the determination of species better equipped to survive the extremes of the desert environment. 
Most studies focus on one type of microorganism for identification and diversity measurements, and ignore possible interdependency or community aspect of microbial populations. Though probably requiring more time and expenses, a thorough investigation of the fungi, protozoa, archaea and bacteria in a single area would prove valuable and establish a basis for further community determinations in similar environments.

The various techniques for the determination of microbial diversity are constantly undergoing improvements. However, culturing bacteria for diversity measurements is no longer appropriate as the sole approach. When characterization of bacteria is required, or when attempting to examine protozoa, culturing is very useful, but molecular techniques and fluorescence microscopy offer a more quantitative approach to evaluating the broader picture of microbial communities.

Future research in microbial diversity of soil communities has many avenues to pursue, based upon the techniques and microorganisms of interest. However, more complete microorganismal studies and comparisons between desert areas offer basic general information that could be incredibly helpful for assessing an overall picture of microbial soil diversity. In turn, this would allow astrobiology researchers to gain a clearer idea of what to possibly expect on dry, cold planets such as Mars. 


\section{Specific Goals of This Study}

The goal of this research is to examine the bacterial and archaeal communities across an annual precipitation gradient to observe the following characteristics:

1. changes in diversity and numbers of Eubacteria and Archaea as a function of available water

2. potential indicator organisms that may reflect trends with regards to desertification

3. novel Eubacteria or Archaea identified by sequence analysis and phylogenetic relatedness

By incorporating two procedures: viable count plates and clone libraries, a more comprehensive understanding of eubacterial and archaeal desert soil communities may result, compared to the limited picture currently provided by a single technique 


\section{References}

1. Alcamo J, Moreno JM, Nováky B, Bindi M, Corobov, R, Devoy RJN, Giannakopoulos C, Martin E, Olesen JE, Shvidenko A ( 2007) Europe Climate Change 2007: Impacts, Adaptation and Vulnerability Contribution of Working Group II to the Fourth Assessment Report of the Intergovernmental Panel on Climate Change, Parry ML, Canziani OF, Palutikof JP, van der Linden PJ, Hanson CE, Eds, Cambridge University Press, Cambridge, UK, 541-580

2. Anisimov OA, Vaughan DG, Callaghan TV, Furgal $C$, Marchant $H$, Prowse TD, Vilhjálmsson $\mathrm{H}$, Walsh JE (2007) Polar regions (Arctic and Antarctic) Climate Change 2007: Impacts, Adaptation and Vulnerability Contribution of Working Group II to the Fourth Assessment Report of the Intergovernmental Panel on Climate Change, Parry ML, Canziani OF, Palutikof JP, van der Linden PJ, Hanson CE, Eds, Cambridge University Press, Cambridge, 653-685

3. Atlas RM, Bartha R (1998) Microbial Ecology, Fundamentals and Applications, Benjamin/Cummings Science Publishing, Menlo Park, California

4. Aguilera LE, Gutierrez JR, Meserve PL (1999) Variation in soil microorganisms and nutrients underneath and outside the canopy of Adesmia bedwellii (Papilionaceae) shrubs in arid coastal Chile following drought and above average rainfall. J Arid Environ 42: 61-70

5. Alćantara-Hernández RJ, Valenzuela-Encinas C, Zavala-Díaz de la Serna FJ, Rodriguez-Revilla J, Dendooven L, Marsch R (2009) Haloarchaeal assimilatory nitrate-reducing communities from a saline alkaline soil. FEMS Microbiol Lett 298; 56-66

6. Bagaley DR (2006) MS Thesis, Louisiana State University, Uncovering bacterial diversity on and below the surface of a hyper-arid environment, the Atacama Desert, Chile

7. Bamforth SS, Bennett LW (1985) Soil protozoa of two Utah cool deserts. Pedobiologia, 28: 423-426 
8. Bastida F, Moreno JL, Hernandez T, Garcia C (2006) Microbiological degradation index of soils in a semiarid climate. Soil Biol Biochem 38: 3463-3473

9. Bending GT, Putland DC, Rayns F (2000) Changes in microbial community metabolism and labile organic matter fractions as early indicators of the impact of management on soil biological quality. Biol Fertil Soils 31: 8-84

10. Boko M, Niang I, Nyong A, Vogel C, Githeko A, Medany M, Osman-Elasha B, Tabo Yanda R (2007) Africa Climate Change 2007: Impacts, Adaptation and Vulnerability Contribution of Working Group II to the Fourth Assessment Report of the Intergovernmental Panel on Climate Change, Parry ML, Canziani OF, Palutikof JP, van der Linden PJ, Hanson CE, Eds, Cambridge University Press, Cambridge UK, 433-467

11. Boyd WL, Boyd JW (1962) Soil microorganisms of the McMurdo Sound area, Antarctica. Appl Microbiol 11: 116-121

12. Cameron RE, King J, David CN (1970) Soil microbial ecology of Wheeler Valley, Antarctica. Soil Sci, 109 (2); 110-120

13. Caton TM, Caton IR, Witte LR, Schneegurt MA (2009) Archaeal diversity at the Great Salt Plains of Oklahoma described by cultivation and molecular analyses. Microb Ecol 58: 519-528

14. Chanal A, Chapon V, Benzerara K, Barakat M, Christen R, Achouak W, Barras F, Heulin T (2006) The desert of Tataouine: an extreme environment that hosts a wide diversity of microorganisms and radiotolerant bacteria. Environ Microbiol 8:524-525

15. Cohan, FM (2002) What are Bacterial Species? Annu Rev Microbiol 56:457-87 
16. Colwell RR (1970) Polyphasic taxonomy of the genus Vibrio: Numerical taxonomy of Vibrio cholerae, Vibrio parahaemolyticus, and related Vibrio species. J Bacteriol 104: 410-433

17. Colwell RR, MacDonell MT, Swartz D (1989) Identification of an Antarctic endolithic microorganisms by $5 S$ rRNA sequence analysis. Syst Appl Microbiol 11:182-186

18. Cruz RV, Harasawa H, Lal M, Wu S, Anokhin Y, Punsalmaa B, Honda Y, Jafari M, Li C, Huu Ninh N (2007) Asia Climate Change 2007: Impacts, Adaptation and Vulnerability Contribution of Working Group II to the Fourth Assessment Report of the Intergovernmental Panel on Climate Change, Parry ML, Canziani OF, Palutikof JP, van der Linden PJ, Hanson CE, Eds, Cambridge University Press, Cambridge, UK, 469-506

19. Derry AM, Staddon WJ, Kevan PG, Trevors JT (1999) Functional diversity and community structure of micro-organisms in three arctic soils as determined by sole-carbon-source-utilization. Biodivers Conserv 8:205221

20. Dunbar J, Takala S, Barns SM, Davis JA, Kuske CR (1999) Levels of bacterial community diversity in four arid soils compared by cultivation and 16SrRNA gene cloning. Appl Environ Microbiol 65:1662-1669

21. Falkow S, Rosenberg E, Schleifer KH, Stackebrandt E, Dworkin M (2006) The Prokaryotes: Volume 1: Symbiotic Associations, Biotechnology, Applied Microbiology, 3rd ed. Springer, New York, NY

22. Field CB , Mortsch LD, Brklacich M, Forbes DL, Kovacs P, Patz JA, Running SW, Scott MJ(2007) North America Climate Change 2007: Impacts, Adaptation and Vulnerability Contribution of Working Group II to the Fourth Assessment Report of the Intergovernmental Panel on Climate Change, Parry ML, Canziani OF, Palutikof JP, van der Linden PJ, Hanson CE, Eds, Cambridge University Press, Cambridge, UK, 617-652

23. Fierer N, Breitbart M, Nulton J, Salamon $P$, Lozupone $C$, Jones $R$, Robeson M, Edwards RA, Felts B, Rayhawk S, Knight R, Rohwer F, Jackson RB (2007) Metagenomic and small-subunit rRNA analyses reveal 
the genetic diversity of bacteria, archaea, fungi and viruses in soil. Appl Environ Microbiol 73:7059-7066

24. Foissner W (1999) Soil protozoa as bioindicators: pros and cons, methods, diversity, representative examples. Agric Ecosyst Environ 74: $95-112$

25. Franzman PD (1996) Examination of Antarctic prokaryotic diversity through molecular comparisons. Biodivers Conserv 5: 1295-1305

26. Friedman El (1993) Antarctic Microbiology. Wiley-Liss. New York, pp 634

27. Gao X, Giorgi $F$ (2008) Increased aridity in the Mediterranean region under greenhouse gas forcing estimated from high resolution simulations with a regional climate model. Glob Planet Change 62:195-209

28. Garcia-Pichel F, Lopez-Cortex A, Nubel U (2001) Phylogenetic and morphological diversity of Cyanobacteria in soil desert crusts from the Colorado Plateau. Appl Environ Microbiol 67: 1902-1910

29. Guiraud P, Steiman R, Seigle-Murandi F, Sage L (1995) Mycoflora of soil around the Dead Sea II - Deuteromycetes (except Aspergillus and Penicillium). Syst Appl Microbiol 18: 318-322

30. Harwood C, Buckley M (2008) The Uncharted Microbial World: microbes and their activities in the environment. Am Soc for Microbiol

31. Hennessy K, Fitzharris B, Bates BC, Harvey N, Howden SM, Hughes L, Salinger J, Warrick R (2007) Australia and New Zealand Climate Change 2007: Impacts, Adaptation and Vulnerability Contribution of Working Group II to the Fourth Assessment Report of the Intergovernmental Panel on Climate Change, Parry ML, Canziani OF, Palutikof JP, van der Linden PJ, Hanson CE, Eds, Cambridge University Press, Cambridge, UK, 507540 
32. Holmes AJ, Bowyer J, Holley MP, O'Donoghue M, Montgomery M, Gillings MR (2000) Diverse, yet-to-be-cultured members of the Rubrobacter subdivision of the Actinobacteria are widespread in Australian arid soils. FEMS Microbiol Ecol 33: 111-120

33. IPCC, 2007: Climate Change 2007: Impacts, Adaptation and Vulnerability Contribution of Working Group II to the Fourth Assessment Report of the Intergovernmental Panel on Climate Change, Parry ML, Canziani OF, Palutikof JP, van der Linden PJ, Hanson CE, Eds, Cambridge University Press, Cambridge, UK, 976pp

34. Kaeberlein T, Lewis K, Epstein SS (2002) Isolating "uncultivable" microorganisms in pure culture in a simulated natural environment. Science 296: 1127-1129

35. Kirk JL, Beaudette, LA, Hart M, Moutoglis $\mathrm{P}$, Klironomos JN, Lee $\mathrm{H}$, Trevors JT (2004) Methods of studying soil microbial diversity. J Microbiol Methods 58:169-188

36. Koeppel A, Perry EB, Skiorski J, Krizanc D, Warner A, Ward DM, Rooney AP, Brambilla E, Connor N, Ratcliff RM, Nevo E, Cohan FM (2008) Identifying the fundamental units of bacterial diversity: a paradigm shift to incorporate ecology into the bacterial systematics. Proc Natl Acad Sci USA 105: 2504-2509

37. Konstantinidis KJ, Tiedje M (2004) Genomic insights that advance the species definition for prokaryotes. Proc Natl Acad Sci USA 102: 25672572

38. Krebs C (2001) Ecology. Benjamin Cummings, San Francisco, CA, pp 617-618

39. Kuske CR, Barns SM, Busch JD (1997) Diverse uncultivated bacterial groups from soils of the arid southwestern United States that are present in many geographic regions. Appl Environ Microbiol 63: 3614-3621 
40. Laity J (2008) Deserts and Desert Environments, John Wiley \& Sons, Ltd, Chester, West Sussex, UK

41. Mola RR, Marquez MC, Arahal DR, Mellado E, Ventosa A (1997) Polyphasic Taxonomy of Nesterenkonia halobia. J System Bacteriol 47: 1231-1235

42. McKay CP (2002) Too dry for life: the Atacama Desert and Mars. Ad Astra, May-June, 30-33

43.43. Meigs $P$ (1957) Arid and semiarid climate types of the world In: Proceedings, International Geographical Union, 17th Congress, 8th General Assembly International Geographical Union, Washington DC, p135-8

44. National Oceanic and Atmospheric Administration (NOAA) Global Climate Normals, 1961-1990 \& World Meteorological Organization, http://www climate-charts com/World-Climate-Index-Map html

45. National Geographic/World Wildlife Fund: WildWorld Ecoregion Profile: Palaearctic Tundra Arctic desert: http://www.nationalgeographic.com/wildworld/profiles/terrestrial/pa/pa1101 $\underline{\mathrm{html}}$

46. Navarro-Gonzalez R, Rainey FA, Molina P, Bagaley DR, Hollen BJ, de la Rosa J, Small AM, Gomez-Silva B, McKay CP (2003) Mars-like soils in the Atacama Desert, Chile, and the dry limit of microbial life. Science, 302: 1018-1019

47. Neufeld JD, Mohn WW (2005) Unexpectedly high bacterial diversity in Arctic tundra relative to boreal forest soils, revealed by serial analysis of ribosomal sequence tags. Appl Environ Microbiol 71: 5710-5718

48. Oba G, Post E, Stenseth NC (2001) Sub-saharan desertification and productivity are linked to hemispheric climate variability. Glob Chang Biol 7: $241-246$ 
49. Panikov NS, Flanagan PW, Oechel WC, Matepanov MA, Christensen TR (2006) Microbial activity in soils frozen to below $-39^{\circ} \mathrm{C}$. Soil Biol Biochem 38: $785-794$

50. Parry ML, Canziani OF, Palutikof JP, Co-authors (2007) Technical Summary Climate Change 2007: Impacts, Adaptation and Vulnerability Contribution of Working Group II to the Fourth Assessment Report of the Intergovernmental Panel on Climate Change, M L Parry, O F Canziani, J $P$ Palutikof, $P \mathrm{~J}$ van der Linden and C E Hanson, Eds, Cambridge University Press, Cambridge, UK, 23-78

51. Persson AO (2006) Hadley's Principle: Understanding and Misunderstanding the Trade Winds. History of Meteorology. 3rd International Commission on History of Meteorology, Proceed of the Intern Comm History of Meteorology

52. Pointing SB, Chan Y, Lacap DC, Lau MCY, Jurgens JA, Farrell RA (2009) Highly specialized microbial diversity in hyper-arid polar desert. Proc Natl Acad Sci USA 106: 19964-19969

53. Prescott L M, Harley JP, Klein DA (2002) Microbiology, 5th ed McGrawHill, New York, NY

54. Prigent M, Leroy M, Confalonieri F, Dutertre M, DeBow MS (2005) A diversity of bacteriophage forms and genomes can be isolated from the surface sands of the Sahara Desert. Extremophiles, 9: 289-296

55. Robinson BS, Bamforth SS, Dobson PJ (2002) Density and diversity of protozoa in some arid Australian soils. J Eukaroyt Microbiol 49: 449-453

56. Seager R, Ting M, Held I, Kushnir Y, Lu J, Vecchi G, Huang H-P, Hamik N, Leetmaa A, Lau J-C, Li C, Velez J, Naik N (2007) Moldel projections of an Imminent transition to a more arid climate in southwestern North America. Science 315: 1181-1184 
57. Sharma R, Ranjan R, Kapardar RK, Grover A (2005) 'Unculturable bacterial diversity: an untapped resource.' Cur Sci 89: 72-77

58. Smith JL, Halvorson JJ, Bolton, Jr H (2002) Soil properties and microbial activity across a $500 \mathrm{~m}$ elevation gradient in a semi-arid environment. Soil Biol Biochem 34: 1749-1757

59. Smith JJ, Ah Tow L, Stafford W, Cary C, Cowan DA (2006) Bacterial diversity in three different Antarctic cold desert mineral soils. Microb Ecol 51: $413-421$

60. Stackebrandt E, Goebel BM (1994) Taxonomic Note: A place for DNADNA reassociation and $16 \mathrm{~S}$ rRNA sequence analysis in the present species definition in bacteriology. Int J Syst Bacteriol 44: 846-849

61. Stackebrandt E, Wilhelm F, Garrity GM, Grimont PAD, Kampfer P, Maiden MCJ, Nesme X, Rossello-Mora R, Swings J, Truper HG, Vauterin L, Ward AC, Whitman WB (2002) Report of the ad hoc committee for the reevaluation of the species definition in bacteriology. Int J Syst Evol Microbiol 52: 1043-1047

62. Stackebrandt E, Ebers J (2006) Taxonomic parameters revisited: Tarnished gold standards. Microbiol Today 33: 152-155

63. Steiman R, Guiraud P, Sage L, Seigle-Murandi F, Fafond JL (1995) Mycoflora of soil around the Dead Sea I - Ascomycetes (including Aspergillus and Penicillium), Basidiomycetes, Zygomycetees. Syst Appl Microbiol 18: 310-317

64. Torok T (2006) Microbial Diversity in Extreme Environments, Presented at Department of Biological Sciences Fall 2006 Graduate Seminars, November 15, 2006

65. Walker AS (2000) Deserts: Geology and Resources, Online Edition, United States Geological Survey, ASIN=B0013WOI74 


\title{
CHAPTER 2
}

Differences in Eubacterial and Archaeal Soil Communities along a Precipitation Transect in the Mojave Desert

\author{
E.P.Bryant ${ }^{1}$, C.P. McKay ${ }^{2}$ and S. Rech ${ }^{1}$ \\ ${ }^{1}$ Department of Biological Sciences, \\ San Jose State University, \\ San Jose, CA 95192-0100, USA \\ ${ }^{2}$ Space Science Division, \\ NASA Ames Research Center \\ Moffett Field, CA 94035, USA
}

\author{
Correspondence to: \\ Elaine Pressly Bryant \\ Department of Biological Sciences \\ One Washington $\mathrm{Sq}$ \\ San Jose, CA 95192-0100 \\ E-mail: Elaine.Bryant@sjsu.edu \\ Date submitted: April 2011
}

Short version of the title: Diversity of Archaea and Eubacteria along a Mojave Desert precipitation transect 


\section{Introduction}

The extreme arid biomes on Earth present microorganisms and higher life forms with unique challenges. All life on Earth requires liquid water, and therefore the discovery of microorganisms existing in soil of the Atacama Desert that receives a single precipitation event of $2.3 \mathrm{~mm}$ of rainfall in a period of four years was quite surprising [16]. The complex desert soil communities of Eubacteria and Archaea have proven difficult to assess, and have yet to be characterized in terms of the identities of the microbes, their function in the ecosystem, and their means of coping with the extremes of arid environments.

Understanding the relationship between microbial communities and precipitation may also prove useful in predicting effects of global warming. Resulting data might indicate possible conditions such as the presence or absence of certain bacteria or archaea, or changes in the microbial community that might reveal the advancement of desertification conditions. Identifying such indicator organisms or communities may allow conservationists and communities' time to develop appropriate responses to the decreasing moisture conditions [3].

The focus of this research is to detail changes in microbial communities along a precipitation transect through the Mojave Desert. The observable changes in vegetation, soil chemistry, and microbial populations provide discrete snapshots of macro and micro communities along the precipitation gradient. As climate change increases desertification, the communities in the higher annual rainfall sites should begin to resemble the communities further down the 
precipitation gradient, and offer insight into the changing microbial soil communities. The precipitation transect allows the identification of Eubacteria and Archaea capable of surviving longtime alteration of precipitation patterns.

The unculturability of many environmental bacteria also leads to difficulty in using traditional laboratory methods for the examination of bacterial communities. Whereas the use of special media allows for the growth and characterization of commensal bacteria, too little is known regarding specific requirements and conditions for the propagation and close study of environmental Eubacteria and Archaea. This results in the application of methods which examine the byproducts of life - chemical signatures which may be discerned from testing, or by examination of community DNA extracted from environmental samples.

With these concerns in mind a polyphasic approach was used to discern changes in microbial communities along a precipitation transect through the Mojave. Associated with decreasing precipitation and high summer temperatures should come decreased vegetation, decreased organic compounds in the soil, and changes in $\mathrm{pH}$ and salt content of the soil. The hypothesis based upon these conditions is that the microbial communities will decrease in number and diversity. The populations of the taxonomic classifications of Eubacteria and Archaea will also be affected due to an organism's ability to function in increasing adverse conditions and community competition. Viable counts and 16S rRNA gene sequences extracted from the microbial soil community will show changes 
in eubacterial and archaeal populations, as well as lead to identification of an organism which might serve as an indicator of increasing desertification.

\section{Methods and Materials}

Precipitation Transect. The data for this research project was collected as part of the NASA Spaceward Bound Mojave 2007, 2008 and 2009 programs. Spaceward Bound is a project sponsored by NASA to bring secondary science teachers and science education majors into the field with research scientists. Participants learn a variety of techniques used in research labs and then effect changes in their approach to teaching science in the middle school or junior high school. The teachers, which were interested in environmental microbiology, assisted with establishing the sample area, collecting samples, and preparing the samples for culture and molecular analysis.

The selection of sampling sites spanning a precipitation transect through southern California was based upon a rainfall map produced by the California Department of Forestry and Fire Protection, Fire and Resources Assessment Program (FRAP) [5]. Taken from annual average precipitation measurements from 1900 to 1960 , the map indicated a progression of annual precipitation from 9 inches $(23 \mathrm{~cm})$ in eastern Kern County to 3.5 inches $(9 \mathrm{~cm})$ around Baker, California. This $260 \mathrm{~km}$ transect follows state route 58 from Bakersfield to Barstow, and interstate 15 from Barstow to Baker, providing access to sampling sites along the precipitation gradient. Figure 1 shows the resulting transect. 


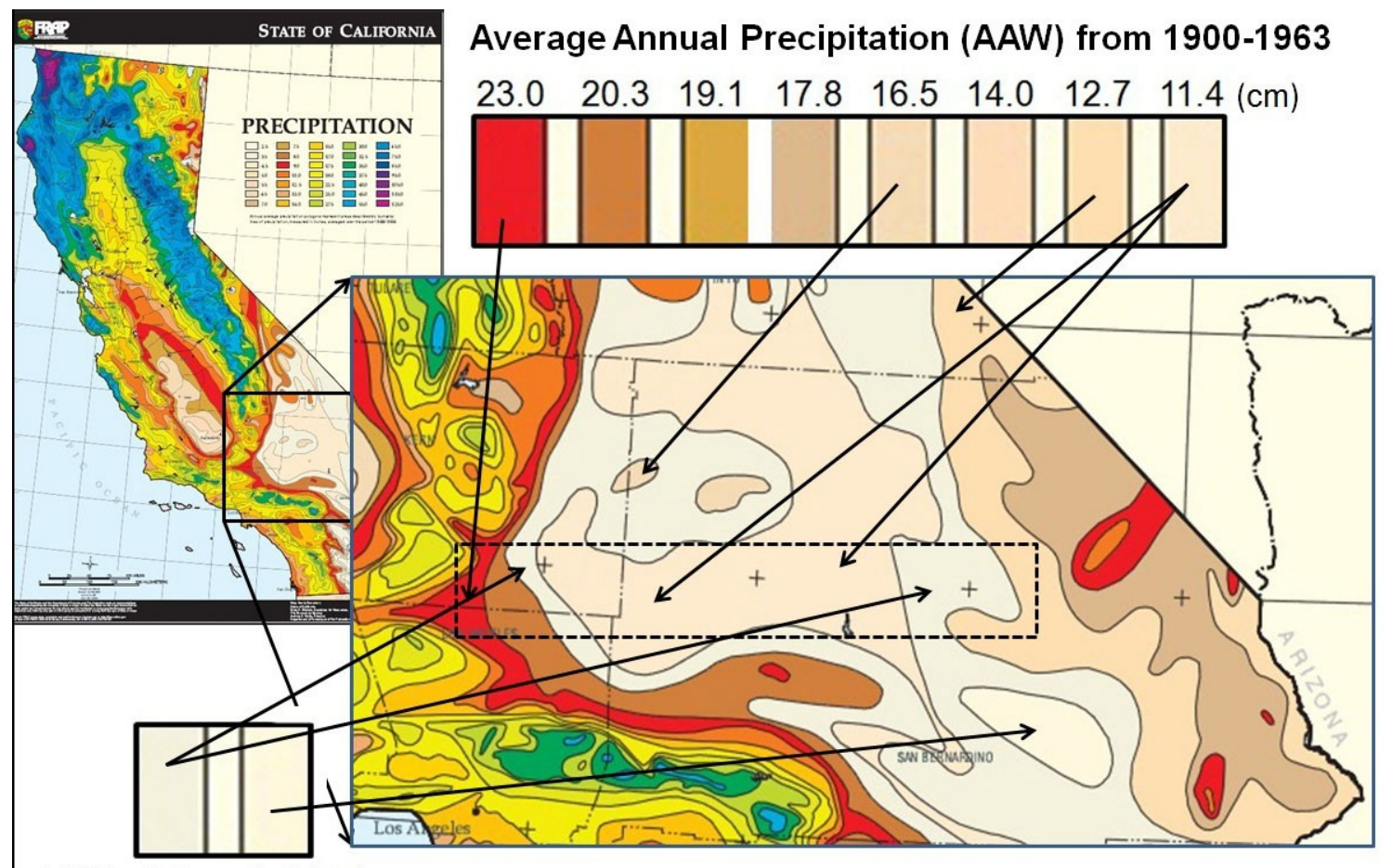

AAW: $8.96 .4(\mathrm{~cm})$

Figure 1. FRAP average precipitation map of California from 1900-1960 with the precipitation transect identified.

The properties between Tehachapi Pass and Zzyzx are primarily governed by the Bureau of Land Management (BLM) and thus required no special permits for sampling. Two of the sites selected in the driest zone of the transect pass through the Mojave National Preserve (MNP). Permits for sample collection were obtained through the NASA Spaceward Bound Program.

The highest annual precipitation site was selected in the Tehachapi Pass, above the town of Mojave, California. Four more sample sites were identified traveling east toward Baker. The immediate areas east and west of Barstow, where were avoided because civilization would have a greater impact upon microbial communities. The final two sampling sites within the MNP were 
established driving along Kelbaker Road. The identification method for the sample sites was based on a previous study. Figure 2 shows the sample sites in relation to major roads and towns in southeastern California. Table 3 indicates the sample designation, name, and location information, as well as the amount of precipitation, for each site.

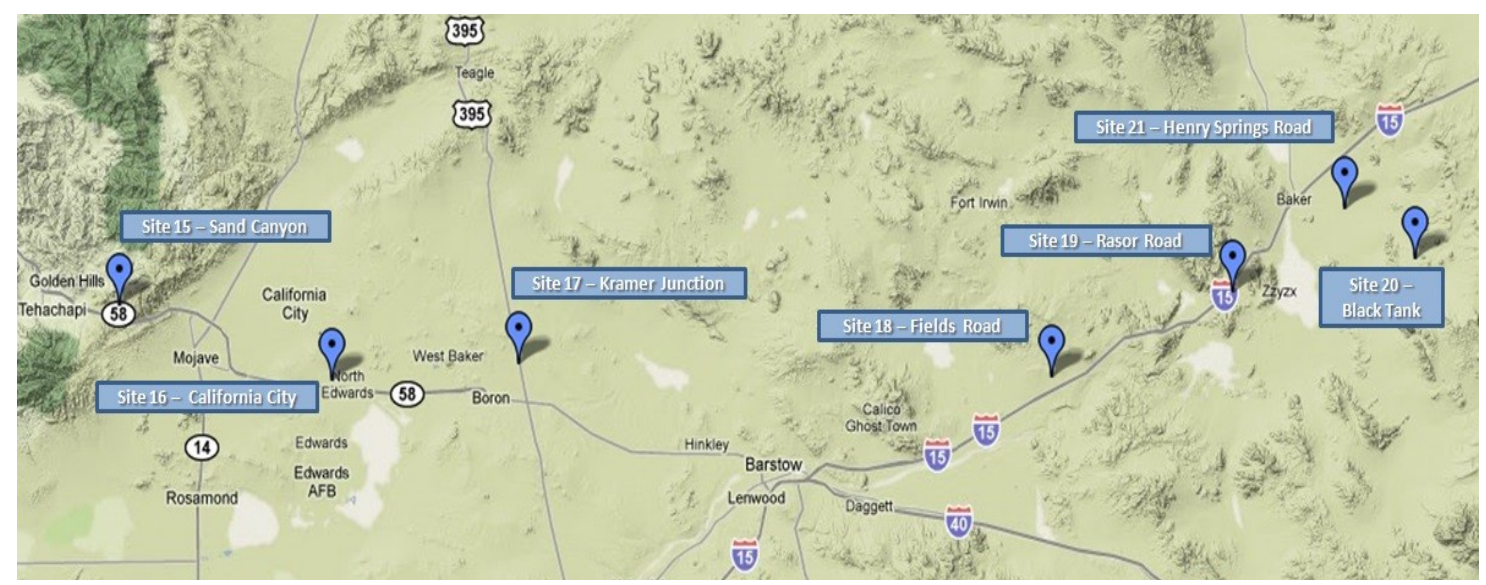

Figure 2. Sample site locations representing a precipitation transect

Table 3. Geographical data for sample sites

\begin{tabular}{clllcc}
\hline Site \# & Site Name & Latitude $\left(^{\circ}\right)$ & Longitude $\left(^{\circ}\right)$ & Altitude $(\mathrm{m})$ & Precip. $^{*}(\mathrm{~cm})$ \\
\hline 15 & Sand Canyon & N35.1230 & -118.3240 & 1212 & 28 \\
16 & California City & N35.0218 & -117.9160 & 736 & 15 \\
17 & Kramer Junction & N35.0431 & -117.5599 & 782 & 13 \\
18 & Fields Road & N35.0260 & -116.5400 & 630 & 12 \\
19 & Rasor Road & N35.1400 & -116.1950 & 466 & 11 \\
20 & Black Tank & N35.1860 & -115.8450 & 771 & 9 \\
21 & Henry Springs Rd & N35.2530 & -115.9790 & 403 & 9 \\
\hline
\end{tabular}

*based on FRAP precipitation map 
Sample Collection. At each sample location, a 10×10 m square was established to minimize the influence of carbon and nitrogen from ground cover or plants. Sterile scoops were used to collect soil down to $8 \mathrm{~cm}$ depth. Samples were placed into sterile collection bags ( $18 \mathrm{oz}$, Nasco Whirl-pak ${ }^{\circledR}$ Fort Atkinson, $\mathrm{WI}$ ) and temporarily stored in a cooler at air temperature for a maximum of $6 \mathrm{~h}$ until arrival at the onsite lab, where the samples were stored at $4^{\circ} \mathrm{C}$. Samples were processed within $24 \mathrm{~h}$ of collection. During the 2007 expedition, 5 samples were collected corresponding to the locations identified with an "*" and a capital letter as is shown in Figure 3a. Sampling for the 2008 and 2009 expeditions was altered to collect three samples per site, as is shown in Figure 3b.

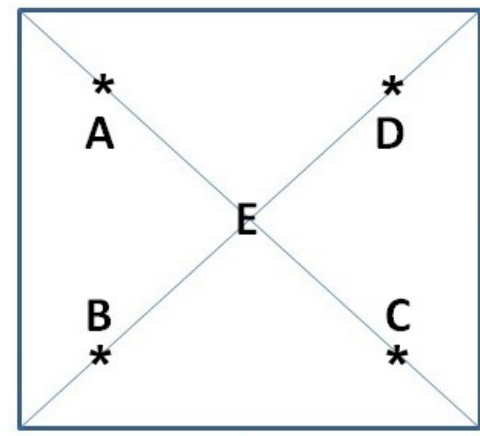

$10 \mathrm{~m}$

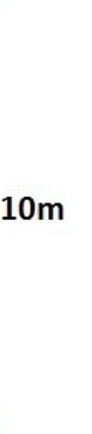

$10 \mathrm{~m}$

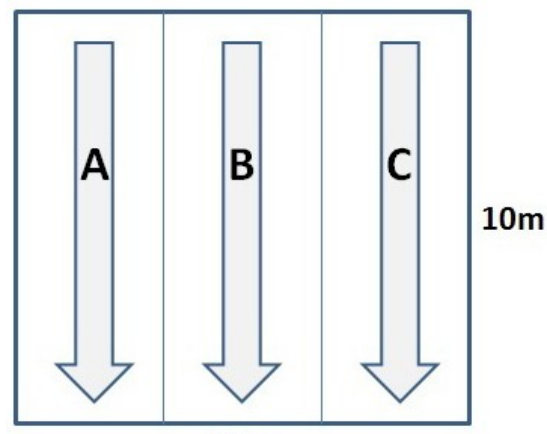

Figure $3 \mathbf{a}$ and $\mathbf{b}$. Location of soil samples taken from each sample site for the (a) 2007 and (b) 2008 - 2010 Spaceward Bound expeditions

In 2009, approximately $400 \mathrm{~g}$ of soil was collected in addition to regular samples and shipped within $24 \mathrm{~h}$ for chemical analysis by Basic Laboratory, Inc. (Reading, California). 
Soil Sample Analysis. Inoculation of viable count plates as well as DNA extraction was performed at the Desert Studies Center (DCS) at Zzyzx. Further DNA extraction and molecular procedures were carried out upon arrival at SJSU.

For the 2007 expedition, soil from samples A and B, as well as samples $C$ and $\mathrm{D}$ were combined in equal $50 \mathrm{~g}$ amounts resulting in three samples per site: $A, B$, and $E$. These three samples were then used as inoculum for viable plate counts. For DNA extraction, $30 \mathrm{~g}$ of each of the five samples was combined and mixed thoroughly, providing a single sample.

The 2008, 2009, and 2010 samples were initially set up as three samples per site, $A, B$, and $C$, by dividing the square into thirds and sampling from one side of the square to its parallel side. Fifty grams of soil from samples A, B and C were combined and thoroughly mixed to produce a single sample for each site. This single sample was then used as inoculum for viable count plates and DNA extraction. All laboratory procedures were performed by attendees under supervision by the primary researcher.

Culture Techniques. Viable count plates were inoculated from 10-fold dilutions of $1 \mathrm{~g}$ of soil in sterile saline. Dilutions of $10^{-3}, 10^{-4}$, and $10^{-5}$ were plated on $1 / 2$ strength Difco ${ }^{\mathrm{TM}} \mathrm{R} 2 \mathrm{~A}$ medium. The plates were incubated at room temperature for 2 weeks. Colony counts were obtained at the end of each week. The 2007 diluted samples were plated in triplicate. Duplicate plates were made for each dilution for the 2008, 2009, and 2010 samples. 
DNA Extraction. Community genomic DNA was extracted from each sample using the UltraClean ${ }^{\mathrm{TM}}$ Soil DNA Isolation Kit (MoBio, Carlsbad, CA) according to the manufacturer's instructions. The quality of the genomic DNA was verified by electrophoresis on $0.1 \%$ analytical grade agarose gels stained with ethidium bromide $(0.5 \mu \mathrm{g} / \mathrm{ml})$. The bands were visualized using a GelDoc ${ }^{\mathrm{TM}}$ XT 170-8171 (BioRad Laboratories, Hercules, CA).

16S rRNA Amplification. The polymerase chain reaction (PCR) was used to amplify the $1500 \mathrm{bp} 16 \mathrm{~S}$ rRNA gene. Primers were synthesized by Operon Biotechnologies, Inc. (Huntsville, AL). All PCR procedures were performed on an MJ Research PTC 100 thermal cycler (Global Medical Instrumentation, Inc., Ramsey, MN).

Prior to PCR, all samples were sheared 30 times using $16 \mathrm{G}$ needles and diluted 10 -fold. The eubacterial $16 \mathrm{~S}$ rDNA was amplified using universal forward primer fD1 and reverse primer rD1 (Table 4) [12]. The reaction mixture for PCR consisted of $1.5 \mathrm{mM} \mathrm{MgCl} 2,200 \mu \mathrm{M}$ of each dNTP, $1 \mu \mathrm{M}$ of primers fD1 and rD1, $4 \mu$ template DNA (5-127 $\mathrm{ng} / \mu \mathrm{l}), 2.5 \mathrm{U} / \mathrm{ml} \mathrm{GoTaq}^{\circledR}$ DNA polymerase, and $1 \mathrm{x}$ GoTaq $^{\circledR}$ reaction buffer (Promega, Madison, WI) in a $40 \mu$ final reaction volume. Purified Escherichia coli DH5- $\alpha$ (100 ng) genomic DNA was obtained following instructions for the QIAGEN Genomic DNA Isolation Kit (Valencia, CA) and used as a positive control. The PCR protocol consisted of denaturation at $95^{\circ} \mathrm{C}$ for 2 min, 35 cycles of $95^{\circ} \mathrm{C}$ for $15 \mathrm{~s}, 55^{\circ} \mathrm{C}$ for $30 \mathrm{~s}, 72^{\circ} \mathrm{C}$ for $2 \mathrm{~min}$, followed by a final 
extension at $72^{\circ} \mathrm{C}$ of $6 \mathrm{~min}$. The presence and approximate concentration of the PCR products were verified by gel electrophoresis using $1 \%$ agarose gels.

Table 4. Primers used for amplification of the $1.5 \mathrm{~kb} 16 \mathrm{~S}$ rRNA gene

\begin{tabular}{llll}
\hline Domain & Primers & Coding & Reference \\
\hline Eubacteria & fD1 & AGAGTTTGATCCTGGCTCAG & Weisburg, et.al. \\
& rD1 & AAGGAGGTGATCAGCC & \\
Archaea & AF25EF & $\begin{array}{l}\text { CTGGTTGATCCTGCCAG } \\
\text { AR1525R }\end{array}$ & RacGGGCGGTGTGTRA et.al. [22] \\
& & & \\
\hline
\end{tabular}

The archaeal 16S rRNA gene was amplified using primers AF25EF and AR1525 (Table 4). The reaction mixture consisted of $1.5 \mathrm{mM} \mathrm{MgCl}_{2}, 200 \mu \mathrm{M}$ of each dNTP, $1 \mu \mathrm{M}$ of AF25EF and AR1525, $4 \mu \mathrm{l}$ template DNA, $2.5 \mathrm{U} / \mathrm{ml} \mathrm{GoTaq}^{\circledR}$ DNA polymerase, and 1x GoTaq ${ }^{\circledR}$ reaction buffer (Promega, Madison, WI) in a $40 \mu$ final reaction volume. Haloarcula marismortui strain DSM 3752 genomic DNA was obtained from $\operatorname{ATCC}^{\circledR}$ (catalog number $43049-5^{\mathrm{TM}}$ ) and used as a positive control. PCR protocol was $94^{\circ} \mathrm{C}$ for $3 \mathrm{~min}, 38$ cycles of $94^{\circ} \mathrm{C}$ for $1 \mathrm{~min}$, $55^{\circ} \mathrm{C}$ for $1.5 \mathrm{~min}, 72^{\circ} \mathrm{C}$ for $2 \mathrm{~min}$ followed by a final extension at $72^{\circ} \mathrm{C}$ for $5 \mathrm{~min}$. The presence and approximate concentration of the PCR products were verified by gel electrophoresis using $1 \%$ agarose gels.

Cloning and sequencing. PCR products were cloned into pGEM ${ }^{\circledR}-\mathrm{T}$ Easy plasmid vectors (Promega, Madison, WI) according to manufacturer's 
instructions and used to transform competent JM109 E.coli cells (Promega, Madison, WI). Plasmids were purified using the Wizard Plus SV Minipreps Kit (Promega, Madison, $\mathrm{WI}$ ). Isolated plasmids were stored at $-20^{\circ} \mathrm{C}$ and screened by restriction analysis using $E c o R I(12 \mathrm{u} / \mu \mathrm{l})$. Plasmids containing the $1.5 \mathrm{~kb}$ gene of eubacterial and archaeal DNA were sequenced by Sequetech (Mountain View, CA) using forward primer M13F for unidirectional sequencing of 1000 nucleotides.

Phylogenetic Analysis. Sequences were visually screened for errors using BioEdit 7.0.9 [10], and vector sequences were edited using Vector Screening (http://blast.ncbi.nlm.nih.gov/Blast.cgi). Bellerophon Chimera Detection programs (http://foo.maths.uq.edu.au/ huber/bellerophon.pl) [11] were utilized to determine the presence of chimera sequences. A level of identification between a sequence and existing database sequences was based upon $\geq 97 \%$ query coverage, an $E$ value $\leq 0.0$ and the highest maximum score calculated by the program [1].

Taxonomic associations for all eubacterial and archaeal 16S rRNA gene sequences were determined using the Greengenes online full-length 16S rRNA gene database (http://greengenes.lbl.gov/) [8]. Sequences from each sample site were aligned using the Greengenes alignment tool, and then processed through the classification tool, which compared the clones to three different databases: Greengenes, Ribosomal Database Project (RDP) and the National Center for Biotechnology Information (NCBI) databases. The resulting files 
grouped the 16S rRNA gene sequences into taxonomic units from Domain down to an operational taxonomic unit (OTU). The OTU designation does not necessarily correlate to the species level, but does indicate the most specific level of classification available. The OTU designations differed between the three databases, indicating that this nomenclature is not a recognized taxonomic label, but is only used to distinguish one phylotype from another. When a $16 \mathrm{~S}$ rRNA gene sequence was classified to a species level, then other sequences which had the same OTU would also be the same species. If a 16S rRNA gene sequence was classified to the level of family, the OTU associated with that classification would indicate any other sequences which had the same OTU would also be of that family.

The resulting classifications were compared between the three databases for consistency at all taxonomic levels indicated in the analysis. The Greengenes and $\mathrm{NCBI}$ databases were most closely aligned in terms of higher level taxonomic assignments, particularly for the Archaea. Further analysis of the sequences for both microorganismal groups was based upon the Greengenes database results.

Diversity Analyses. Rarefaction curves were obtained using Analytic Rarefaction 1.3 by Steven Holland (http://www.uga.edu/ strata/software/), to represent the richness of the microbial community and determine the degree of species saturation. The Shannon-Wiener function was utilized to estimate diversity of Archaea and Eubacteria at both sites according to: 


$$
\mathrm{H}=-\sum_{i=1}^{s}\left(p_{i}\right)\left(\ln p_{i}\right)
$$

where $\mathbf{H}$ = information content of the sample (bits/individual) or index of species diversity, $\mathbf{s}=$ number of species, and $\boldsymbol{p}_{\boldsymbol{i}}=$ proportion of total sample belonging to the i-th species [12].

\section{Results}

Vegetative Coverage. Each sample site was visually examined to determine the amount and type of vegetation present. The vegetation was divided into three groups: the herbal; small shrubs, and large shrubs or trees. The herbal vegetation consisted of grasses, often growing in clumps, flowering plants, and weeds, typically under $10 \mathrm{~cm}$ high and covering an area $4-8 \mathrm{~cm}$ in diameter. The coverage of vegetation varied with the sampling year, and reflected the different amounts of precipitation during the previous 12 months. The progression along the transect toward the driest sites presented an obvious visible decrease in plant coverage, regardless of the sampling year. With the exception of the wettest sampling site, Sand Hill Road, which was basic pasture land, the vegetation was predominately grasses, herbs, and scrub. Included in these groups of flora are saltbush and desert holly (Atriplex ssp.), creosote (Larrea tridentate), and sagebrush (Artimisia tridentata). 
Because the actual $10 \times 10 \mathrm{~m}$ sampling area was selected to minimize the presence of vegetation, an estimation of the vegetative covering combined the immediate sample area and the surrounding $100 \mathrm{~m}$ areas. The percent of vegetative cover at each site is indicated in Table 5 as a range, indicating the minimum and maximum over the four-year study period. During low rainfall seasons, the continuity of the grass/herbal coverage became separated by noticeable stretches of open soil.

Table 5. Vegetative coverage of sample sites by type and size of vegetation.

\begin{tabular}{cccc}
\hline Site \# & Name & $\begin{array}{c}\text { \% Vegetation } \\
\text { coverage }\end{array}$ & $\begin{array}{c}\text { Precipitation } \\
(\mathbf{c m})^{*}\end{array}$ \\
\hline 15 & Sand Canyon & $85-100$ & 23 \\
16 & California City & $60-75$ & 15 \\
17 & Kramer Junction & $50-70$ & 12.7 \\
18 & Fields Road & $40-60$ & 12.7 \\
19 & Rasor Road & $45-60$ & 12.7 \\
20 & Black Tank & $45-60$ & 9 \\
21 & Henry Springs Road & $25-45$ & 8.9 \\
\hline
\end{tabular}

*estimated from FRAP annual precipitation map

Black Tank and Kramer Junction sample sites had large, wide creosote bushes which were over $180 \mathrm{~cm}$ tall and up to $140 \mathrm{~cm}$ wide. These sites appear to be situated in the zones receiving $11.4-12.7 \mathrm{~cm}$ of precipitation yearly. By comparison, the sample sites at Fields and Henry Springs roads had 3 - 10 small shrubs, approximately $40 \mathrm{~cm}$ wide by $30 \mathrm{~cm}$ tall. The sample site furthest east, Black Tank, supported more vegetation than the site immediately west, Henry 
Springs Road. According to the FRAP maps, a continuation of the precipitation transect eastward toward Las Vegas, Nevada indicates an increase in annual precipitation, with the minimum average rainfall occurring just south of Baker, CA. Based upon the map and comparison of vegetation, sample site \#21 on Henry Springs Road is considered to represent the driest site of the transect.

Soil Characteristics. The observable characteristics of the soil varied across the precipitation transcript. Sand Canyon soil, site 15, was very dark, moist, and captured amongst a network of fine roots from the herbaceous ground cover. The soil at site $16,45 \mathrm{~km}$ east at the road to California City, was much lighter in color and consistency, with more sand, and small, distinct particles. Progression further east along the precipitation transect showed finer sand, and a general increase in the presence of a mineral crust overlying the sand and silt. The number and size of rocks did not follow any trend, being abundant at some sites and scarce at others. (Table 6)

Table 6. Soil and rock descriptions of sampling sites

\begin{tabular}{cllc}
\hline Site & Soil type & Rock type & Crust (\%) \\
\hline 15 & rich, humic & none & 0 \\
16 & sandy silt & angular quartz, feldspar & 0 \\
17 & sandy silt & angular quartz, feldspar & 100 \\
18 & sandy silt & feldspar, granite; very rocky & 30 \\
19 & sandy silt & quartz, basalt; compacted dirt & sparse \\
20 & sandy silt & lava, feldspar, sparse gravel & 15 \\
21 & sandy silt & quartz, feldspar, 5\% basalt & 80 \\
\hline
\end{tabular}


The rockiest sample site was Fields Road, where a mixture of feldspar, granite, and quartz was exposed on top of sandy soil. These rocks ranged from large pebbles $(20-30 \mathrm{~mm})$ to small cobbles $(70-100 \mathrm{~mm})$. Basalt rocks up to $15 \mathrm{~cm}$ in length were found at Rasor Road and Black Tank, indicating proximity to 10,000 year old lava flows. Quartz rocks with hypolithic cyanobacterial communities were found at Fields Road, Black Tank, and Henry Springs Road sample sites.

Initial chemical analyses of the soil at each sampling site were performed by Raphael Navarro-Gonzalez in 2007. From independently collected soil samples, Navarro-Gonzalez determined the ratio of organic nitrogen to total nitrogen for each sample site, as shown in Table 7 (private correspondence, $R$ Navarro-Gonzalez). In 2009, similar measurements of the organic nitrogen

Table 7. Nitrogen content at sample sites

\begin{tabular}{lcccc}
\hline Site & Org N & Tot N & org/tot '09 & org/tot ‘07 \\
\hline 15 & 1310 & 1330 & 0.985 & 0.985 \\
16 & 234 & 238 & 0.983 & 0.983 \\
17 & 933 & 940 & 0.993 & 0.993 \\
18 & 274 & 285 & 0.961 & 0.961 \\
19 & 62.9 & 65.1 & 0.966 & 0.966 \\
20 & 494 & 500 & 0.988 & 0.988 \\
21 & 109 & 111 & 0.982 & 0.982 \\
\hline
\end{tabular}


and total nitrogen were made by Basic Laboratories, Inc. (Redding, California) and the results from these determinations are also shown in Table 7 . The ratios of organic nitrogen to total nitrogen at each sample site were the same for both years, indicating a relatively stable chemical environment.

Further chemical analysis of the soils from the sample sites was also performed by Basic Laboratories, Inc. (Redding, California). Four hundred grams of soil from each of the seven sample sites was analyzed for edaphic factors known to influence microbial growth in soil communities, such as moisture content, salt content, $\mathrm{pH}$ and percent organic carbon. The resulting chemical quantities at each sample site are in Table 8.

Table 8. Chemical analysis of soil samples

\begin{tabular}{cccccc}
\hline $\begin{array}{c}\text { Sample } \\
\text { Site }\end{array}$ & $\mathrm{pH}$ & $\begin{array}{c}\text { Percent } \\
\text { Moisture }\end{array}$ & $\begin{array}{c}\text { \% org } \\
\text { Carbon }\end{array}$ & $\begin{array}{c}\text { Sodium } \\
(\mathrm{mg} / \mathrm{kg})\end{array}$ & $\begin{array}{c}\text { Chlorine } \\
(\mathrm{mg} / \mathrm{kg})\end{array}$ \\
\hline 15 & 7.18 & 18.5 & 1.34 & 1080 & 4.98 \\
16 & 7.60 & 1.2 & 0.26 & 68 & 4.57 \\
17 & 7.12 & 0.6 & 0.53 & 78 & 3.34 \\
18 & 7.34 & 0.6 & 0.11 & 146 & 2.08 \\
19 & 7.76 & 0.6 & 0.27 & 158 & 1.71 \\
20 & 7.71 & 0.4 & 0.15 & 560 & 8.68 \\
21 & 7.88 & 0.4 & 0.18 & 128 & 5.94 \\
\hline
\end{tabular}

The observed decrease in percent moisture of the soil samples mirrors the FRAP annual precipitation values in the west to east direction of the transect. The decreased support for vegetation along the transect is due to the decreased 
amounts of organic nitrogen and carbon. The one sample site which may be considered anomalous with regards to the salt and organics, site 15 - Rasor Road, is a popular, all-wheel terrain vehicle area, thus the soil chemistry is highly likely to be affected by anthropomorphic influences.

The $\mathrm{pH}$ levels along the transect indicate a tendency toward a more basic environment, as is shown in Figure 4. Values of $\mathrm{pH}$ vary due to vegetation, soil, and anthropomorphic differences, and may serve as a predictor of microbial community composition [14]. The $\mathrm{pH}$ values are from samples along the transect range from 7.12 to 7.88 , a difference of 0.76 . This small change in $\mathrm{pH}$ has been shown to affect the diversity of soil bacteria communities, and may affect the microbial communities studied [15].

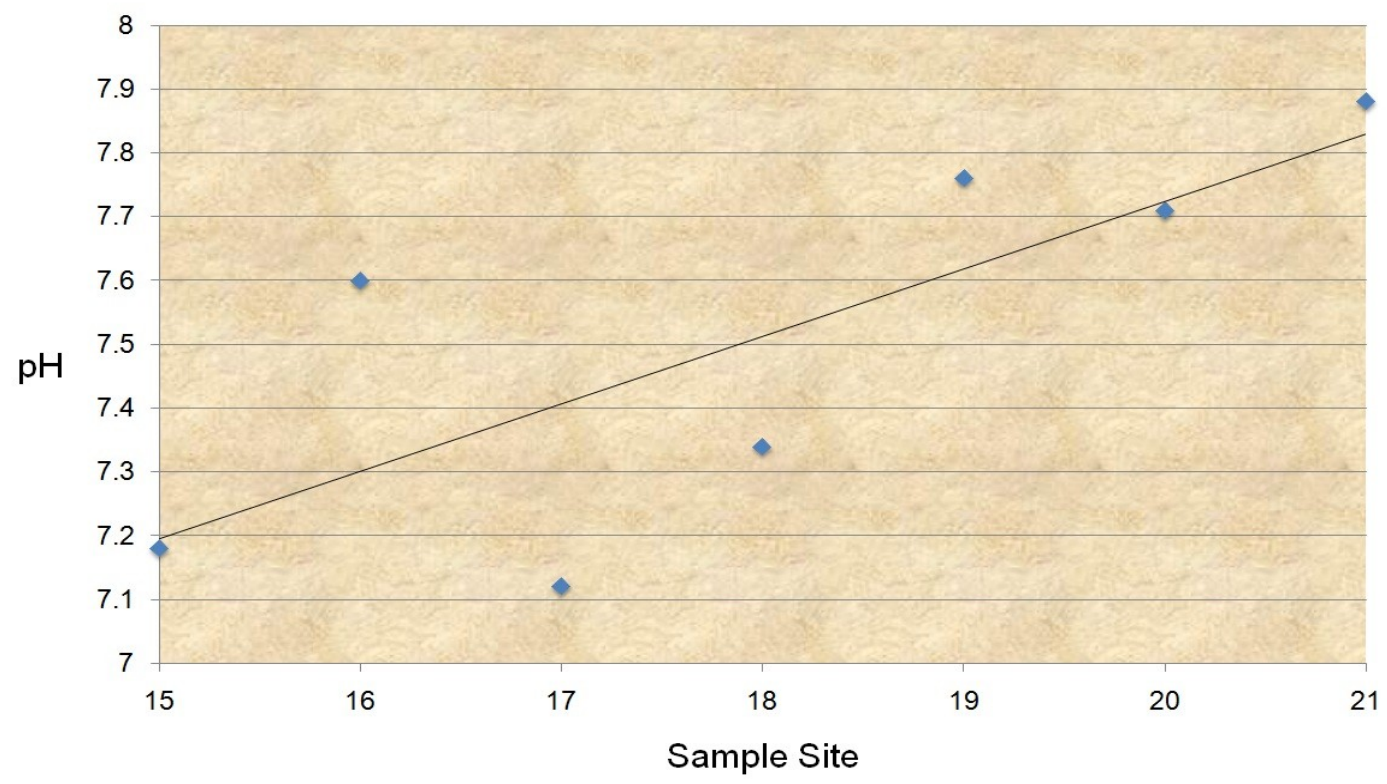

Figure 4. Scatter plot of $\mathrm{pH}$ values along precipitation transcript including a linear regression trend line. 
Tables 6 and 7 reveal localized conditions along the precipitation transect. The organic nitrogen and carbon levels decrease along the length of the sample zone; however sites 17, 19, and 20, California City, Rasor Road, and Black Tank, show extreme divergence from this trend. The presence of sodium and chlorine also shows discontinuity from an overall trend due to the Black Tank results.

These characteristics of the sample sites may contribute to differences in the microbial soil communities regardless of annual precipitation levels

Viable Plate Colony Count. Table 9 presents the colony forming units per gram (CFUs/g) of soil for four sampling years. The final column presents an average over the four-year period as a means of equalizing local effects of higher or lower than normal precipitation. The data indicates a decrease in the number of culturable microorganisms by 10 fold between the wettest and driest sites.

Table 9. Averaged colony forming units for statistically significant dilution plates for four years of sampling. Values are in terms of CFUs/g soil.

\begin{tabular}{cccccc}
\hline Site & 2007 & 2008 & 2009 & 2010 & Avg \\
\hline 15 & $4.4 \times 10^{6}$ & $1.5 \times 10^{8}$ & $1.5 \times 10^{7}$ & $4.2 \times 10^{7}$ & $5.29 \times 10^{7}$ \\
16 & $2.9 \times 10^{5}$ & $1.7 \times 10^{7}$ & $2.3 \times 10^{6}$ & $2.7 \times 10^{7}$ & $1.16 \times 10^{7}$ \\
17 & $2.5 \times 10^{5}$ & $1.5 \times 10^{7}$ & $3.2 \times 10^{7}$ & $2.6 \times 10^{7}$ & $1.83 \times 10^{7}$ \\
18 & $2.6 \times 10^{5}$ & $1.3 \times 10^{7}$ & $3.3 \times 10^{7}$ & $3.4 \times 10^{6}$ & $1.24 \times 10^{7}$ \\
19 & $1.3 \times 10^{5}$ & $1.5 \times 10^{7}$ & $1.5 \times 10^{7}$ & $2.1 \times 10^{6}$ & $8.06 \times 10^{6}$ \\
20 & NA & $1.3 \times 10^{7}$ & $2.5 \times 10^{6}$ & $2.0 \times 10^{6}$ & $5.83 \times 10^{6}$ \\
21 & $2.7 \times 10^{4}$ & $3.0 \times 10^{6}$ & $2.7 \times 10^{6}$ & $2.8 \times 10^{6}$ & $2.13 \times 10^{6}$ \\
\hline
\end{tabular}


16S rRNA Gene Sequencing. Eubacterial 16S rRNA genes were sequenced for all seven sampling sites, but four of the sampling sites were chosen to represent the transect. Due to anthropomorphic interference at Rasor Road (site 19) this site was dropped from analysis. Soil chemistry and viable count plate similarities between sites 16 and 17 , as well as 17 and 18 , resulted in using sequence results from sites 16 and 18 . Site 20 was dropped from analysis due to the observed increase in vegetation, indicating it was not as dry as site 21 , as well as the similarity in $\mathrm{pH}$, moisture content, percent organic carbon, and the organic /total nitrogen ratio.

The number of Eubacterial and Archaeal 16S rRNA genes sequenced for each remaining sample site is indicated in Table 19. The initial goal was to obtain over 100 eubacterial sequences per site, and 60 archaeal sequences. The resulting numbers indicate the maximum number of $16 \mathrm{~S}$ rRNA genes positively classified. Several archaeal genes were classified as eubacterial sequences, particularly by the RDP database, which decreased the total number of archaeal sequences for all the sites.

Table 10. Number of $16 \mathrm{~S}$ rRNA genes sequenced for transect

\begin{tabular}{llcc}
\hline Site \# & Site Name & \# Eubacteria & \# Archaea \\
\hline 15 & Sand Canyon Road & 107 & 9 \\
16 & California City Road & 104 & 60 \\
18 & Fields Road & 96 & 32 \\
21 & Henry Springs Road & 108 & 45 \\
\hline
\end{tabular}


Eubacterial 16S rRNA Gene Sequences, Phyla Classification. The sequences from the eubacterial soil community at the site of highest annual precipitation, Sand Canyon, were classified into six phyla, shown in Figure 5. The Proteobacteria were dominant at $89 \%$ of the total community. Numbers of $16 S$ rRNA sequences were also identified for the Actinobacteria, Aquificae, Bacteriodetes, Firmicutes, and Thermotogae. Firmicutes were the next largest population at $6 \%$, followed by Actinobacteria and Bacteriodetes at $2 \%$ each. Aquificae and Thermotogae were represented by a single sequence, or $1 \%$ of the total eubacterial population. Sequences from the Thermotogae were identified only at this site.

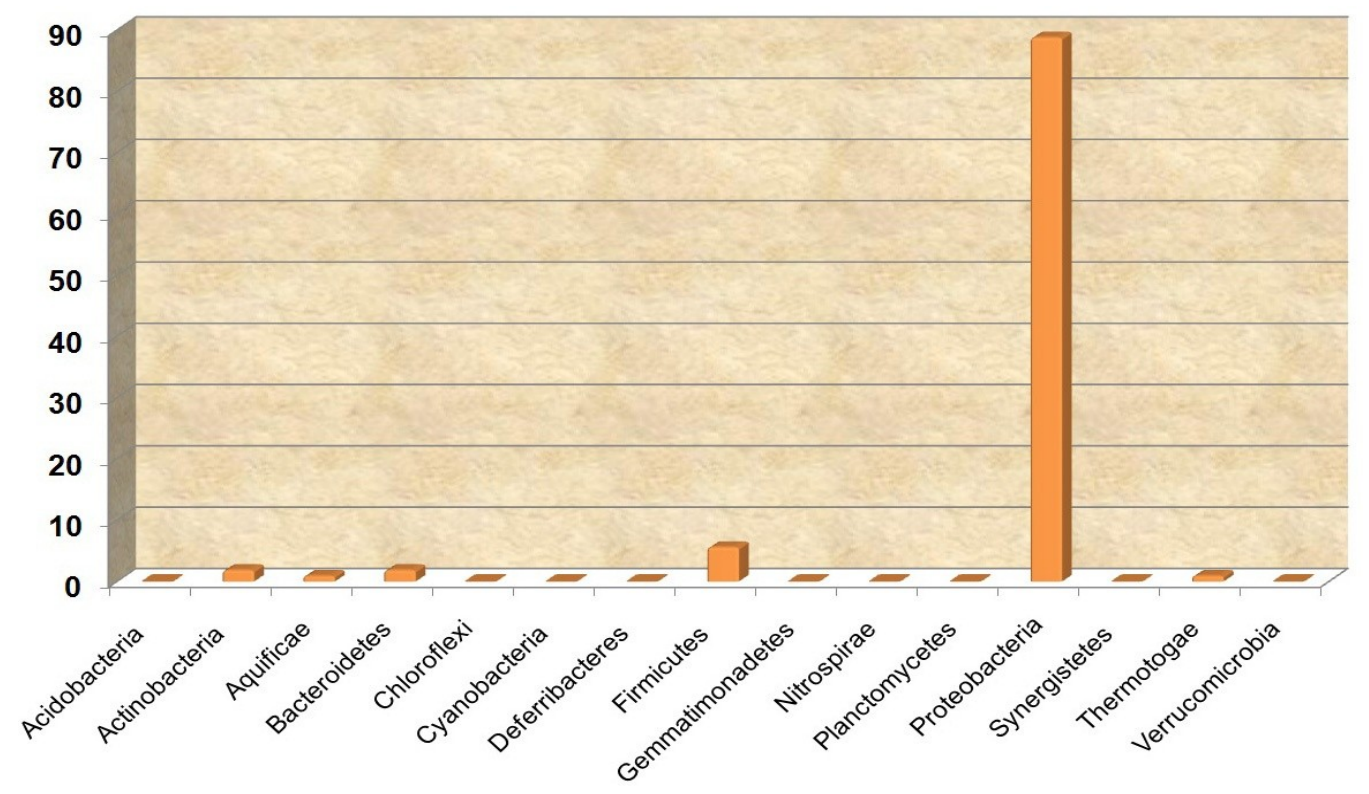

Figure 5. Relative abundance of $16 \mathrm{~S}$ rRNA gene sequences at the Phylum taxonomic level from Sand Canyon, Site 15 
Eubacterial 16S rRNA gene sequences from site 16, California City, showed an increase in the number of phyla. The Proteobacteria were still the dominant phylum, but only comprised $82 \%$ of the population. The number of sequences in Firmicutes decreased from $6 \%$ to $4 \%$. New phyla at this site included the Acidobacteria, Cyanobacteria, Planctomycetes, and Verrucomicrobia. The number of sequences in Actinobacteria increased to 7. Figure 6 shows the relative abundance of phyla at this site. Planctomycetes were identified only at this sample site.

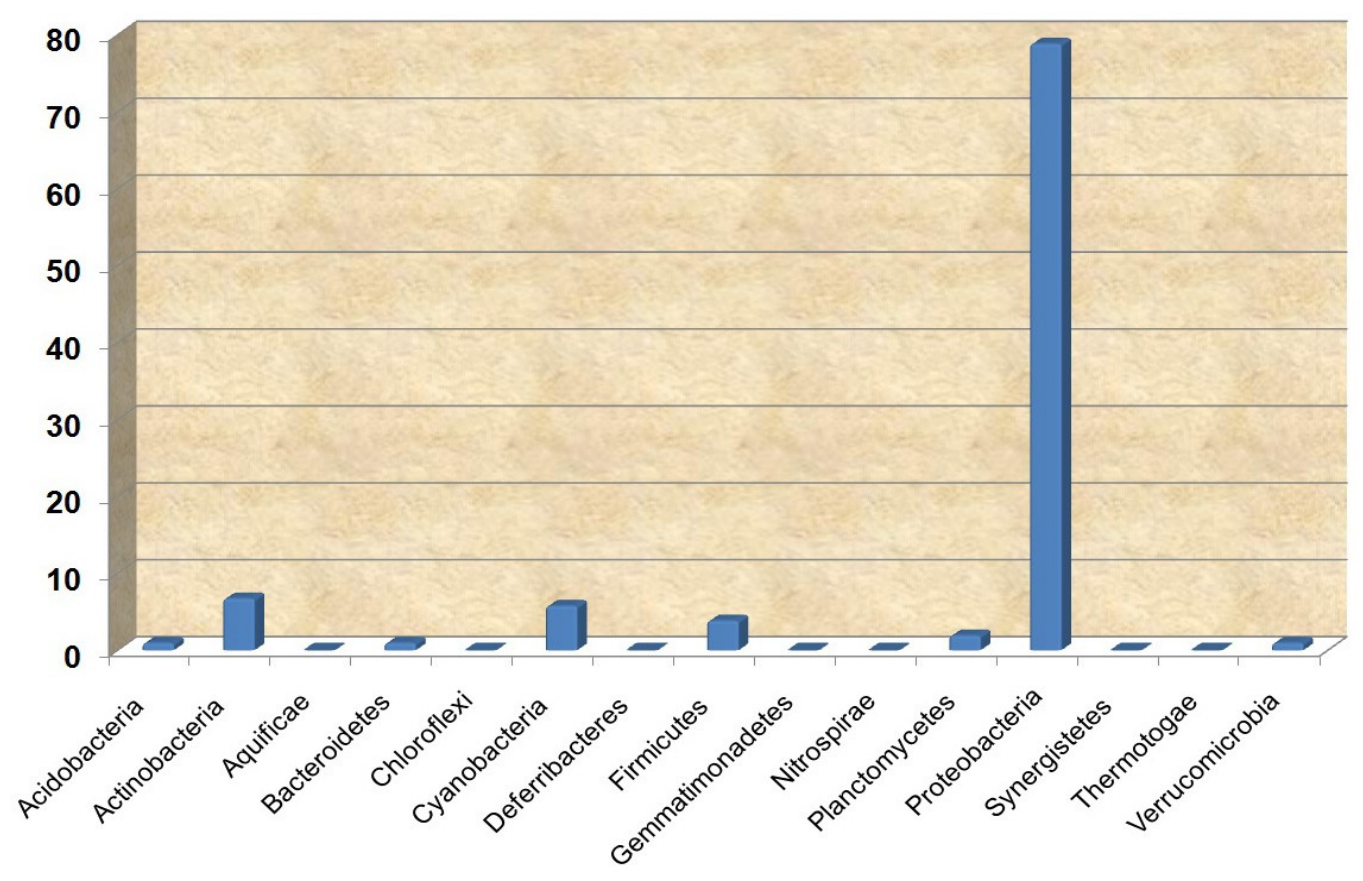

Figure 6. Relative abundance of $16 \mathrm{~S}$ rRNA gene sequences at the Phylum taxonomic level from California City, Site 16

The 16S rRNA gene sequences from Fields Road showed a further decrease in the Proteobacteria, and an increase in the proportion of 
Acidobacteria to $5 \%$, Cyanobacteria to $8 \%$, and Firmicutes up to $10 \%$.

Deferribacteres and Synergistetes were two phyla represented only at Fields

Road, and accounted for $2 \%$ and $1 \%$ of the microbial community respectively.

Bacteriodetes, Planctomycetes, and Verrucomicrobia also were represented but each at $1 \%$ of the microbial community. (Figure 7 )

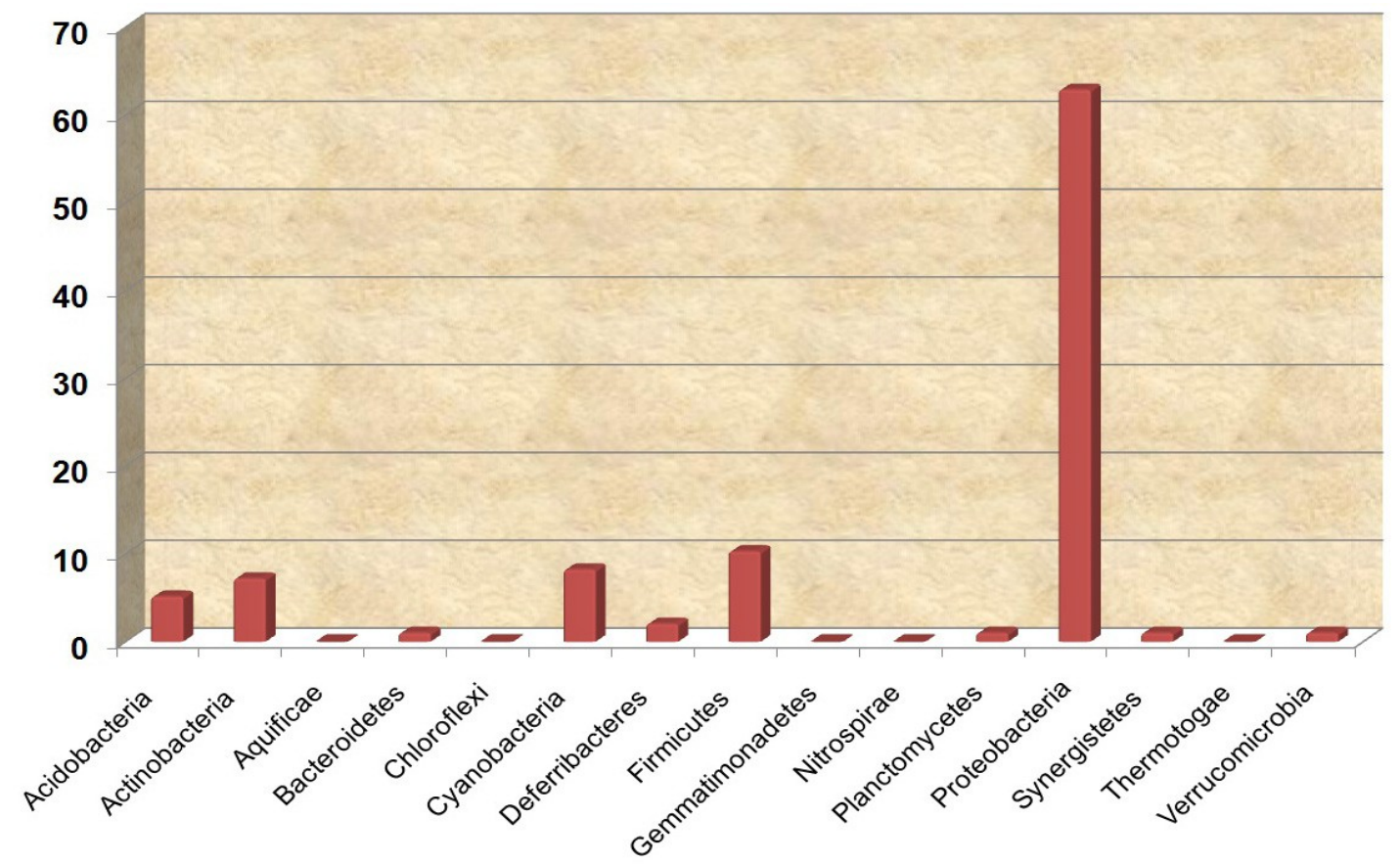

Figure 7. Relative abundance of $16 \mathrm{~S}$ rRNA gene sequences at the Phylum taxonomic level from Fields Road, Site 18

The driest site of the precipitation transect, Henry Springs Road, presented a more diverse eubacterial community. Single sequences from Chloroflexi, Gemmatimonadetes, and Nitrospirae were present, representing a total of $3 \%$ of the community. A continued decrease in the proportion of Proteobacteria - down to $53 \%$, Acidobacteria at $1 \%$, and Actinobacteria 
decreased to $4 \%$. The proportion of Cyanobacteria increased to $31 \%$, but Firmicutes decreased to $6 \%$. Bacteriodetes and Aquificae were also represented with $1 \%$ of the microbial community each (Figure 8 ).

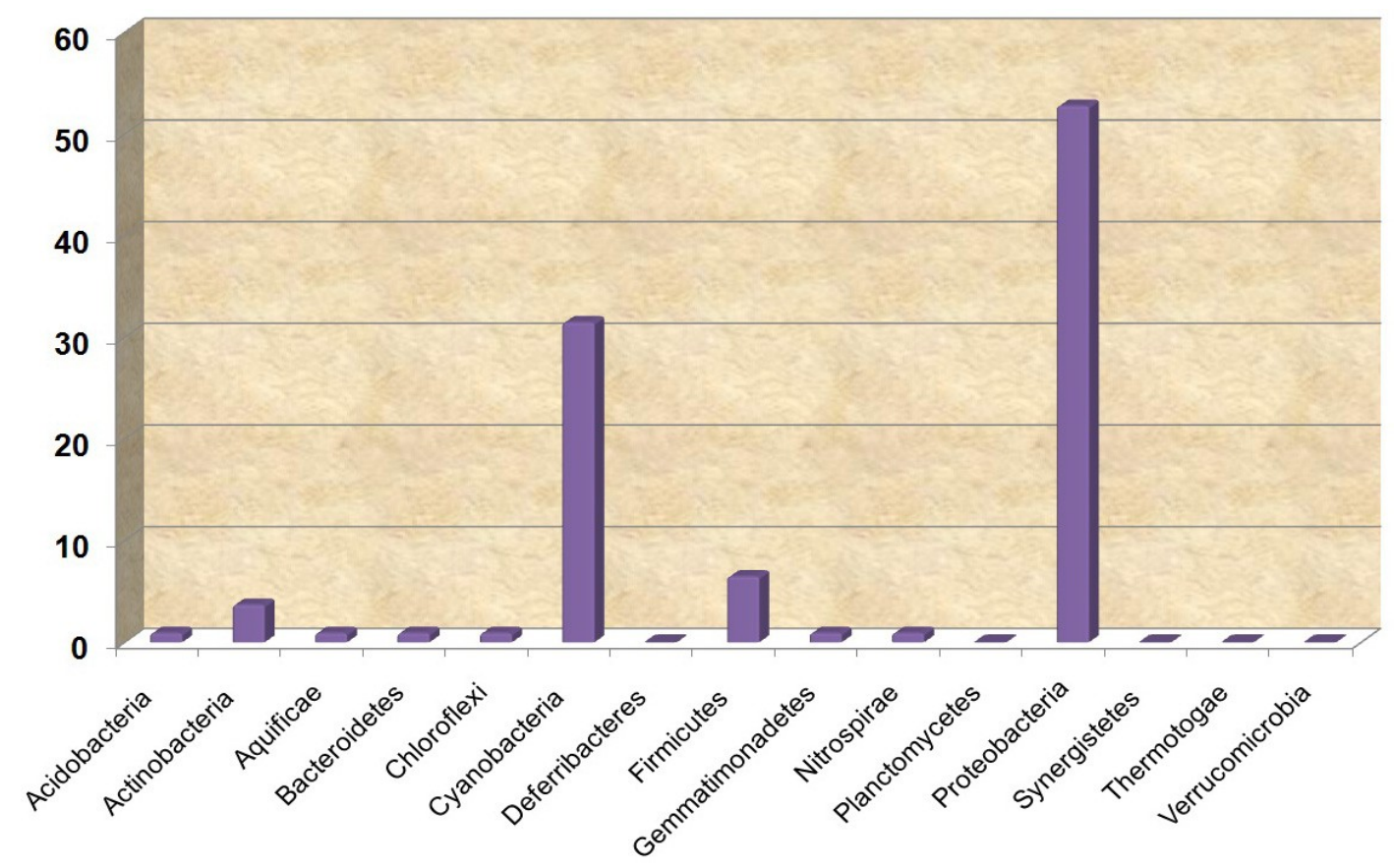

Figure 8. Relative abundance of $16 \mathrm{~S}$ rRNA gene sequences at the Phylum taxonomic level from Henry Springs Road, Site 21

The trend in terms of the taxonomic classification of Eubacteria at the phyla level indicates that the diversity of the microbial communities increases as annual precipitation levels decrease. In particular, the Proteobacteria proportion of the community decreased from $89 \%$ to $53 \%$, though it remains the dominant phylum. Of equal note, the Cyanobacterial proportion of the eubacterial community dramatically increased from $0 \%$ at Sand Canyon to $31 \%$ at Henry Springs Road. 
Eubacterial $16 S$ rRNA Gene Sequences, Class Classification. At the taxonomic level of class several of the trends along the transect become more obvious, and reflect more specifically what eubacterial groups are influenced by different rainfall amounts. The further grouping of sequences along taxonomic divisions indicates the increasing diversity, because distinctions can be made about each group of sequences. Classification progression from phylum to class indicated several taxonomic groups of which all the 16S rRNA gene sequences from a phylum were grouped into a single class. An example of this is seen in the phylum Bacteriodetes. All 5 sequences in this phylum were assigned to the class Sphingobacteria, and thus are identical at this level of detail. The Acidobacteria sequences were grouped into two classes, the Solibacteres and "unclassified." Thus, further diversity analysis is not assisted by class distinction for the Bacteriodetes, but it is for the Acidobacteria.

Insight into diversity at the class taxonomic level was based upon those sequences from a phylum included two or more classes. Table 11 shows the number of sequences per site associated with a class designation. The table also indicates that members of the Alphaproteobacteria community decrease by $40 \%$ along the precipitation transect. Conversely, sequences in Oscillatoriophycideae, the primary Cyanobacterial class, show an increase along the precipitation transect. 
Table 11. Number of eubacterial $16 \mathrm{~S}$ rRNA gene sequences assigned to specific class designations. Phyla with one sequence per class are indicated.

\begin{tabular}{|c|c|c|c|c|c|}
\hline \multirow[b]{2}{*}{ Phylum } & \multirow[b]{2}{*}{ Class } & \multicolumn{4}{|c|}{ Number of sequences at site } \\
\hline & & 15 & 16 & 18 & 21 \\
\hline \multirow[t]{2}{*}{ Acidobacteria } & Solibacteres & 0 & 0 & 3 & 0 \\
\hline & Unclassified & 0 & 1 & 2 & 1 \\
\hline \multirow[t]{3}{*}{ Actinobacteria } & Actinobacteria & 2 & 5 & 5 & 3 \\
\hline & Rubrobacterales & 0 & 2 & 2 & 0 \\
\hline & Solirubrobacterales & 0 & 0 & 0 & 1 \\
\hline Aquificae & Aquificales & 1 & 0 & 0 & 1 \\
\hline Bacteroidetes & Sphingobacteria & 2 & 1 & 1 & 1 \\
\hline Chloroflexi & Chloroflexi & 0 & 0 & 0 & 1 \\
\hline \multirow[t]{4}{*}{ Cyanobacteria } & Chloroplast & 0 & 0 & 1 & 0 \\
\hline & Gloeobacterophycideae & 0 & 1 & 0 & 0 \\
\hline & Nostocophycideae & 0 & 0 & 0 & 16 \\
\hline & Oscillatoriophycideae & 0 & 5 & 7 & 18 \\
\hline Deferribacteres & Deferribacteres (class) & 0 & 0 & 2 & 0 \\
\hline \multirow[t]{2}{*}{ Firmicutes } & Bacilli & 0 & 1 & 8 & 2 \\
\hline & Clostridia & 6 & 3 & 2 & 5 \\
\hline Gemmatimonadetes & Gemmatimonadetes & 0 & 0 & 0 & 1 \\
\hline Nitrospirae & Nitrospira & 0 & 0 & 0 & 1 \\
\hline Planctomycetes & Planctomycea & 0 & 2 & 1 & 0 \\
\hline \multirow[t]{5}{*}{ Proteobacteria } & Alphaproteobacteria & 78 & 66 & 52 & 36 \\
\hline & Betaproteobacteria & 10 & 10 & 4 & 13 \\
\hline & Deltaproteobacteria & 4 & 6 & 4 & 4 \\
\hline & Gammaproteobacteria & 2 & 0 & 1 & 4 \\
\hline & Unclassified & 1 & 0 & 0 & 0 \\
\hline Synergistetes & Synergistia & 0 & 0 & 1 & 0 \\
\hline Thermotogae & Thermotogae & 1 & 0 & 0 & 0 \\
\hline Verrucomicrobia & Verrucomicrobiae & 0 & 1 & 1 & 0 \\
\hline
\end{tabular}

Also of note is the difference in the two classes of Firmicutes. Clostridium $16 \mathrm{~S}$ rRNA gene sequences can be found at all sites, whereas Bacilli are found only at the drier sites. The Actinobacteria in the class Actinobacteria show a 
preference for the intermediate precipitation sites, as do those from the class Rubrobacterales. The Acidobacteria also prefer the drier sites, though those from the class Solibacteres were only associated with Fields Road. While the Alphaproteobacteria class of the Proteobacteria showed proportional changes along the transect, the beta, delta, and gamma classes remained basically consistent.

Eubacterial 16S rRNA Gene Sequences, Family Classification. A comparison of the 16S rRNA gene sequences at the family taxonomic level produced further clarification of the organisms in flux along the precipitation transects. Three Alphaproteobacterial families, the Bradyrhizobiaceae, the Rhodospirillaceae and the Rhodobacteraceae, demonstrated a decrease in the proportion of the eubacterial community from wet to dry conditions:

Bradyrhizobiaceae decreased from 34 to 15 sequences, Rhodospirillaceae, from 15 to 1 sequence, and Rhodobacteraceae decreased from 6 to 2 sequences. Figure 9 shows the trend for these families. Interestingly, two other alphaproteobacterial families demonstrated very different patterns. The proportion of sequences from the Methylobacteriaceae were consistent across the transect except at California City, where the number of sequences doubled. Only the Sphingomonadaceae showed preference for the dry sample sites, and preferred conditions at Fields Road -4 sequences, to those at Henry Springs -2 sequences. 


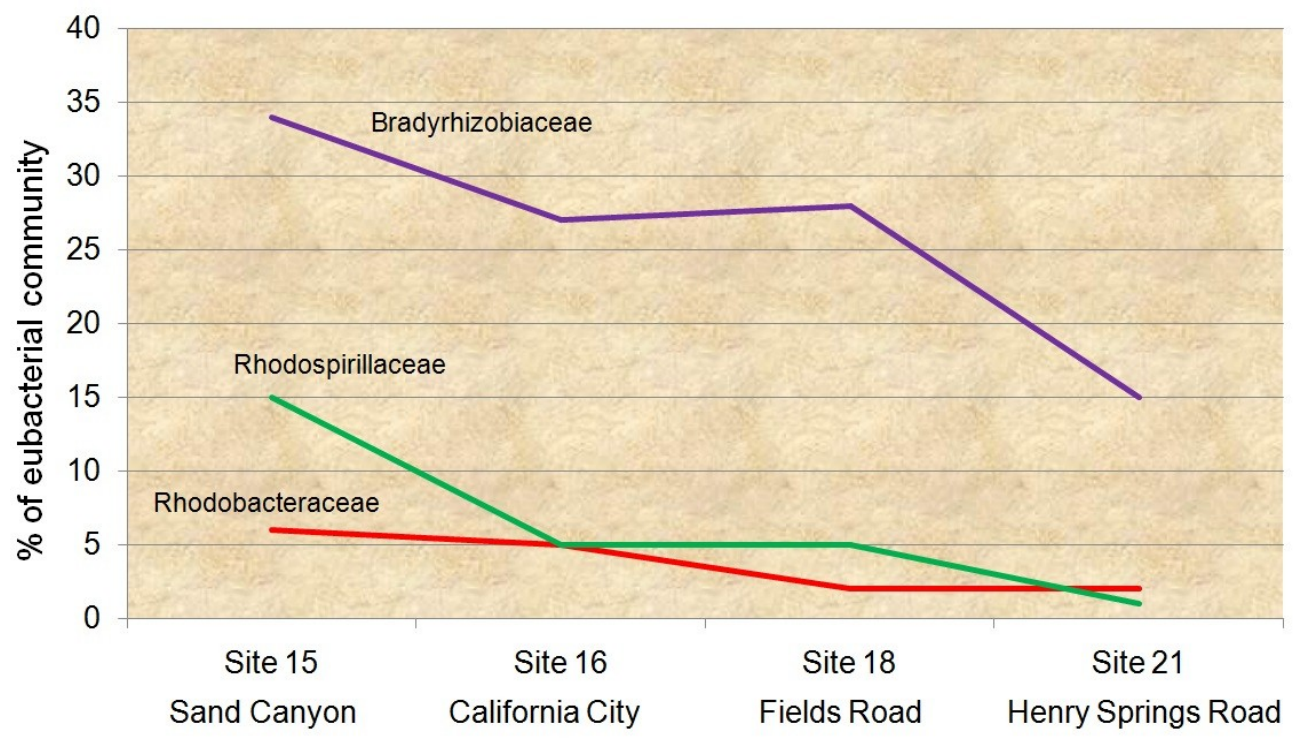

Figure 9. Comparisons of the proportion of major Alphaproteobacteria families which vary along the precipitation transect.

Other family classifications of interest are for the phyla Cyanobacteria, Firmicutes, and Betaproteobacteria. Figure 10 shows the trends in community proportion for two families of each phyla with the greatest variation across the transect. The cyanobacterial trends indicate the rapid rise of the Nostocaceae as the precipitation levels decrease, as well as the presence of $16 \mathrm{~S}$ rRNA gene sequences from the Phormidiaceae only at the Henry Springs Road.

Figure 10 also demonstrates the opposing trends of Bacilli and Clostridia as their dominant families, Bacillaceae and Sulfobacillaceae, respond to decreasing levels of precipitation. Often associated with deserts, the Bacilli appeared to find Fields Road to be an optimal environment compared to Henry Springs Road. 

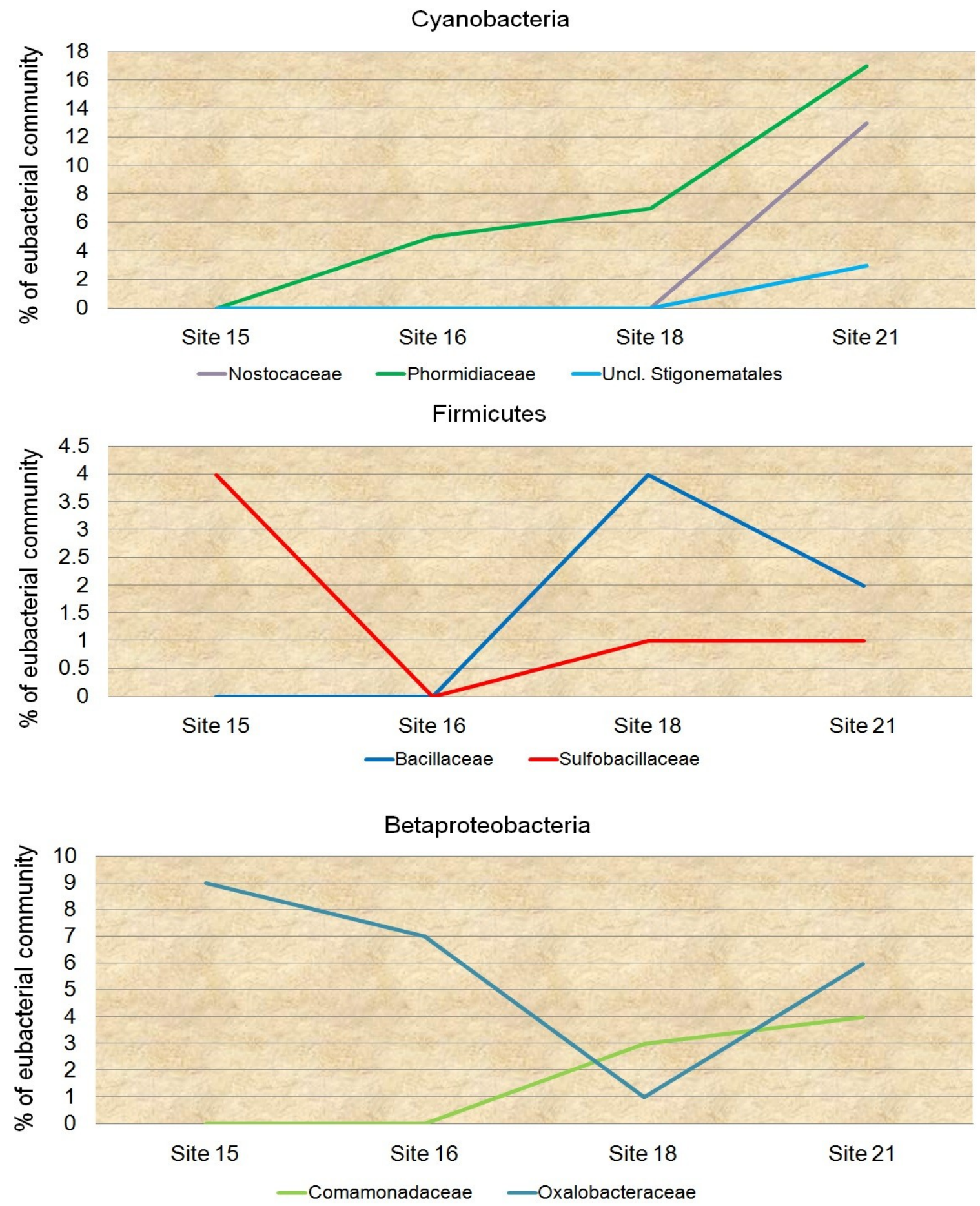

Figure 10. Family classification indicating interesting trends in eubacterial community proportions along the precipitation transect. 
The third panel of Figure 10 shows opposing trends for the two dominant betaproteobacterial families. The Oxalobacteraceae appear to prefer wetter conditions of the western sample sites, whereas the Comamonadaceae appear in the drier sites. Whether these trends represent actual preferences for a specific soil chemistry and precipitation level or if there is simply less competition allowing the increase in some families is not discernable.

Eubacterial 16S rRNA Gene Sequence, Operational Taxonomic Unit Classification. Greengenes defines the operational taxonomic unit (OTU) as "the terminal level at which that taxonomy classifies the sequences." The term "that taxonomy" refers to the database selected: NCBI, RDP, or Greengenes databases. The OTU designations are thus database specific.

An example concerns two 16S rRNA gene sequences from Henry Springs Road, site 21 . Both sequences, $21 \mathrm{~F} 5$ and $21 \mathrm{U} 2$, were classified by all three databases as Domain Bacteria, Phylum Cyanobacteria. The Greengenes database placed both sequences in the class Nostocophycideae, NCBI did not assign a class, and RDP placed one sequence in the cyanobacterial class, and the other in no class. All three databases placed both sequences in the order Nostocales. Family assignments for sequence $21 \mathrm{U} 2$ were the same for all three databases, as Nostocaceae. Sequence 21F5 was also placed in Nostocaceae by Greengenes and NCBI but was classified as "Family" I by RDP. The genus name assigned by Greengenes and NCBI was Nodularia, but RDP put $21 \mathrm{U} 2$ in Nodularia and 21F5 in "Gp1." Species assignments were made only by 
Greengenes for sequence 21F5, and the rest were unclassified. Greengenes further assigned sequence 21F5, Nodularia sphaerocarpa, OTU_1430.

Sequence 21U2, Nodularia spp., was OTU_1429. NCBI classified these two sequences as Nodularia unclassified and gave them both the designation OTU_1214. RDP assigned sequence 21F5 to the genus GP1 with an unclassified species and OTU_1997. For the sequence 21U2, RDP agreed with NCBI for all taxonomic classifications. (Table 12)

Table 12. Classification for two 16S rRNA gene sequences by three databases

\begin{tabular}{|c|c|c|c|c|}
\hline Sequence & Designation & Greengenes & $\mathrm{NCBI}$ & RDP \\
\hline \multirow[t]{7}{*}{$21 \mathrm{~F} 5$} & Phylum & Cyanobacteria & Cyanobacteria & Cyanobacteria \\
\hline & Class & Nostocophycideae & -------- & Cyanobacteria \\
\hline & Order & Nostocales & Nostocales & --------- \\
\hline & Family & Nostocaceae & Nostocaceae & Family I \\
\hline & Genus & Nodularia & Nodularia & Gp1 \\
\hline & Species & sphaerocarpa & Unclassified & Unclassified \\
\hline & OTU & OTU_1430 & OTU_1214 & OTU_1997 \\
\hline \multirow[t]{7}{*}{$21 \cup 2$} & Phylum & Cyanobacteria & Cyanobacteria & Cyanobacteria \\
\hline & Class & Nostocophycideae & ------- & -------- \\
\hline & Order & Nostocales & Nostocales & Nostocales \\
\hline & Family & Nostocaceae & Nostocaceae & Nostocaceae \\
\hline & Genus & Nodularia & Nodularia & Nodularia \\
\hline & Species & Unclassified & Unclassified & Unclassified \\
\hline & OTU & OTU 1429 & OTU 1214 & OTU 1214 \\
\hline
\end{tabular}

The use of OTU assignments allows further association at a classification, beyond the taxonomic level of family. Its use is also beneficial in the examination of the richness of the microbial communities. An increase or decrease observed 
in the number of sequences grouped in the same OTU is as important as the appearance or disappearance of a higher taxonomic group.

The Greengenes classifier placed the 414 16S rRNA gene sequences into 157 different operational taxonomic units. OTU assignments may be compared in terms of taxonomic designations at all levels. This type of examination indicates diversity within taxonomic categories such as phylum and order, and can help illuminate characteristics of groups of sequences in terms of ability to adjust to different physical characteristics, such as precipitation or $\mathrm{pH}$, which might affect microbial populations. Table 13 lists a phylum or class designation, the number of OTUs, and 16S rRNA gene sequences associated with that group of Eubacteria.

Table 13. Number of OTUs and $16 S$ rRNA gene sequences in a bacterial taxon

\begin{tabular}{lcc}
\hline & & \# of $16 S$ rRNA \\
Phylum & \# of OTUs & gene sequences \\
\hline Acidobacteria & 2 & 7 \\
Actinobacteria & 13 & 20 \\
Aquificae & 1 & 2 \\
Bacteroidetes & 4 & 5 \\
Chloroflexi & 1 & 1 \\
Cyanobacteria & 15 & 48 \\
Deferribacteres & 1 & 2 \\
Bacilli & 10 & 11 \\
Clostridia & 9 & 16 \\
Gemmatimonadetes & 1 & 1 \\
Nitrospirae & 1 & 1 \\
Planctomycetes & 2 & 3 \\
Alphaproteobacteria & 56 & 232 \\
Betaproteobacteria & 17 & 37
\end{tabular}


Table 13. (Continued)

Deltaproteobacteria

Gammaproteobacteria

Uncl. Proteobacteria

Synergistia

Thermotogae

Verrucomicrobiae

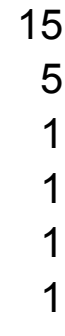

157
17

8

1

1

1

2

411

The location of different OTUs along the precipitation transect provides a refinement of what populations in the microbial communities are changing. Of the 157 OTUs, 117 , or $40 \%$ are associated with a single sample site. These OTUs represent 166 , or $40 \%$ of the total number of $16 \mathrm{~S}$ rRNA gene sequences. Grouped by the dominant taxonomic classifications, Table 14 lists the number of OTUs located at a single sampling site, and the associated number of sequences. As was previously mentioned, Sand Canyon had the highest percentage of Alphaproteobacteria sequences of all the sample sites. The OTU analysis indicates that 16 of the 56 alphaproteobacterial OTUs or $28 \%$ of all alphaproteobacterial diversity is associated with that site. At Henry Springs Road eleven OTUs were found, representing $69 \%$ of Cyanobacterial diversity. Fields Road had 7 of 10 OTUs assigned to the Bacilli, indicating that $70 \%$ of the diversity associated with Bacilli was found only at that sample site. 
Table 14. Number of OTUs found at a single sample site and the number of actual 16S rRNA gene sequences represented.

\begin{tabular}{|c|c|c|c|c|c|}
\hline Site 15 only & $\begin{array}{l}\text { \# of } \\
\text { OTUs }\end{array}$ & $\begin{array}{c}\text { \# of } \\
\text { Clones } \\
\end{array}$ & Site 16 only & $\begin{array}{l}\text { \# of } \\
\text { OTUs }\end{array}$ & $\begin{array}{c}\text { \# of } \\
\text { Clones }\end{array}$ \\
\hline Bacteriodetes & 2 & 2 & Actinobacteria & 4 & 5 \\
\hline Clostridia & 2 & 5 & Bacteriodetes & 1 & 1 \\
\hline$\alpha$-Proteobacteria & 16 & 23 & Cyanobacteria & 1 & 1 \\
\hline$\beta$-Proteobacteria & 2 & 3 & Bacilli & 1 & 1 \\
\hline$\delta$-Proteobacteria & 4 & 4 & Planctomycea & 1 & 1 \\
\hline$\gamma$-Proteobacteria & 1 & 1 & $\alpha-$ Proteobacteria & 7 & 7 \\
\hline Unclassified & 1 & 1 & $\beta$-Proteobacteria & 5 & 5 \\
\hline Thermotogae & 1 & 1 & $\delta$-Proteobacteria & 4 & 5 \\
\hline Site 18 only & $\begin{array}{l}\text { \# of } \\
\text { OTUs }\end{array}$ & $\begin{array}{c}\text { \# of } \\
\text { Clones }\end{array}$ & Site 21 only & $\begin{array}{l}\text { \# of } \\
\text { OTUs }\end{array}$ & $\begin{array}{c}\text { \# of } \\
\text { Clones }\end{array}$ \\
\hline Acidobacteria & 1 & 3 & Actinobacteria & 3 & 4 \\
\hline Actinobacteria & 3 & 4 & Chloroflexi & 1 & 1 \\
\hline Cyanobacteria & 1 & 1 & Cyanobacteria & 11 & 33 \\
\hline Deferribacteres & 1 & 2 & Bacilli & 2 & 2 \\
\hline Bacilli & 7 & 8 & Clostridia & 4 & 4 \\
\hline$\alpha-$ Proteobacteria & 6 & 6 & Gemmatimonadetes & 1 & 1 \\
\hline$\beta$-Proteobacteria & 3 & 3 & Nitrospirae & 1 & 1 \\
\hline$\delta$-Proteobacteria & 3 & 4 & $\alpha$-proteobacteria & 6 & 6 \\
\hline \multirow[t]{3}{*}{ Synergistia } & 1 & 1 & $\beta$-proteobacteria & 4 & 9 \\
\hline & & & $\delta$-proteobacteria & 4 & 4 \\
\hline & & & $\gamma$-Proteobacteria & 2 & 3 \\
\hline
\end{tabular}

Seven OTUs were identified at all four sampling sites. Six of these were associated with the Alphaproteobacteria, and the seventh OTU was from the Betaproteobacteria. This group of OTUs included those with the highest number of actual $16 \mathrm{~S}$ rRNA gene sequences, representing 143 , or $34 \%$ of the total number of sequences. OTU_2503 had 62 total 16S rRNA gene sequences 
which were primarily located at Sand Canyon and Fields Road. Significant numbers were also found at California City; however Henry Springs Road showed a definite decrease in the presence of this OTU. The second largest group of $16 \mathrm{~S}$ rRNA gene sequences was for OTU_2508 with 30 sequences, which decreased in numbers along the transect. OTU_2552 had 20 associated 16S rRNA gene sequences, and was fairly evenly distributed except for an increase at California City. (Figure 11)

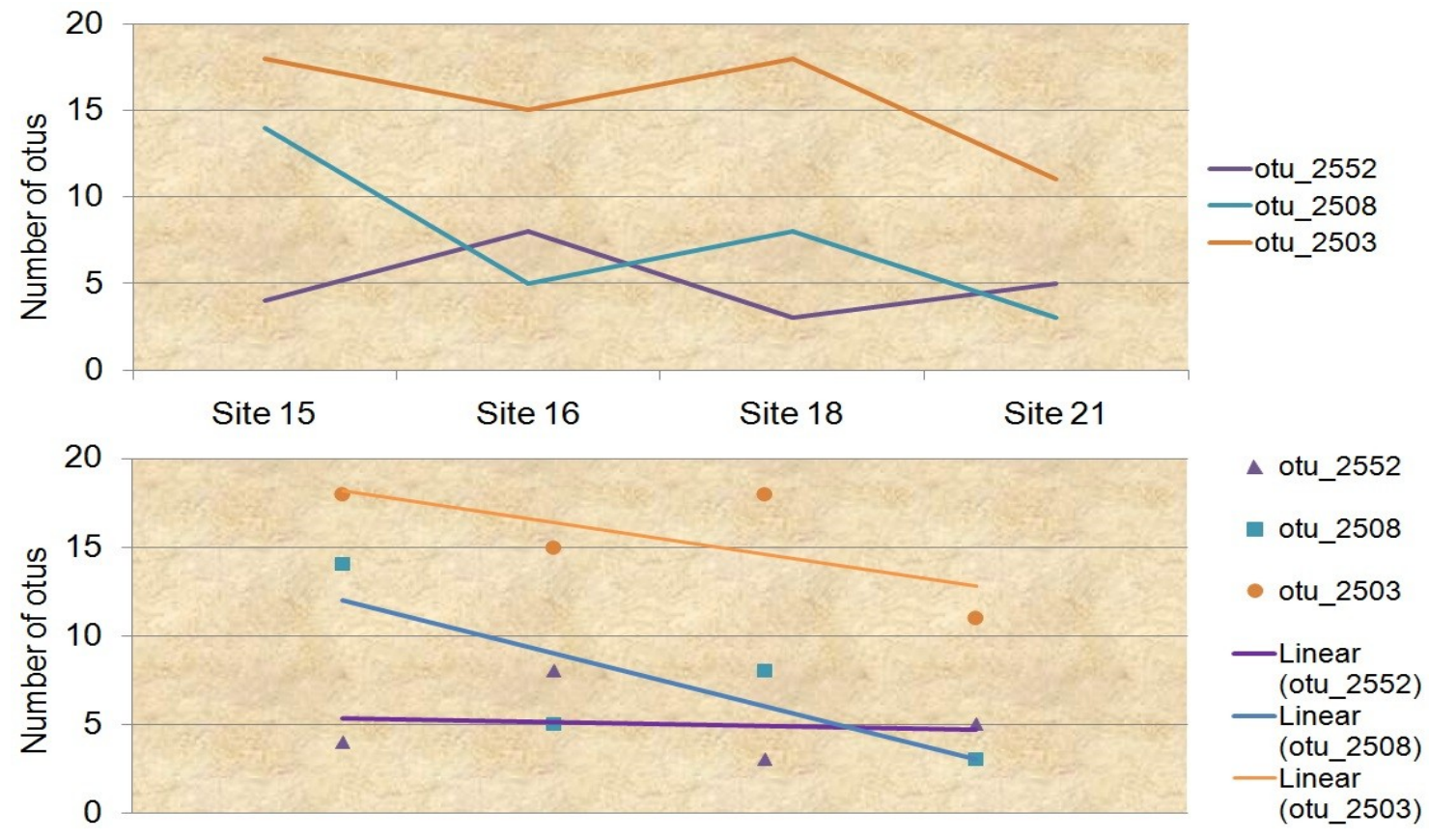

Figure 11. Upper graph: Number of OTUs per sample site for the most highly populated OTUs found at all sites along the precipitation transects. Lower graph: trend lines for each numbers of OTUs at each sample site.

The four remaining OTUs were found at all four sample sites represent fewer numbers of $16 \mathrm{~S}$ rRNA gene sequences. Two of these OTUs, 2511 and 
2786, increase in numbers at California City, then decrease, whereas the other two OTUs, 2697 and 3075 have their maximum number of sequences at Sand Canyon. The overall trend for each of these OTUs shows a decrease in numbers as the precipitation levels decrease. (Figure 12)

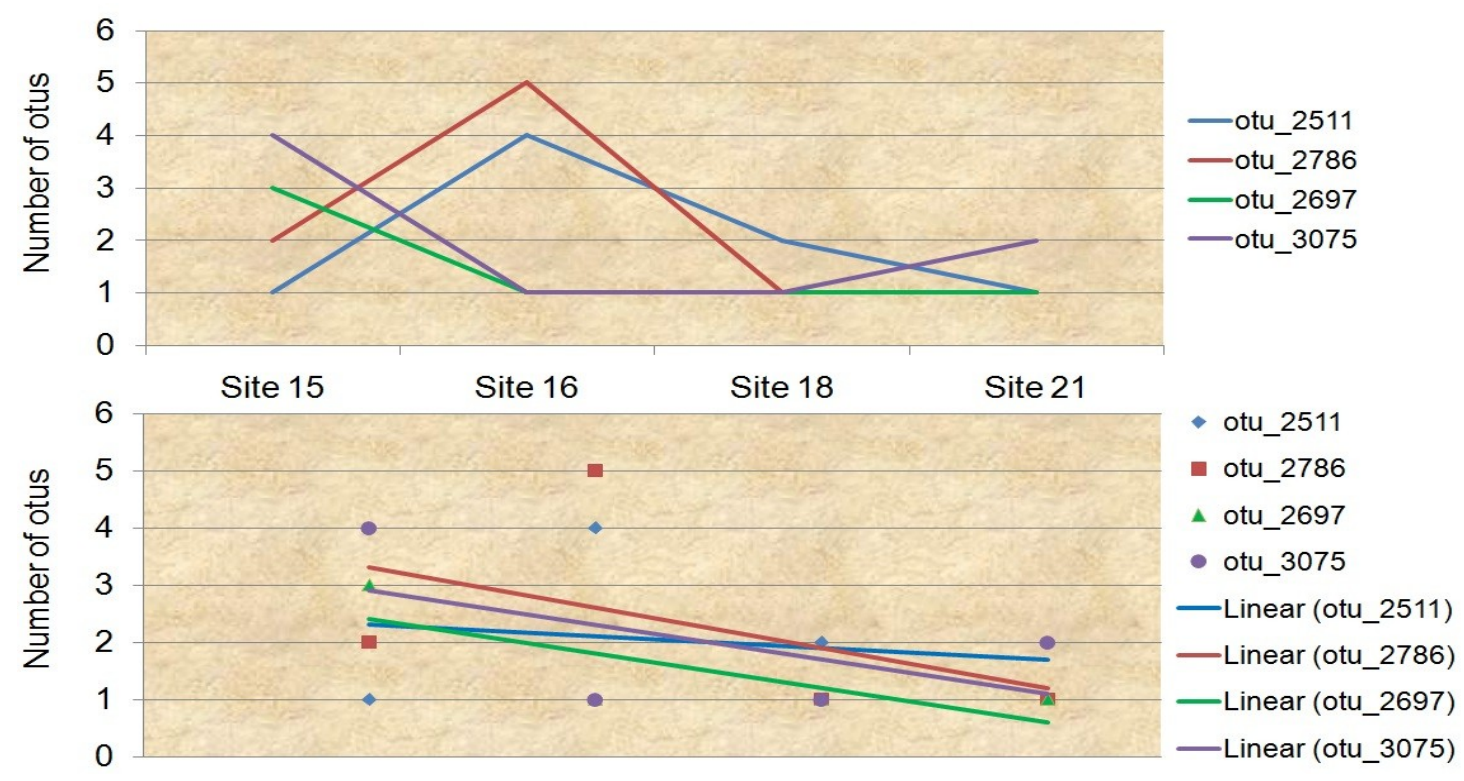

Figure 12. Upper graph: Minor OTUs associated with all four sample sites. Lower graph: trend lines for each numbers of OTUs at each sample site.

Seven OTUs were specifically associated with only the driest sites, and showed no definite trend in the number of $16 \mathrm{~S}$ rRNA gene sequences. These groups contained 16 sequences, classified as Cyanobacteria, Firmicutes, Alphaproteobacteria, Acidobacteria, and Bacteroidetes.

At the western end of the transect, eight OTUs spanned from Sand Canyon to California City or Fields Road. These 24 16S rRNA gene sequences were from the Alpha- and Betaproteobacteria, Firmicutes, and the Actinobacteria. 
Several of these OTUs demonstrated a decreasing population trend eastward along the transect.

The remaining OTUs spanned the transect in no apparent pattern. Eighteen OTUs represented 57 16S rRNA gene sequences, and were primarily associated with the Alphaproteobacteria. The Beta and Gammaproteobacteria were also represented in this group, as well as 2 OTUs from the Actinobacteria, and single OTUs from Aquificae, Cyanobacteria, Firmicutes, Planctomycetes and Verrucomicrobia

Archaeal 16S rRNA Gene Sequences. The analysis of the archaeal sequences for the sample sites of the precipitation transect was much less complex than for the Eubacteria. Sand Canyon did not yield a quantity of $16 \mathrm{~S}$ rRNA gene sequences comparable to the number of sequences for California City, Fields Road, and Henry Springs Road. Thus, only the eastern most sites were used for analysis of archaeal diversity.

Greengenes classification placed all the archaeal 16S rRNA gene sequences into the phylum Euryarchaeota. Sequences were further classified into five classes: Archaeoglobi, Methanomicrobia, Methanopyri, Thermococci and Thermoplasmata. Figure 13 shows the proportion of each class at each sample site. Unlike the Eubacteria, the Archaea do not appear to show trends along the transect. The greatest diversity in the proportion of 16S rRNA gene sequences along the precipitation transect is at Fields Road, and thus suggests 
that one or more factors other than precipitation affects the archaeal communities in the desert.

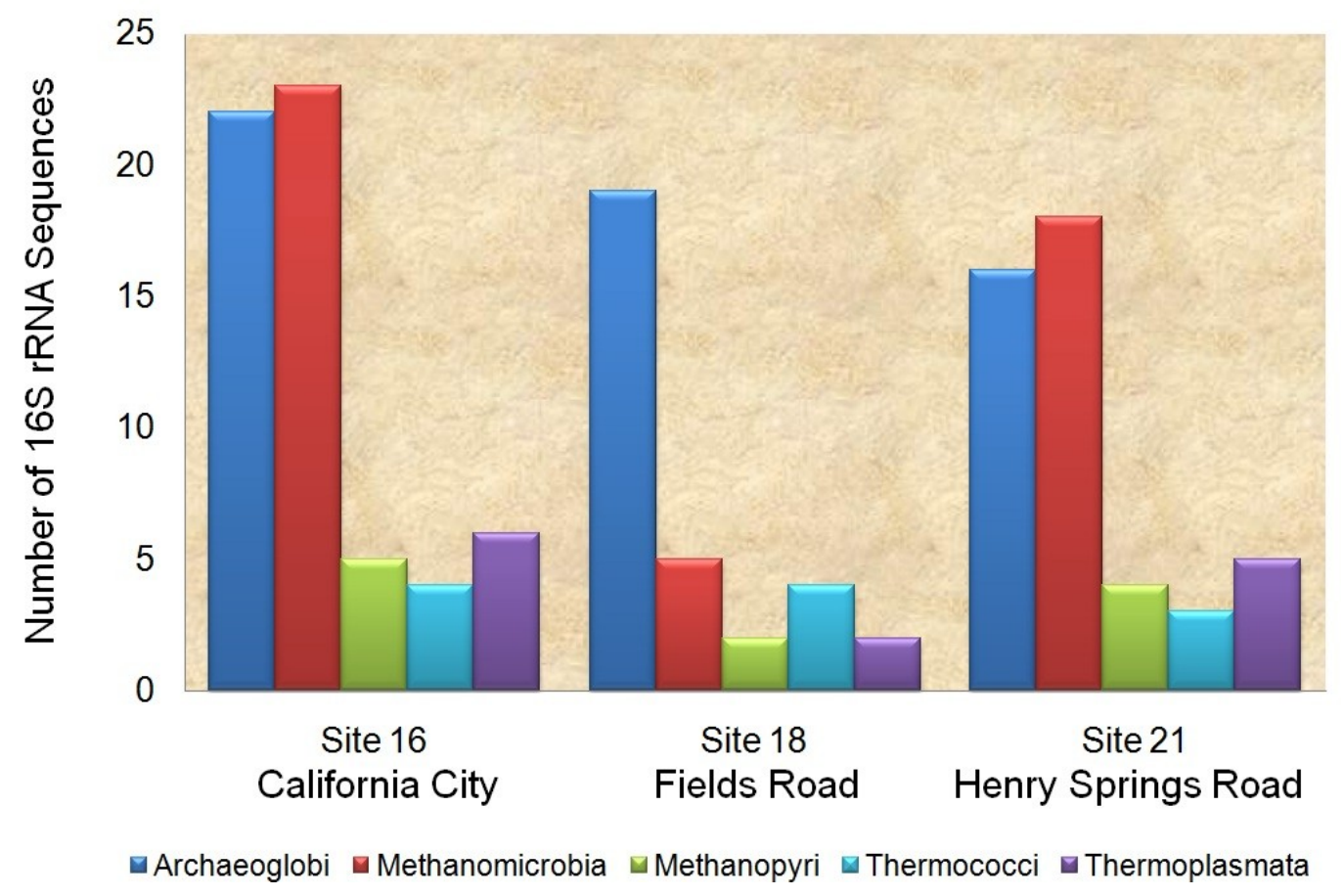

Figure 13. Taxonomic classes and corresponding number of archaeal $16 \mathrm{~S}$ rRNA gene sequences

Further analysis of taxonomic levels introduced two families for the class Thermococcus, but continued to group the rest of the sequences into single families within the related class. The OTU assignments indicated that all $16 \mathrm{~S}$ rRNA gene sequences within a class or family are the same Archaean microorganism.

Diversity Analysis. Rarefaction curves were produced for the Eubacteria and Archaea based upon the OTU designations assigned by the Greengenes classifier. (Figure 14) Eubacterial 16S rRNA gene sequences from all four 
sample sites were combined to compare the overall coverage of the microbial soil communities. None of the curves approach a plateau, indicating that the number of sequences per site is not sufficient to fully represent the total number of distinct bacterial organisms. The similar shape and slope of the four curves also indicate that similar numbers of $16 \mathrm{~S}$ rRNA gene sequences would be needed at all sites to fully represent the richness of the bacterial communities. An extrapolation of the curves suggests the need for another 70 to $10016 \mathrm{~S}$ rRNA gene sequences to statistically encompass these communities.

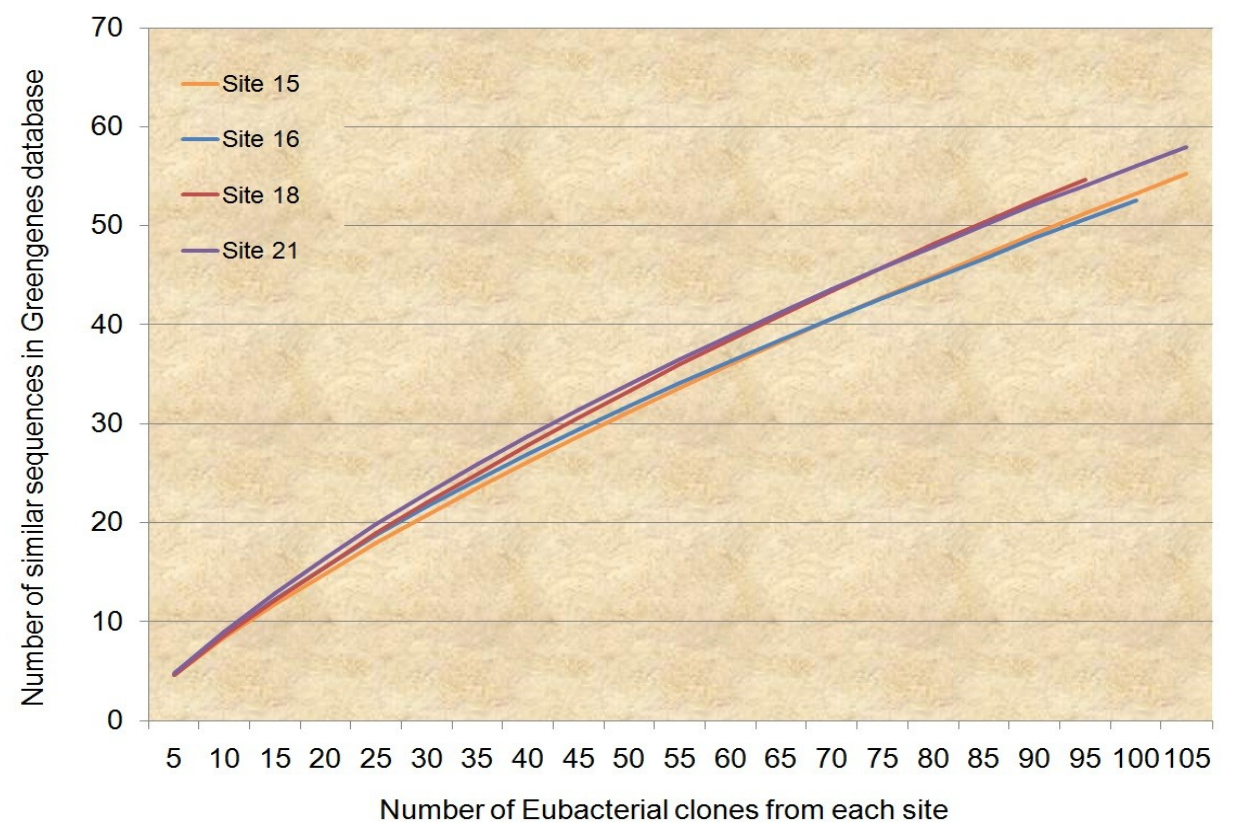

Figure 14. Rarefaction curves for the Eubacterial 16S rRNA gene sequences for the four sample sites of the precipitation transect.

Figure 15 shows the rarefaction curves for the Archaea sequenced along the precipitation transect. The number of $16 \mathrm{~S}$ rRNA gene sequences for each sample site appears to adequately represent the diversity of the Archaeal 
communities sampled. Site 15 (Sand Canyon) was included in this analysis to indicate the lack of sufficient sequences to properly assess this sample site.

Because there was so much similarity between the Archaea taxonomic associations at sites 16,18 , and 21 , the resulting rarefaction curve for these three samples were identical. The curve for these sites does flatten at around 55 $16 S$ rRNA gene sequences, indicating that the sample size for California City, Fields Road, and Henry Springs Road adequately represents the diversity sampled.

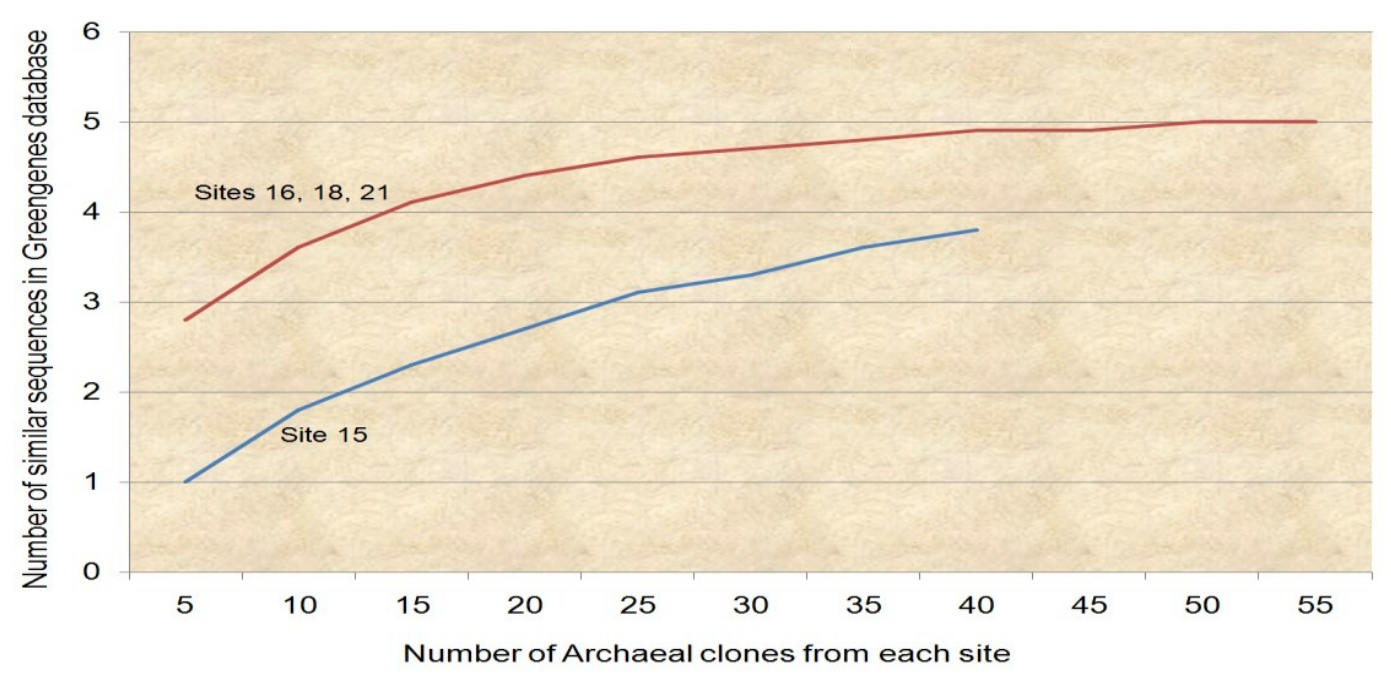

Figure 15. Rarefaction curves for the Archaeal 16S rRNA gene sequences for the four sample sites of the precipitation transect.

In order to quantitatively determine the diversity of the microbial communities sampled along the precipitation transect, the Shannon-Weiner function was calculated. Based upon species richness and the evenness of the species individuals, the function is used to assess the uncertainty of correctly 
predicting the next species identify due to a random selection from a sample.

The lower the diversity the closer $\mathrm{H}$ is to zero, thus increasing values of $\mathrm{H}$ indicate increasing diversity.

The analysis was based upon the classification of sequences to the level of OTU. The values for the Eubacteria showed a high level of diversity compared to that for the Archaea. For both groups of microorganisms, there was a notable decrease in diversity at Fields Road, followed by an increase in diversity at Henry Springs Road. The values for $\mathrm{H}$ are shown in Figures 16 and 17.

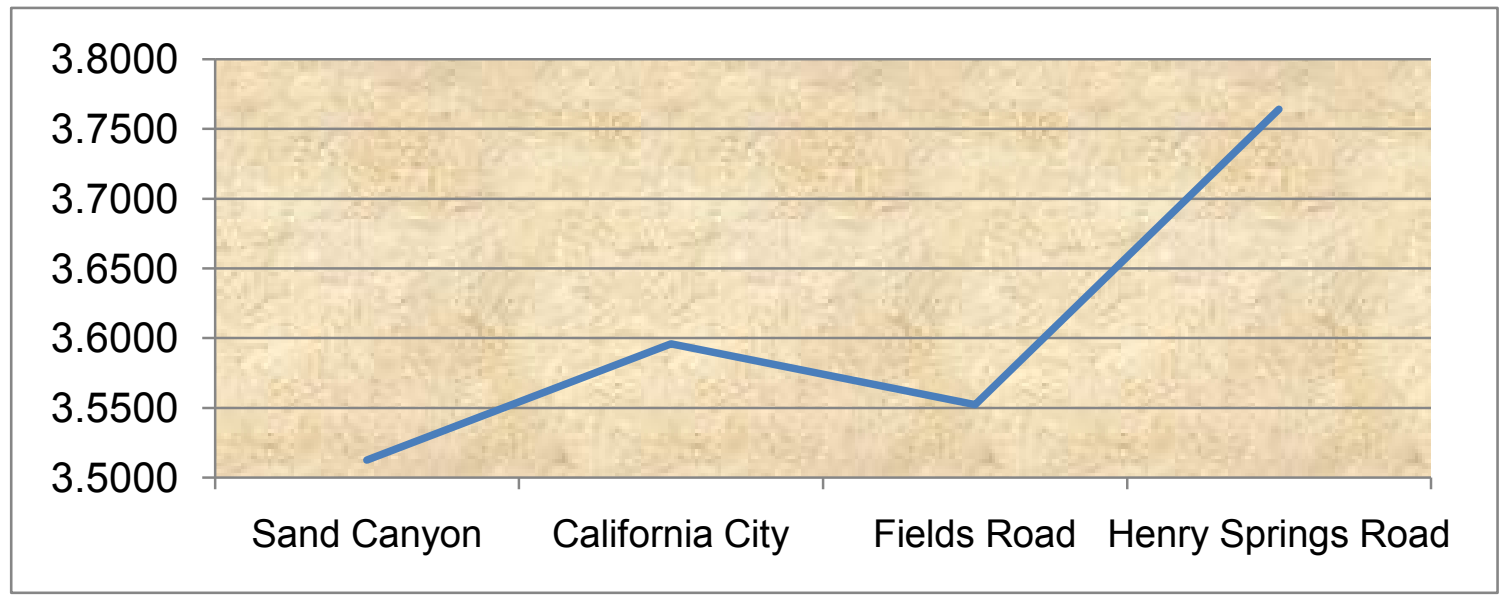

Figure 16. Shannon-Weiner function for Eubacteria 16S rRNA gene sequences 


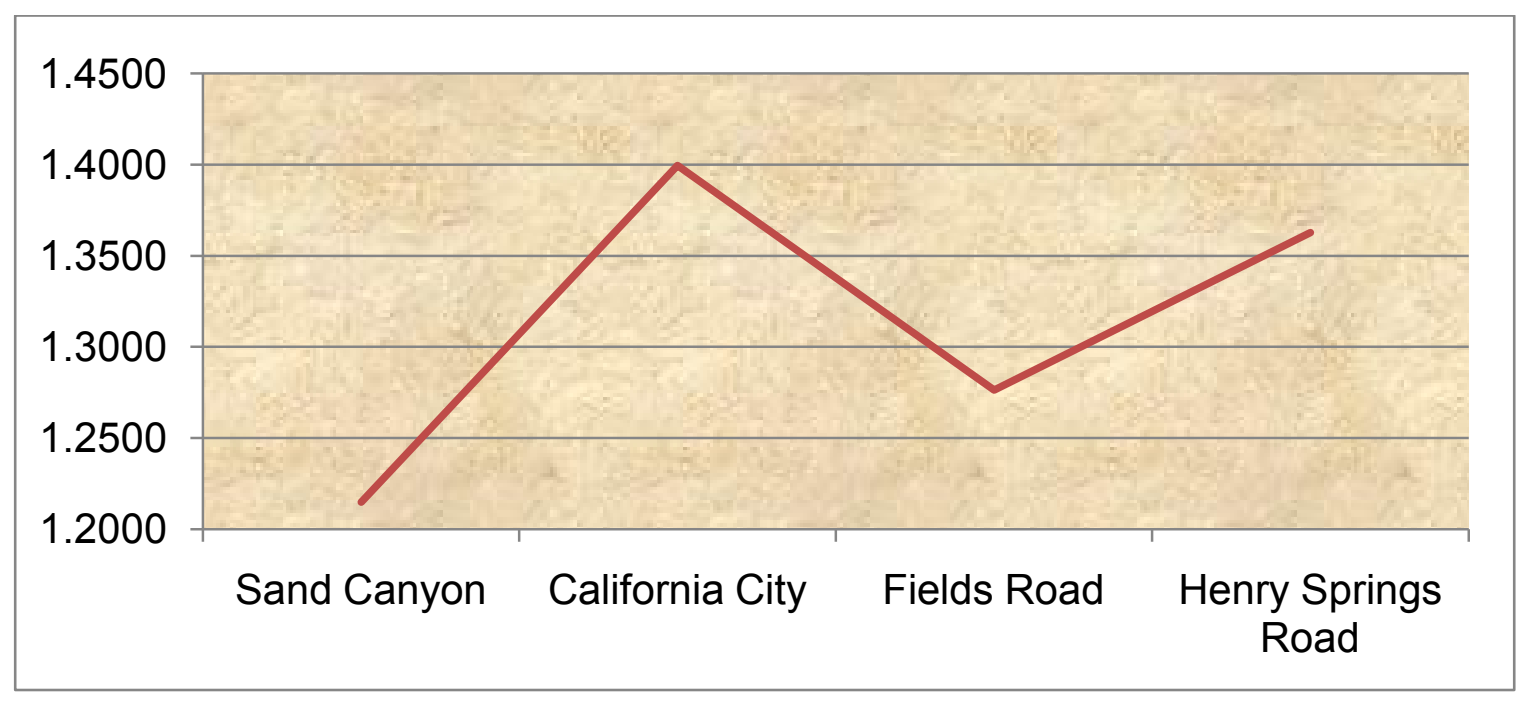

Figure 17. Shannon-Weiner function for Archaea $16 S$ rRNA gene sequences

\section{Discussion}

Sample Site Considerations. Any discussion of microbial communities must take into account several considerations. One consideration is the size of the sampling area. This study encompassed a zone $225.5 \mathrm{~km}$ west to east, 24 $\mathrm{km}$ north to south, and elevations from $403-1212 \mathrm{~m}$. The National Geographic records the size of the Mojave Desert as $130,600 \mathrm{~km}^{2}$, and, covers elevations from the lowest and driest point in the United States - Badwater, California, at $146 \mathrm{~m}$ below sea level, to over $1600 \mathrm{~m}$ in the mountains surrounding Death Valley. Thus, the sampling zone represents only $4 \%$ of the Mojave Desert. The precipitation transect was selected based upon ease of access, reference points, or towns, which had precipitation records, and observed physical differences indicative of decreasing annual rainfall levels. 
A second consideration for microbial diversity studies is the scale of the sample site. Microbes are quite sensitive to differences in temperature, soil types, soil moisture, $\mathrm{pH}$, organic content on a scale of millimeters. The initial analysis included breaking the $10 \mathrm{~m}^{2}$ sample site into thirds and examining the differences across the site. Viable count plates recorded different CFUs/gm soil depending upon the segment of the site. Locations closest to plants also resulted in increased organic carbon content, thus affecting the microbial community in terms of richness and diversity.

Vegetation and Soil Characteristics. The contribution of available vegetation as a source of organic materials, and the chemical constituents of the soil cannot be ignored when discussing microbial populations in the soil. Many of the observed differences in types of vegetation and plant coverage are directly related to the amount of available liquid water. Though none of the sample sites were considered pristine, with the exception of Sand Canyon and Rasor Road, they had infrequent contribution of organic materials from anthropomorphic sources. Sand Canyon displayed indications of having been used as pasture lands, and Rasor Road is a known off-road vehicle excursion site. All sites were selected from 15 to $40 \mathrm{~m}$ from a roadway, but prevailing winds possibly introducing chemical or mineral agents from automobiles, were not taken into consideration.

The types of vegetation observed along the transect was consistent with the exception of Sand Canyon, which displayed plants associated with pasture 
lands. The obvious distinction in vegetation was the size of specific plants. Kramer Junction and Black Tank exhibited very large creosote bushes, on the order of $2 \mathrm{~m}$ high and often grouped covering zones of $24 \mathrm{~m}^{2}$. The sagebrush was ubiquitous, though grew as smaller, individual plants as the sample sites became drier. Very little grass was observed at any of the sites beyond Sand Canyon, though herbal, flowering plants were a major part of the vegetative cover at Kramer Junction.

The soil chemistry reflected the vegetative coverage of the soil, thus reflecting the precipitation gradient, with a couple of examples. Considering the general trend of decreasing levels, the organic carbon levels were unusually high at Kramer Junction and Black Tank. This was also reflected in levels of organic nitrogen. These two sites are nestled against higher landforms. The Kramer Junction site is just south of an elevated area which $110 \mathrm{~m}$ higher elevation. The presence of this hill may result in an increase in precipitation as air masses are lifted over it. A localized effect such as this would explain the increase in organic material as well as the large plant size and extensive herbal ground cover observed. Rasor Road is located between hills as well, though not as high as those north of Kramer Junction.

The levels of sodium and chlorine also displayed interesting variation. The Henry Springs Road site is on drainage for a dry lake bed. Due to occasional variation in the monsoonal precipitation, that site is often exposed to heavy runoff from precipitation events. Evaporative effects and winds over the 
lake would affect the levels of salt at sites eastward. This would explain the increase in chlorine levels at this location. However, the sodium levels across the precipitation transect do not increase here. The sodium levels are highest at Sand Canyon, then drop to a minimum at California City, gradually increase along the intermediate sites, until reaching the dry zone of the transect. Black Tank soil shows a sharp increase in sodium levels, but Henry Springs Road sample site drops back to levels close to those of the intermediate sites. This sudden increase in sodium level at Black Tank is interesting because it is in a protected area, surrounded by volcanic hills. Possibly this is related to characteristics specific to the geology and geography of this site.

Viable Plate Counts and Precipitation Totals. Viable plate counts were performed in order to determine the relative size of microbial communities along the precipitation transect. With the understanding that the numbers of CFUs/g soil only represent the culturable members of the community, the comparison is a valid means of assessing differences in microbial communities between sites.

Because the viable plate counts were performed for each of the four years, the average was taken to normalize the counts susceptible to localized weather effects. The CFUs/g dry soil showed an overall decrease in the number of culturable microorganisms progressing west to east along the precipitation gradient. The 2007 and 2008 analyses showed the greatest difference between plate counts with a 100-fold decrease noted between Sand Canyon and Henry Springs Road. The CFUs/g dry soil calculations for 2009 and 2010, however, 
indicated only a 10 -fold difference. For 2007 , the middle transect sites: California City, Fields Road, and Rasor Road, showed relatively small changes in CFUs/g soil, and presented an reasonable value between the two precipitation extremes. The following three years presented a similar relationship, though the overall numbers averaged 100 -fold higher that in 2007 . California City deviates from the trend in 2009, and Fields Road does the same in 2010, indicating decreased precipitation during the previous twelve months.

The variations in plate counts observed in 2009 do not appear correlated directly to the levels of organic carbon or nitrogen measured that same year. Otherwise, the CFUs/g dry soil would be highest at Kramer Junction than at any other site (with the exception of Sand Canyon.) Nor do they appear related to levels of salt in the soil.

$\mathrm{PH}$ changes may affect microbial populations at the sample sites from year to year. Local precipitation levels directly impact plant growth and soil coverage, which directly impacts the $\mathrm{pH}$. The current population data does not provide the level of detail necessary to determine further association.

If sites 17,19 , and 20 are removed (due to previously stated reasons), the CFUs/g soil pattern does not necessarily clarify the trend, however the average trend becomes very clear (Figure 18). The California City and Fields Road sites show a relatively flat curve or plateau for the number of culturable microbes directly related to the precipitation pattern used to establish the transect. 


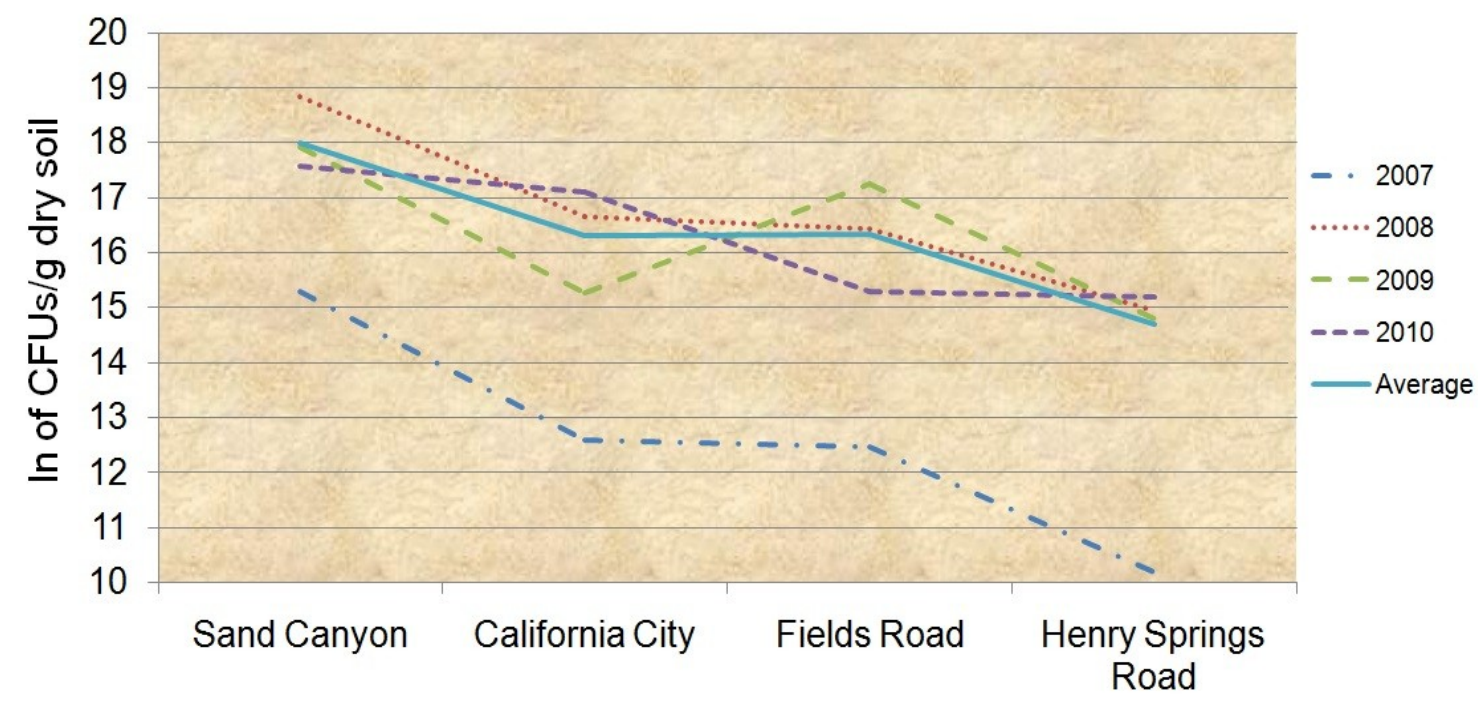

Figure 18. Trend in CFUs/g soil as $\ln (\mathrm{CFUs})$ vs. sample site.

Precipitation measurement devices were not deployed due to possible inadvertent or malicious interruption of the equipment. However, meteorological stations located across the Western United States are maintained by the Desert Research Institute (DRI) in Las Vegas, Nevada. Several DRI stations were located in close proximity to the transect and provided localized precipitation amounts throughout the 4-year study. Though south of the driest sampling sites, the Desert Studies Center (DSC) at Zzyzx, California, also maintains a weather station. This station and the Baker DRI station bracketed the Henry Springs Road site. Table 15 shows recorded precipitation totals for 12 months prior to each sampling expedition. 
Table 15. Annual precipitation amounts $(\mathrm{cm})$ at DRI weather stations and the DSC for 12-month period prior to each expedition.

\begin{tabular}{lccccc}
\hline Period & Tehachapi & Mojave & Barstow & Baker & Zzyzx \\
\hline $2006-7$ & 16.12 & 1.35 & 3.81 & 5.51 & 2.62 \\
$2007-8$ & 22.40 & 7.54 & 8.02 & 10.77 & 5.89 \\
$2008-9$ & 22.73 & 5.21 & 10.31 & 6.78 & 3.12 \\
$2009-10$ & 20.69 & 7.62 & 13.28 & 11.40 & NA \\
& & & & & \\
\hline
\end{tabular}

The driest 12-month period was prior to the first sampling expedition in 2007. The wettest 12-month period is not as easily discerned due to decreases in CFUs/g soil calculated for California City, Fields Road and Black Tank for various years. There appear to be localized factors, such as the proximity of mountains, which effect storm movement and result in rainfall patterns counter to the decreasing precipitation trend observed over a sixty-year period (Figure 19).

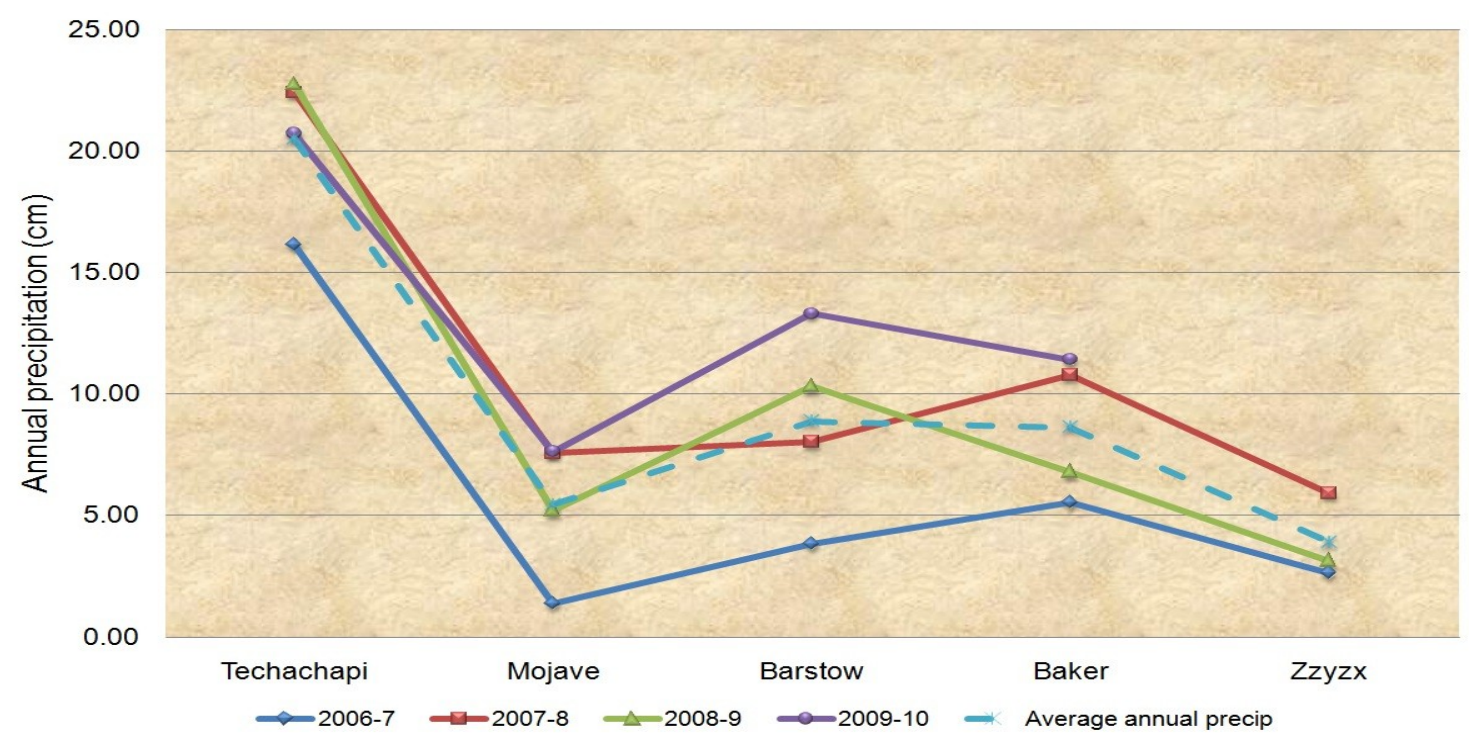

Figure 19. The recorded precipitation amounts for specified years along the precipitation transect. 
The Mojave weather station consistently recorded precipitation amounts lower than the other DRI stations, perhaps as a result of the rain shadow effect of the Tehachapi Mountains. Orographic precipitation, where moist air is thrust upwards and water vapor condenses, then falls on the western side of mountains, usually results in the eastern side of the mountain range receiving very little precipitation. This is actually observed on the FRAP precipitation map as a small zone of decreased rainfall $-8.9 \mathrm{~cm}$ instead of the $11.4 \mathrm{~cm}$ just east. The resulting low annual precipitation zone would indicate that CFU counts in this proximity might be unusually low compared to sample sites further east. This was not observed at the California City site. Three of the four years of viable counts established this site as having the largest culturable population west of the Tehachapi Mountains. Based upon the these results, the California City sample site, $23.4 \mathrm{~km}$ east of the DRI Mojave weather station, appears to be just outside the zone of low precipitation, but not so far from it that low counts, such as seen 2009 , cannot occur.

The Henry Springs Road sample site is almost halfway between the Baker $\mathrm{DRI}$ and the Zzyzx weather stations, and thus probably receives annual precipitation amounts between the amounts recorded at the weather stations. This possibility is supported by the viable count plates showing this site to have the lowest CFUs/g soil averaged over the four year study period. Black Tank, a bit further east at the edge of a lava flow, has presented fewer CFUs/g soil for the 
2009 and 2010 years, however it yielded ten times more for the 2008 sample year.

The number of culturable bacteria and the decrease in number is low moisture soils correlate with values determined by other desert studies. Rainey, et al. compared desert soil samples from the Sonoran Desert to the Atacama. The Sonoran Desert is considered an arid environment and receives an average of less than $20 \mathrm{~cm}$ precipitation per year. The Atacama is a hyperarid desert and may go for several years without measurable rainfall. The relative humidity ranges from $30-50 \%$, depending upon seasons. The Sonoran viable count plates produced $10^{6} \mathrm{CFUs} / \mathrm{g}$ dry soil whereas the Atacama samples ranged from $2.2 \times 10^{4}$ to $1.8 \times 10^{5}$ CFUs/g dry soil [21].

Another desert environment, the Negev Highlands of Israel, was sampled beneath shrubs and in between vegetation during the four seasons of 2001 . This temperate desert is very similar to the Mojave in terms of rainfall, with average precipitation of $9.8 \mathrm{~cm}$, with fog contributing another $3.4 \mathrm{~cm}$ precipitation per year. Temperatures range between $5-14^{\circ} \mathrm{C}$ in the winter and up to $32^{\circ} \mathrm{C}$ in the summer, and thus there is less fluctuation in temperature as in the Mojave. Plates cultured from the soil under the shrubs yielded $4.6 \times 10^{6}-1.07 \times 10^{7} \mathrm{CFUs} / \mathrm{g}$ soil, and the intershrub areas recorded $6.56-8.75 \times 10^{6} \mathrm{CFUs} / \mathrm{g}$ dry soil. These values of culturable microbes have the same order of magnitude as from the Mojave, though all the Mojave sample sites were intershrub and were $10^{5} \mathrm{CFUs} / \mathrm{g}$ soil for two years. In the Negev Highlands, the contribution of condensation from fog 
may provide enough additional liquid water, particularly around the vegetation, to increase the culturable counts to those of a wet year in the Mojave [2].

Zdanowski and Węgleński made serial dilutions of soil from thirteen sample sites on King George Island, Antarctica, and plated them on full-strength NA medium. These sites were from a designated protected zone indicating restricted from anthropomorphic influences, and thus affected strictly by natural conditions of cold, no permanent snow cover, and organic material deposited from plants and animals. Eight of the sample sites were from exposed soil, while the remainder was taken from soil at the bottom of pools of water. The results for the soils averaged from $1.42 \times 10^{8} \mathrm{CFUs} / g$ soil around the Ecology Glacier, and $4.8 \times 10^{6} \mathrm{CFUs} / \mathrm{g}$ dry soil on hills away from the glacier. The higher culturable counts adjacent to the glacier are likely due to proximity of liquid water when temperatures increase to above freezing [27].

Soil dilutions from areas in and around campsites at a subalpine lake in western Montana were plated on R2A medium to detect soil compaction and other anthropomorphic influences on microbial communities. The resulting plates indicated CFU values of $6.5 \times 10^{6}$ for campsites or human-affected areas, and $5.9 \times 10^{6}$ for the soil between campsites (less disturbed zones), indicating little anthropomorphic influence on campsite soil [26].

16S rRNA Sequence Analysis, Database Selection. The primary purpose of this research was to investigate the Eubacterial and Archaeal soil communities along a precipitation transect through the Mojave Desert. In order to analyze 
16S rRNA sequence data and address this topic the decision was made to utilize the classification system provided by Greengenes rather than to use information from GenBank via BLAST. A comparison of BLAST results to Greengenes results present an interesting discrepancy in the purpose of the different databases. NCBI GenBank resides primarily as the research depository for all sequence information, regardless of taxonomic associations. Thus, when the sequences for Sand Canyon and California City were classified using BLAST, the majority of the sequences were associated with uncultured bacteria. Of the 107 sequences for Sand Canyon, $56 \%$ were in this category. Another $28 \%$ were uncultured, but associated with the Proteobacteria. Only $14 \%$ of the sequences were identified as a taxonomically distinct bacterium. A similar situation was observed for the California City sequences: $45 \%$ were uncultured bacteria, $14 \%$ were uncultured Proteobacteria and $28 \%$ were identified as a taxonomically unique bacterium. The maximum identity is a value calculated by the BLAST routine to provide a level of similarity between sequences. The standard values for taxonomic classification are $\geq 97 \%$ for the same species, $\geq 94 \%$ for the same genus. The maximum identity for the Sand Canyon sequences yielded $62 \%$ at $\geq$ $97 \%$ (species identification), another $30 \% \geq 93 \%$ (genus assignment), and only $5 \%$ below $90 \%$. The values for the California City sequences were $71 \%, 25 \%$, and $2 \%$ below $90 \%$ maximum identity.

The databases utilized by Greengenes allowed for comparisons between NCBI, RDP, and the Greengenes repositories of sequence data which 
associated each sequence with some level of taxonomic classification. These offered slightly different interpretations of some of the sequences, resulting in different classification. Table 16 compares the percentage of sequences assigned to each phylum by the three databases for the four sample sites of interest. By adding the minimum percentage of $16 \mathrm{~S}$ rRNA gene sequences designated by a database to a phylum, some level of agreement on classification may be determined.

Table 16. Comparison of phylum assignments by three Greengenes databases for classification of sequences at two sites. Values are $\%$ of total sequences.

\begin{tabular}{lcccccc}
\hline & \multicolumn{3}{c}{ Sand Canyon } & \multicolumn{3}{c}{ Henry Springs Road } \\
Phylum & GG & RDP & NCBI & GG & RDP & NCBI \\
\hline Acidobacteria & 0 & 0 & 0 & 1 & 1 & 1 \\
Actinobacteria & 2 & 3 & 3 & 4 & 0 & 3 \\
Aquificae & 1 & 0 & 0 & 1 & 3 & 0 \\
Bacteroidetes & 2 & 0 & 2 & 1 & 1 & 1 \\
Chloroflexi & 0 & 0 & 0 & 1 & 1 & 1 \\
Cyanobacteria & 0 & 0 & 0 & 31 & 31 & 31 \\
Deferribacteres & 0 & 0 & 0 & 0 & 0 & 0 \\
Deinococcus-Thermus & 0 & 0 & 7 & 0 & 0 & 0 \\
Firmicutes & 6 & 7 & 7 & 6 & 7 & 8 \\
Gemmatimonadetes & 0 & 0 & 0 & 1 & 1 & 1 \\
Nitrospirae & 0 & 0 & 0 & 1 & 1 & 1 \\
Planctomycetes & 0 & 0 & 0 & 0 & 0 & 0 \\
Proteobacteria & 89 & 90 & 81 & 53 & 53 & 50 \\
Synergistetes & 0 & 0 & 0 & 0 & 0 & 0 \\
Thermotogae & 1 & 0 & 0 & 0 & 0 & 0 \\
Verrucomicrobia & 0 & 0 & 0 & 0 & 0 & 0 \\
Unclassified & 0 & 0 & 1 & 0 & 1 & 3 \\
& & & & & & \\
\hline
\end{tabular}


Eighty-nine percent of the Sand Canyon sequences were consistently classified in the same phyla regardless of database. This consensus was observed at the other three sample sites, with the Henry Springs Road sequences showing $92 \%$ classification agreement by the three databases. The differences in phylum assignments does not reflect a discernable pattern related to the databases, thus an explanation for RDP did not classify any sequences as Bacteriodetes and both Greengenes and NCBI did is not obvious.

Another interpretation of the database classification to the phylum level is to observe which phyla were fairly consistent across the databases. The Acidobacteria and the phyla associated with a single sample site, such as the Chloroflexi, the Gemmatimonadetes, Synergistetes, were grouped together by the three databases. The Cyanobacteria had 5 of 50 sequences, or $10 \%$ that were not consistently placed within this taxonomic unit. The Greengenes database placed two of these sequences in other phyla. The NCBI database had three of the 5 sequences separated into two different eubacterial phyla and actually identified one of these sequences as a eukaryotic organism. The RDP database placed two of these 5 sequences in Firmicutes and one in Bacteriodetes. Interestingly, the classification of these questionable sequences was only partially clarified by blasting them against GenBank. Table 17 indicates the results of all four databases concerning the sequences in question. 
Table 17. 16S rRNA gene sequences of doubtful classification as determined by the Greengenes, NCBI, RDP and GenBank databases. ("Unc" $\rightarrow$ uncultured)

\begin{tabular}{lllll}
\hline Seq \# & GG & NCBI & RDP & GenBank \\
\hline $15 \mathrm{M} 2$ & Firmicutes & Actinobacteria & Actinobacteria & Unc Bacterium \\
$16 \mathrm{I}$ & Firmicutes & Cyanobacteria & Firmicutes & Unc Bacterium \\
$16 \mathrm{Q} 3$ & Cyanobacteria & Actinobacteria & Bacteroidetes & Unc Bacterium \\
$16 \mathrm{~V} 4$ & Bacteroidetes & Cyanobacteria & Cyanobacteria & Cyanobacteria \\
$16 \mathrm{H} 2$ & Cyanobacteria & Firmicutes & Firmicutes & Unc Planctomycetes \\
$18 \mathrm{~L}$ & Cyanobacteria & Eukaryote & Cyanobacteria & Unc Bacterium \\
$21 \mathrm{Y} 2$ & Actinobacteria & Firmicutes & Firmicutes & Unc Bacterium \\
& & & & \\
\hline
\end{tabular}

The confusion between classifications based upon database is not something resolvable at this time. The same situation arose when classifying Archaeal sequences. Using the same databases, NCBI and Greengenes tended to agree upon archaeal classifications more often than RDP or GenBank, which tended to associate the sequences amplified by confirmed archaeal primers as bacterial. Thus, the decision was made to use a single database for all the sequences and sampling sites, thereby gaining consistency across the project and establishing a basis for future analysis. The Greengenes database was selected for this analysis because it offered taxonomic specifications for class, order family, genus, and species, where applicable.

$16 S$ rRNA Sequence Analysis, Classification Parameters. The Greengenes alignment routine compares sequence information to its own rRNA gene database and produces an alignment of 7,682 characters. The user is asked to determine a minimum length of bases depending upon the length of the edited sequence length. The default is 1250 bases; however, 500 bases were 
selected for this analysis due to resulting sequence lengths of approximately 700 bases for some of the sequences. There is also a selection for minimum percent identity. This value is not related to the classification of a sequence to a specific taxonomic level. Rather, it is a minimum association requested for comparison to the template sequence selected by the NAST (Near Alignment Space Termination) algorithm. The default setting for this value is $75 \%$, which was used for this analysis. When that value was increased, the result was an increase in sequences which did not meet the minimum percent identity to the template sequence, so more sequences were dropped from the alignment and classification.

To test this distinction, alignments were run at the suggested $75 \%$ as well as 80,85 and $90 \%$ minimum identity. For site 15 or Sand Canyon sequences, the difference between the 75,80 , and $85 \%$ identity resulted in the loss of a single sequence. When examined by BLAST, that sequence was classified as an uncultured bacterium but with only a $89 \%$ maximum identity. Running the alignment at $90 \%$ minimum percent identity resulted in the loss of eight more sequences. When these sequences were compared to GenBank, the resulting maximum identity ranged from 83 to $98 \%$. These sequences were classified as uncultured bacteria though two were identified as members of the class Deltaproteobacteria. The results of this process using the sequences from the Henry Springs Road site were more dramatic. At each incremental $5 \%$ change in minimum percent identity from 75 to $85 \%$ dropped an additional sequence from 
the analysis. When the minimum percent identity was increased to $90 \%$, a total of twenty-nine sequences were lost.

The rarefaction curves for the eubacterial communities of the transect indicated that a total of 107 - 108 16S rRNA gene sequences for Sand Canyon and Henry Springs Road were not sufficient to adequately describe the existing communities. Thus, the loss of sequences due to higher levels of identity to a template sequence was not justifiable. Furthermore, because this exclusion from the alignment did not correspond to increasing the certainty of identification of the 16S rRNA gene sequences suggest that using the $75 \%$ level for maximum identity to a template sequence for the purpose of alignment was a satisfactory assignment.

16S rRNA Sequence Analysis, Eubacteria. The resulting classification provided by Greengenes for the 16S rRNA gene sequences from the four sample sites along the precipitation transect present are in agreement with the proportions of phyla along the transect. The predominant phylum was the Proteobacteria, with the highest number of sequences associated with the class Alphaproteobacteria. The numbers of Alphaproteobacteria decreased eastward along the precipitation gradient. Conversely, the Cyanobacteria were not observed at Sand Canyon, but became a part of the soil community and increased as precipitation levels decreased eastward along the transect, until it was within $7 \%$ of the population of alphaproteobacterial sequences. None of the 
other phyla were present at levels near that of the Cyanobacteria or Alphaproteobacteria.

Research in other desert environments reveals a slightly different assessment of predominant bacterial phyla. The Eubacterial and Archaeal soil communities of the Tataouine Desert of Tunisia were examined using 16S rRNA gene analysis. The Tataouine Desert is considered an arid environment with an average precipitation of $11.5 \mathrm{~cm}$. Like the Mojave, temperatures range from 5 to $40^{\circ} \mathrm{C}$, and vegetation is sparse. It differs from the Mojave because of the occurrence of Sirocco winds $10 \%$ of the year. Soil samples were taken from the top $5 \mathrm{~cm}$ of soil and used to create a $16 \mathrm{~S}$ rRNA gene library. The sequences were classified using GenBank and the results of the culturable bacteria indicated affiliations with the Actinobacteria, Proteobacteria, Firmicutes, and a single isolate labeled CFB group 1(distantly associated with Flexibacter). The molecular analysis of the $16 \mathrm{~S}$ rRNA gene indicated that $83 \%$ of the 117 sequences tested belonged to the Proteobacteria (41\%), Actinobacteria (25\%), and Acidobacteria (17\%). Of the remaining sequences, associations with Green Non-sulfur (GNS) bacteria, Deinococcus-Thermus, Planctomycetes, Verrucomicrobia and Firmicutes were present, and none were associated with Cyanobacteria. The largest number of $16 \mathrm{~S}$ rRNA gene sequences classified as Proteobacteria was actually associated with the Deltaproteobacteria. Of the 117 sequences, $78 \%$ were classified using GenBank and labeled uncultured bacterium [6]. 
The level of precipitation would associate the Tataouine study with the intermediate precipitation sample sites, specifically Fields Road. This site also showed the represented phyla to include Proteobacteria, Firmicutes, Acidobacteria, Planctomycetes, Verrucomicrobia, and Actinobacteria. Fields Road also included a sequence for Synergistetes, and 8 sequences for the Cyanobacteria. Neither of these phyla appears in the Tataouine study.

The arid soils of northern Arizona were the focus of a study comparing the pinyon-juniper woodlands of the Coconino National Forest to basaltic soils around Sunset Crater National Monument. Though not as hot as the Mojave or Sonoran deserts, the area is considered arid and subjected to many of the same weather patterns as the surrounding deserts. Soil samples were taken from two sites approximately $19 \mathrm{~km}$ apart at the time of year corresponding to maximum available moisture. Gene libraries were made from the $3216 S$ rRNA genes which were then identified by GenBank. Twenty sequences were associated with Proteobacteria, Gram Positive bacteria and 'flexibacteria', which come from a genus name, Flexibacter, in the phylum Bacteroidetes. The remaining sequences grouped into clades associated with uncultured soil bacteria. Four of these clades were clustered with Acidobacteria when classified on a maximumlikelihood phylogenetic tree. The remaining group of sequences fell between the Planctomycetes and the GNS bacteria. Compared to the Mojave sequences, the Proteobacteria, Bacteroidetes and Acidobacteria were identified, however, no sequences were categorized with the Cyanobacteria [13]. 
Numerous research projects on bacteria soil communities have been done in the extremely arid Atacama Desert. Drees et al. sampled the Punta Negra transect through the hyperarid zone of the Atacama. The 16S rRNA gene was amplified from extracted community DNA, then sequenced and analyzed. Two bacteria communities were identified, one associated with the limited plant growth along the transect, and the other from absolute desert - no vegetative growth. The sequences were classified using GenBank and resulted in the majority of 16S rRNA gene sequences being labeled as "uncultured bacterium clone". Using parsimonious phylogenetic trees these sequences were grouped with the Acidobacteria, Gemmatimonadetes, and Planctomycetes. Compared to the Mojave study, the Acidobacteria and Gemmatimonadetes were found at the driest location [9].

A different analysis of the Atacama utilized phospholipid-fatty acid (PLFA) analysis as well as DNA extraction and amplification to examine the bacterial diversity of the soil. Ninety-four percent of the sequences were associated with the Actinobacteria, with the remainder of the sequences classified as Proteobacteria, Firmicutes and TM7 (an environmental bacterium associated with human diseases of the oral cavity). The PLFA analysis identified Actinobacteria, Proteobacteria, and Firmicutes as the dominant taxonomic groups [7].

Research on bacterial soil communities in arid environments has identified predominant taxonomic classifications as the Actinobacteria, the Firmicutes, and Proteobacteria. The Mojave data agrees with the predominance of the 
Proteobacteria; however the populations of the Actinobacteria and Firmicutes were much lower than the population of Cyanobacteria. None of the related research has specified the existence of free-living Cyanobacteria as an important constituent of desert microbial communities. Because the majority of the related research incorporated sequence classification from GenBank, consistency between the Greengenes database and GenBank was examined. All of the cyanobacterial sequences from Henry Springs Road (site 21) were blasted against GenBank. The results indicated that 3 of the 34 sequences were not classified as Cyanobacteria by GenBank. Because this $8 \%$ difference is comparable to differences in assignment of sequences to phyla by the three Greengenes databases, and this difference does not indicate major discrepancies between the four databases.

Cyanobacterial microbes were detected in very cold arid environments. Neufeld and Mohn examined the microbial diversity of two sites in the Arctic tundra compared to forest soil from northern Canada. Samples from the top $10 \mathrm{~cm}$ of soil were taken from $20 \times 20 \mathrm{~m}$ areas representative of the surrounding landscape. Ribosomal sequence tags and DGGE were used as template for amplification of the 16SrRNA gene. Sequences were classified by GenBank and identified the phylum Proteobacteria as the dominant group, as well as Actinobacteria, Acidobacteria, Firmicutes, Bacteriodetes, Verrucomicrobia, and Cyanobacteria. The proportion of cyanobacteria at all sample sites was highest 
at the tundra sites, but very low overall compared to the other mentioned phyla (specific data was not available) [18].

Research in the Dry Valleys of Antarctica also produced evidence of Cyanobacteria in eubacterial soil communities. Smith, et al. sampled mineral soil from three locations: underneath a decaying seal carcass along the coast, a midslope area at $225 \mathrm{~m}$ altitude, and a mountain pass at $584 \mathrm{~m}$. The $16 \mathrm{~S}$ rRNA genes were amplified from extracted DNA. Clone libraries were created and classified by GenBank to establish microbial populations by phyla designations. The coastal and mid-altitude sites were dominated by the Actinobacteria, Acidobacteria, and environmentally uncultured groups of bacteria. Chloroflexi, Bacteriodetes, and the Alpha and Betaproteobacteria were identified at the coastal site. The mid-latitude site showed the presence of Verrucomicrobia, Chloroflexi, Bacteriodetes and a group of unclassified bacteria. The high-altitude soil community was predominantly Cyanobacteria, with Bacteriodetes, Actinobacteria, and environmental uncultured bacterial groups present in lower proportion and minimal contribution from Verrucomicrobia, Acidobacteria, and unclassified bacteria. The explanation of the dominance of Cyanobacteria at the high-altitude site was the presence of hypolithic strata [23].

A different project examined soil communities which including Archaea and eukaryotic microbes. The sample area was McKelvey Valley, and was described as frost polygons against sandstone and quartz substrates. Ten samples were taken from soil. The top $2.5 \mathrm{~cm}$ of loose soil was removed, and 
then samples taken down to a depth related to the depth of hypolithic colonies. Samples were examined using quantitative PCR and restriction digests. The resulting clone libraries for the $16 \mathrm{~S}$ and $18 \mathrm{~S}$ rRNA genes were classified by GenBank. Results indicated the actual soil did not include Archaea, eukaryotic microbes or Cyanobacteria. The predominant phyla were Acidobacteria, Actinobacteria and unidentified bacteria, with Bacteriodetes, Chloroflexi, Deinococcus-Thermus, Gemmatimonadetes, and Betaproteobacteria making small contributions to the soil community. Cyanobacteria, algae, and fungi were associated with hypoliths, endoliths, and chasmoliths [20].

The samples from the Mojave Desert did not include sampling cyanobacterial crusts, though these established communities were present along the transect, particularly at Black Tank. There were also hypolithic quartz rocks found at Fields Road, Black Tank, and Henry Springs Road. There may be a limit to the availability of liquid water where the Cyanobacteria cease existing freely in the soil and can only survive in larger protective environments such as crack in rocks or mats.

The proportion of the eubacterial population represented by the Firmicutes was smaller than expected based upon other desert soil results. Because of the survivability of Bacillus spores, the low presence of this class was noted. In the previous discussion regarding the selection of a database for classification purposes, the comparison of the sequences which were of questionable assignment included several that were assigned to Firmicutes in difference to 
one or the other database. The discrepancies were not removed by analysis using GenBank, because many of those sequences were labeled uncultured bacterium.

The relative low proportion of Actinobacteria was also of interest, though in many studies, the sequencing is performed on cultured organisms, rather than DNA extracted from the entire soil community. Culturing soil bacteria then sequencing those organisms would skew the resulting analysis toward those organisms which can be cultured, and would represent $<1 \%$ of the total soil community. Interestingly, several of the more recent studies based sequencing on DNA extraction from the soil samples, still indicates the Actinobacteria to be a predominant phylum.

16S rRNA Sequence Analysis, Archaea. The analysis of Archaeal sequences along the Mojave precipitation transect reveal a community comprised of the same groups of 5-6 organisms: Archaeoglobi, Methanomicrobia, Methanopyri, Thermococci and Thermoplasmata. Where the diversity of Eubacteria presented a definite increasing trend with decreasing precipitation, the Archaeal communities showed very little change related to precipitation or any of the other soil characteristics measured.

Early research on Archaea in soils from an agricultural research station near Madison, WI showed the predominant archaeal sequences to most resemble Crenarchaeota sequences associated with marine samples [4]. In 2002, Pesar and Widmer first isolated sequences from the Euryarchaeota in 
forest soil, including the presence of Thermoplasmales which are a member of the class Thermoplasmatales, and were also identified along the Mojave precipitation transect [19].

Four semi-arid soils of northwestern New South Wales, Australia were sampled and sequencing produced equal percentages of 16S rRNA gene sequences from the Crenarchaeota and the Euryarchaeota. The diversity of the archaeal communities was highest for the sample from a cotton-wheat field, and did not differ significantly for the remaining soils from a park, a nature preserve and a national park. The latter two sites had been previously cleared and used for agriculture and grazing in the 1950s [17].

A lack of diversity in archaeal soil communities was observed in a comparison of biological soil crust (bcs) communities found in four North American deserts: the Chihuahuan, the Colorado Plateau, the Great Basin, and the Sonoran. The bcs is defined as aggregations of microorganisms on plant interfaces, and were observed in the Mojave. Two to five phylotypes of Archaeal sequences were identified from 12 bcs samples produced from DGGE analysis, demonstrating a rather low diversity similar to that of the Mojave precipitation gradient. To further investigate the low diversity, clone libraries were created from pooled samples previously used for DGGE. A total of $5216 \mathrm{~S}$ rRNA sequences were found to be of six phylotypes related to the Crenarchaeota [24]. Diversity Analysis of $16 S$ rRNA Gene Sequence. The diversity of the microbial communities of the sample sites along the precipitation transect in the 
Mojave Desert was analyzed both by taxonomic level increases, as well as by calculation of the Shannon-Weiner diversity function. The increase in diversity appears related to the effects of reduced rainfall. At Sand Canyon, the vegetation was uniform, and the Alphaproteobacteria dominated all other groups of Eubacteria. As the precipitation decreased, the vegetation types and numbers changed allowing for more niches for bacteria. At Henry Springs Road, the conditions favored the Cyanobacteria, which do not depend upon organic sources of carbon and nitrogen. The lack competition by Alphaproteobacteria also allowed the minority Eubacteria to establish themselves as part of the community. The Archaea which did not demonstrate as much of a change in their communities, apparently are less sensitive to precipitation related conditions.

The possibility of identifying a bacterial or archaeal organism which might be useful as an indicator organism for desertification does not present itself from this data. The original examination of the data suggested that a member of the Cyanobacteria might be an optimal candidate to reflect the level of desiccation and decreasing organic levels in soils. However, the lack of recognition by other desert microbial studies questions the primary requirement that the organism be a consistent constituent of the community and conditions in question. It is possible that the conditions in other arid and semi-arid environments, such as soil types, chemical composition, and weather extremes do not support cyanobacterial life in the soil. Further analysis of soil communities from deserts 
with different conditions would be necessary to clarify the associations of such characteristics on Cyanobacteria.

\section{Summary}

The data from the Mojave Desert precipitation transect indicated an inverse relationship between the diversity of eubacterial soil communities and precipitation amounts. The viable counts gave an indication of overall decreasing numbers of culturable bacteria, but were not a factor for the examination of diversity. Further analysis of $16 \mathrm{~S}$ rRNA gene sequences from the following three years of sampling will help determine if the trends observed for the Eubacteria and Archaea are consistent for the precipitation gradient, or reflect localized conditions. Clone libraries for the following three years may also clarify differences noted in taxonomic groups in the Mojave compared to other desert environments.

Two other techniques for diversity analysis will be utilized for the Mojave transect. Denaturing Gradient Gel Electrophoresis (DGGE) allows the comparison of Eubacteria and Archaea at the genus and possibly species level. This technique allows site to site comparisons of the two Domains and may suggest a relationship between them not yet observed.

Also of interest would be to assess community level physiological profiles (CLPP) of the eubacterial communities using Biolog GN sole-carbon-source 
microplates. Analysis of the carbon-source utilization patterns offers a different approach to diversity and may present interesting trends related to the precipitation gradient. 


\section{References}

1. Altschul SF, Gish W, Miller W, Myers EW, Lipman DJ (1990) Basic Local Alignment Search Tool. J Mol Biol. 215:403-410

2. Barness G, Rodriguez Zaragoza S, Shmueli I, Steinberger Y (2009) Vertical distribution of a soil microbial community as affected by plant ecophysiological adaptations in a desert system. Microb Ecol 57: 36-49

3. Bastida F, Moreno JL, Hernandez T, Garcia C (2006) Microbiological degradation index of soils in a semiarid climate. Soil Biol Biochem 38: 3463-3473

4. Bintrim SB, Donohue TJ, Handelsman J, Roberts GP, Goodman RM 1997) Molecular phylogeny of Archaea from soil Proc Natl Acad Sci USA 94: $277-282$

5. California Department of Forestry and Fire Protection, Fire and Resource Assessment Program (FRAP) 1998

6. Chanal A, Chapon V, Benzerara K, Barakat M, Christen R. Achouak W, Barras F, Heulin T (2005) The desert of Tataouine: an extremes environment that hosts a wide diversity of microorganisms and radiotolerant bacteria. Environm Microbiol 8: 514-525

7. Connon SA, Lester ED, Shafaat HS, Obenhuber DC, Ponce A (2007) Bacterial diversity in hyperarid Atacama Desert soils. J Geophys Res 112: 1-9

8. DeSantis TZ, Hugenholtz P, Larsen N, Rojas M, Brodie EL, Keller K, Huber T, Dalevi D, Hu P, Andersen GL (2006) Greengenes, a ChimeraChecked 16S rRNA Gene Database and Workbench Compatible with ARB. Appl Environ Microbiol 72:5069-72 
9. Drees KP, Neilson JW, Betancourt JL, Quade J, Henderson DA, Pryor BM, Maier RM (2006) Bacterial community structure $n$ the hyperarid core of the Atacama Desert, Chile. Appl Environm Microbiol 72: 7902-7908

10. Hall TA (1999) Bioedit: A user-friendly biological sequence alignment editor and analysis program for Windows 95/98/NT. Nucl Acids Symp. Ser 41: $95-98$

11. Huber T, Faulkner G, Hugenholtz P (2004) Bellerophon; a program to detect chimeric sequences in multiple sequence alignments.

Bioinformatics 20:2317-2319

12. Krebs C (2001) Ecology. Benjamin Cummings, San Francisco, CA, pp 617-618

13. Kuske CR, Barns SM, Busch JD (1997) Diverse uncultivated bacterial groups from soils of the arid southwestern United States that are present in many geographic regions. Appl Environ Microbiol 63: 3614-3621

14. Lauber CL, Strickland MS, Bradford MA, Fierer N (2008) The influence of soil properties on the structure of bacterial and fungal communities across land-use types. Soil Biol Biochem 40: 2407-2415

15. Lauber LL, Hamady M, Knight R, Fierer N (2009) Pyrosequencing-based assessment of soil $\mathrm{pH}$ as a predictor of soil bacterial community structure at the continental scale. Appl Environm Microbiol 75: 5111-5120

16. McKay CP (2002) Two dry for life: the Atacama Desert and Mars. Ad Astra, May-June, 30-33

17. Midgley DJ, Saleeba JA, Stewart MI, McGee PA (2007) Novel soil lineages of Archaea are present in semi-arid soils of eastern Australia. Can J Microbiol 53: 129-138 
18. Neufeld JD, Mohn WW (2005) Unexpectedly high bacterial diversity in Arctic tundra relative to boreal forest soils, revealed by serial analysis of ribosomal sequence tags. Appl Environ Microbiol 71: 5710-5718

19. Pesaro M, Widmer F (2002) Identification of novel Crenarchaeota and Euryarchaeota clusters associated with different depth layers of a forest soil. FEMS Microbiol Ecol 42: 89-98

20. Pointing SB, Chan Y, Lacap DC, Lau MCY, Jurgens JA, Farrell RA (2009) Highly specialized microbial diversity in hyper-arid polar desert. Proc Natl Acad Sci USA 106: 199h-19969

21. Rainey FA, Ray KE, Ward-Rainey N (1999) Camels of the prokaryotic world. Reviewed Proceedings of The Eighth International Symposium on Microbial Ecology (ISME-8) Halifax, Canada August 1998

22. Robb FT, Place AR, Sowers KR, Schreier HJ, DasSarma S, Fleischman EM (1995) Archaea: A Laboratory Manual. Vol. 1. Cold Springs Harbor Press, Danvers, NY, pp 270-271

23. Smith JJ, Ah Tow L, Stafford W, Cary C, Cowan DA (2006) Bacterial diversity in three different Antarctic cold desert mineral soils. Microb Ecol 51: $413-421$

24. Soule T, Anderson IJ, Johnson SL, Bates ST, Garcia-Pichel F (2009) Archaeal populations in biological soil crusts from arid lands in North America Soil Biol Giochem 41: 2069-2074

25. Weisburg WG, Barns SM, Pelletier DA, Lane DJ (1991) 16S ribosomal DNA amplification for phylogenetic study. J. Bacteriol. 173:697-703

26. Zabinski CA, Gannon JE (1997) Effects of recreational impacts of soil microbial communities. Environ Managem 21: 233-238 
27. Zdanowski MK, Węgleński P (2001) Ecophysilogy of soil bacteria in the vicinity of Henryk Arctowski Station, King George Island, Antarctica. Soil Biol Biochem 33: 819-829 